\title{
Pain-related toxins in scorpion and spider venoms: a face to face with ion channels
}

\author{
Sylvie Diochot ${ }^{1 *}$ (1)
}

${ }^{1}$ Institut de Pharmacologie Moléculaire et Cellulaire (IPMC), Centre National de la Recherche Scientifique (CNRS) UMR 7275 et Université Côte d'Azur (UCA), 06560 Valbonne, France.

\section{Keywords:}

Venom

Toxin

Spider

Scorpion

Pain

Ion channels

\begin{abstract}
Pain is a common symptom induced during envenomation by spiders and scorpions. Toxins isolated from their venom have become essential tools for studying the functioning and physiopathological role of ion channels, as they modulate their activity. In particular, toxins that induce pain relief effects can serve as a molecular basis for the development of future analgesics in humans. This review provides a summary of the different scorpion and spider toxins that directly interact with pain-related ion channels, with inhibitory or stimulatory effects. Some of these toxins were shown to affect pain modalities in different animal models providing information on the role played by these channels in the pain process. The close interaction of certain gating-modifier toxins with membrane phospholipids close to ion channels is examined along with molecular approaches to improve selectivity, affinity or bioavailability in vivo for therapeutic purposes.
\end{abstract}

* Correspondence: diochot@ipmc.cnrs.fr https://doi.org/10.1590/1678-9199-JVATITD-2021-0026

Received: 08 March 2021; Accepted: 10 May 2021; Published online: 06 December 2021 


\section{Background}

Scorpions and spiders are venomous animals belonging to the arachnid class of arthropods. These small elusive arthropods have a long history of terrifying their victims, including humans. No less than 49,000 species of spiders (https://wsc.nmbe.ch/) and 1,900 species of scorpions can be found throughout the world, with an especial diversity and density in sub-tropical and tropical regions. Their venom, a tool for catching prey or defending against aggressors, is composed of a few dozen to several hundred toxins having high specificity and affinity for tissues. Depending on the venom considered and the dose injected, these toxins act together to cause paralysis, which facilitates the escape, or the sudden death of the aggressor. Arachnid venoms contain small molecules (ions, amino acids, monoamines, polyamines), a great number of peptides but also proteins and enzymes. Scorpion venom peptides mainly consist of neuropeptides, cardiopeptides and antimicrobial peptides with cytotoxic activities [1], whereas spider venom is composed of more neuroactive peptides, a few cardiotoxic and antimicrobial peptides, and enzymatic proteins contributing to paralysis, death and tissue digestion during prey feeding [2-4].

\section{Scorpion Stings and Spider Bites}

With more than 1.2 million stings a year and more than 3250 deaths, scorpionism is a major public health problem in subtropical areas worldwide [5] despite the fact that less than 25 species are considered dangerous to humans. The "Old Word" (Africa) species of medical interest belong to Andoctonus, Buthus, Hottentota, Leiurus genera while "New World" (America) species are part of Centruroides and Tityus genera, all in the Buthid family (Figure 1). Severe envenomation in humans primarily occurs in tropical regions and during hot seasons (North and Sub-Saharan Africa, Middle East, Asia, Latin America), with stings inoculating a few microliters of venom. Incidence (number of scorpion stings per 100,000 inhabitants) varies in each country as well as within rural and urbanized areas (250 and 15 respectively in Morocco), with the majority of stings occurring in the summer months. In Tunisia, before the extensive use of antivenom, the mortality rate reached 6.67 per 100000 inhabitants with an incidence of 1500 [5]. Alarming cases predicting severe envenomation (5\% of envenomation cases) include local symptoms (pain and paresthesia) associated with systemic gastrointestinal, respiratory, cardiopulmonary
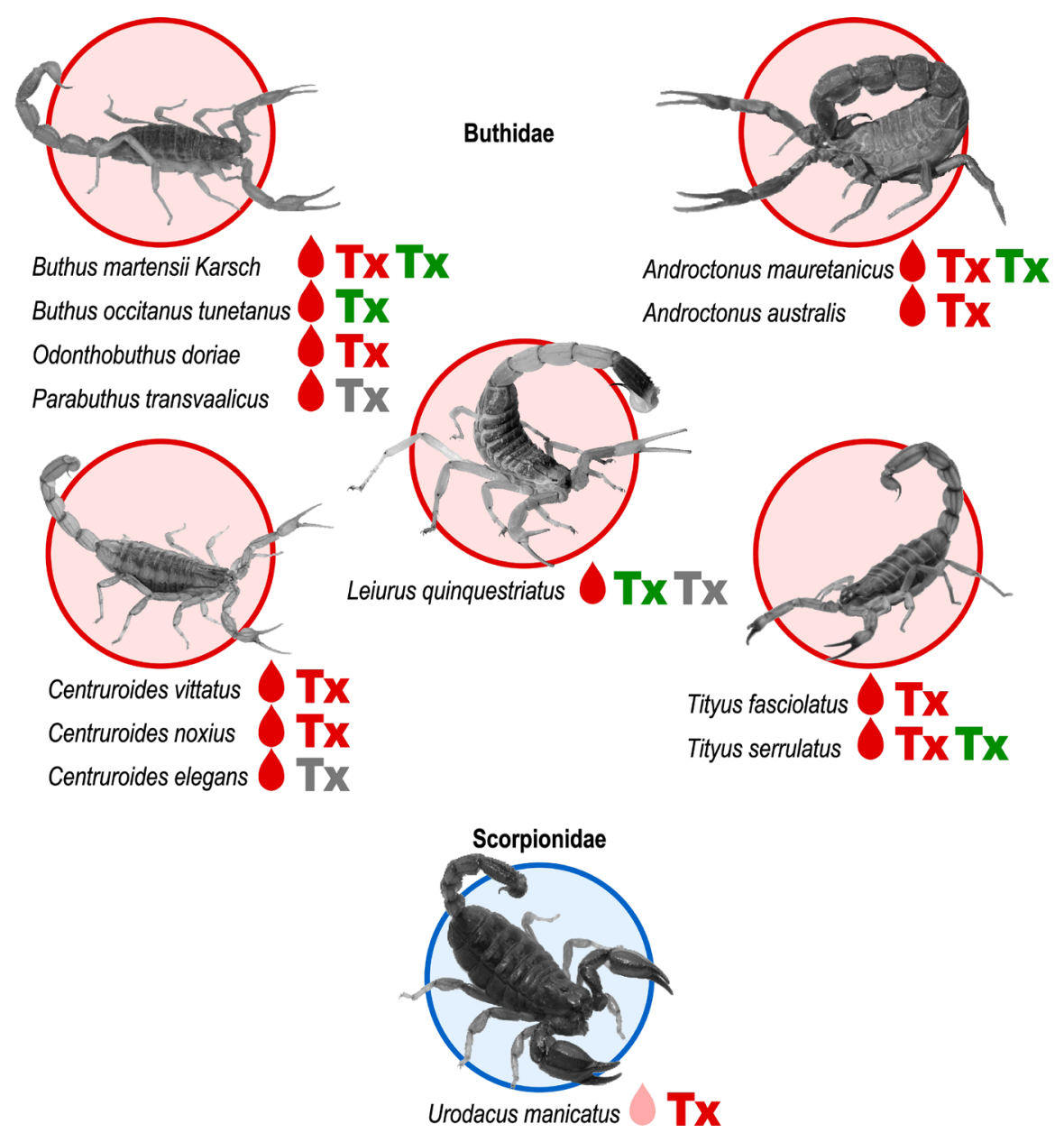

Figure 1. Pain-related scorpion species. Scorpion species of medical importance are circled in red, those that are harmless to humans are circled in blue. Red drop: scorpions with highly painful stings; pink drop: scorpions whose sting is mildly painful. Tx: presence of pro-algic toxins in the venom; Tx: presence of antinociceptive toxins in the venom; Tx: presence of toxins having an effect only on pain-related channels. 
and neurological symptoms [6-8]. Envenomation is particularly dangerous for children under 15 years where bites often result in acute pulmonary edema leading to death [9].

Envenomation by spider bites is considered dangerous for humans in a few species. Large spiders and in particular mygalomorphs are not the most dangerous, except for the genera Atrax or Hadronyche (Atracidae, Australia) and Missulena
(Actinopodidae, Australia) [10]. In the araneomorph group, genera Phoneutria (Ctenidae, South America), several species of Loxosceles (Sicariidae, mainly found in North and South America) and Latrodectus (Theridiidae, in South and sub-tropical regions all other the world) are responsible for severe envenomation but rarely are these fatal when treated symptomatically or with anti-venom serology [11] (Figure 2).

\section{MYGALOMORPH}

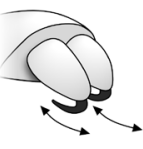

Paraxial fangs

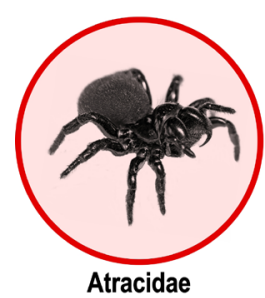

Atracidae

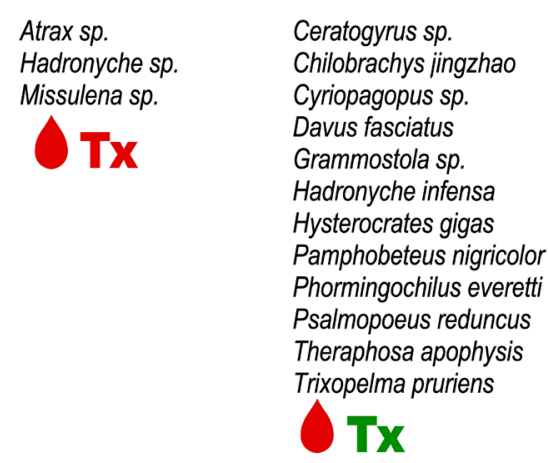

Psalmopoeus cambridgei Heteroscodra maculata

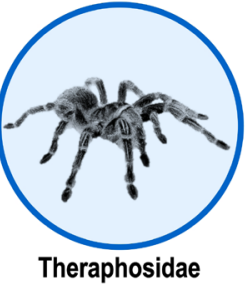

Ceratogyrus sp. Chilobrachys jingzhao riopagopus sp.

Davus fasciatus Hadronyche infensa Pamphobeteus nigricolor Phormingochilus everett Psalmopoeus reduncus Trixopelma pruriens Tx Tx
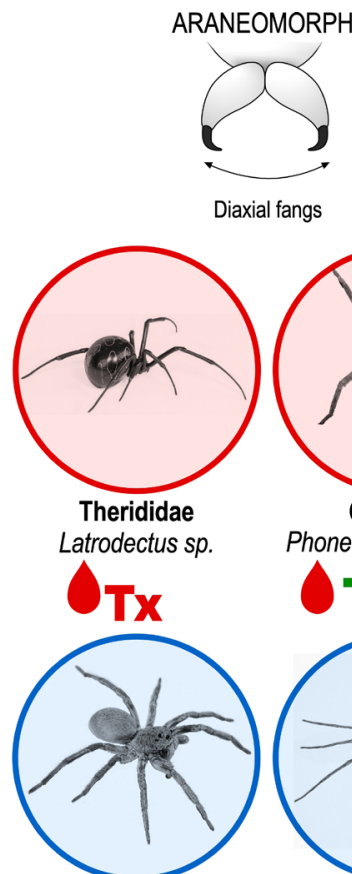

Lycosidae Geolycosa sp.

OTx

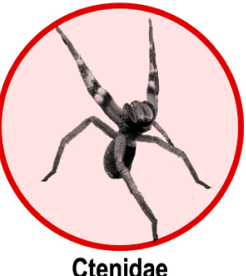

Ctenidae

Phoneutria nigriventer

Tx Tx

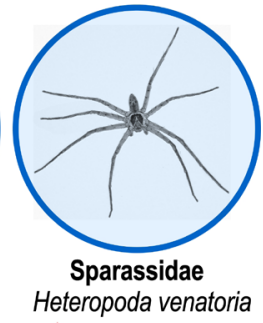

Heteropoda venatoria

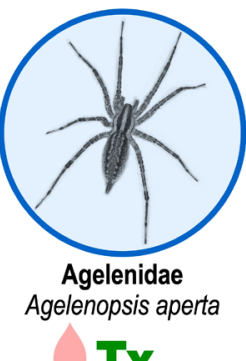

Tx Tx

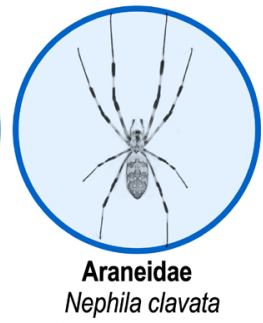

Tx

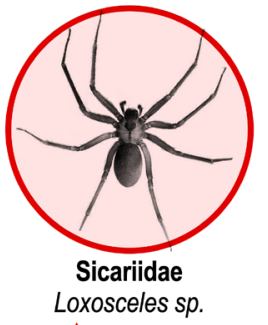

Tx

Figure 2. Pain-related spider species. Mygalomorph and araneomorph spiders are differentiated by their morphologic chelicerae position. Mygalomorph have primitive orthognath position, with parallel fangs, whereas araneomorph have labidognath position, in which their fangs move side to side, like a pair of scissors. Spider species of medical importance are circled in red, those that are harmless to humans are circled in blue. Red drop: spiders with highly painful bites, some (Latrodectus and Loxosceles) have a late onset of pain (a few hours after the bite); pink drop: spiders whose bite is mildly painful. Tx: presence of pro-algic toxins in the venom; Tx: presence of antinociceptive toxins in the venom and/or toxins with high affinity for pain-related channels. 
A necrotizing araneism is described in bites by several species of Loxosceles, without neurotoxicity, leading to skin lesions with necrosis sometimes requiring skin grafts, or thrombocytopenia responsible for hemorrhage. In severe forms, a viscerocutaneous syndrome characterized by fever, hemolytic jaundice, and nephropathy can result in the death of the victim [11,12]. A neurotoxic araneism is described in cases of bites by species of Atrax, Missulena, Phoneutria and Latrodectus genera associating respiratory, cardiac and digestive symptoms. These cases of envenomation present a common picture of localized pain, discomfort, nausea, sweating, vomiting, tachycardia, hyper/ hypotension, and muscle fasciculations. These symptoms worsen with the onset of dyspnea, cardiovascular collapse, respiratory failure, which can be fatal $[13,14]$. More characteristic symptoms of Latrodectus bites include sustained muscle cramps, mental confusion, and abdominal pain $[10,15]$.

\section{Pain Processing During Envenomation}

Cases of envenomation by arachnid bites or stings, always provoke first peripheral symptoms due to the effect of the venom toxins on the excitable nerve endings. Some spider venoms, such as Loxosceles, cause additional cytolytic effects characterized by tissue necrosis due to the presence of enzymes such as phospholipases $\mathrm{D}$ (sphingomyelinases $\mathrm{D}$ ) highly responsible for venom dermonecrotic activity $[12,16,17]$. Scorpion stings always cause sharp, constant and lasting pain, regardless of whether the species is dangerous or not $[5,18]$. In victims, the pain is immediate, and very intense, first local, then loco-regional, it can subside over short periods of time, which may suggest an improvement in general condition, but often remains intense for one to two days $[5,19]$. In the case of poisoning by dangerous species, the pain will gradually be accompanied within a few hours by other symptoms such as nausea, sweating, vomiting, agitation, malaise, and hypertension [20].

A comparative work between Buthidae and Vaejovidae venom suggests that stings of Buthid scorpions, the most dangerous for humans, are more painful to mammals than sting from non-Buthid scorpions (Vaejovis spiniferus) [21]. Observations of peripheral venom injected to rodents show immediate pain characterized by continuous flinching and licking on the injected paw. Thermal and mechanical hypersensitivity to pain associated with edema, which reflects inflammation, can extend to several days or weeks $[22,23]$.

The pain felt when bitten by a spider is undoubtedly more variable, sometimes discreet but becoming intense dependent upon the species considered. The pain profile can evolve during the course of the symptomatology ranging from simple localized sharp pain, to radiating pain towards the limbs, or generalized pain associating a burning sensation (evoking inflammation), muscle cramps, or itching. In the case of spiders, the intensity of the pain is by no means synonymous with a worrying evolution $[10,11,24]$. Spider venoms are very complex in nature and the combined effect of all the venom components induce a wide range of neurotoxic symptoms that resemble those described for scorpion envenomation.

The immediate, acute pain that appears following a spider bite or scorpion sting is the consequence of the effect of toxins on receptors in the peripheral nervous system. The pain sensation typically originates in primary sensory afferent neurons known as nociceptors, through which pain signals are relayed from the periphery to central nervous system. The hyperexcitability of primary sensory neurons is one of the mechanisms that can lead to exaggerated sense of pain, such as spontaneous pain and hyperalgesia [25-27].

These venoms contain small molecules such as monoamines (dopamine, epinephrine, norepinephrine, histamine, octopamine, serotonin, tyramine) which, by activating their specific receptor, are pro-algesic $[28,29]$. Others, such as certain neurokinins, cytokines, ATP, NO, excitatory amino acids also modulate pain and inflammation [26,30]. Most of these venoms contain peptides with excitatory activity, which target ion channels on sensory neurons and initiate the rapid nociceptive response. Enzymes such as sphingomyelinases, phospholipase A2, hyaluronidases, induce an inflammatory response causing the release of proinflammatory cytokines and lipid mediators, leading to later onset of secondary pain [12,16]. Protease inhibitors have also been involved in the prolonged pain behavior induced by scorpion crude venom [31].

In scorpion venoms, a few toxins with analgesic activity in mammals have been identified and their molecular target determined [32-34]. The situation is quite different for spider venoms, where in parallel with the discovery of excitatory toxins inhibiting potassium channels or activating sodium channels, a large number of peptides with analgesic properties have been isolated [35-37]. These analgesic toxins target ion channels involved in pain transmission pathways and are becoming essential tools for the study of pain mechanisms $[38,39]$. They could also be promising, as drug candidates for treating various types of intractable pain, and to enrich the existing pharmacopoeia.

\section{Ion Channels and Pain}

Ion channels are ubiquitous transmembrane proteins permeable to ions and activated by a variety of stimuli (voltage, temperature, ligands, $\mathrm{pH}$...) specific to each ion channel family. They represent the molecular basis of the mechanisms of propagation of action potentials of excitable cells and thus modulate neuronal, muscular, and cardiac physiology [40,41]. More than a hundred genes have been cloned encoding ion channels with a high diversity of structure, functions, regulations and pharmacology $[42,43]$. In the vertebrate nervous system, certain subtypes of ion channels are involved in the detection, transmission and integration of different nociceptive stimuli [44]. The best characterized ion channels in the context of pain belong to the super family of voltage-dependent sodium channels (Nav), voltage-dependent calcium channels (Cav), Acid-Sensing 
Ion Channels (ASICs), some potassium channels, channels in the Transient Receptor Potential (TRP) family, ionotropic (P2X, Serotonin and Glutamate) receptors, and certain mechanosensitive channels (SACs, Piezo) [44,45]. The role of ion channels in pain was demonstrated in particular with the use of specific pharmacological tools such as animal toxins that activate or block their functioning, when the gene deletion models (knockout (KO) or knockdown mice) did not reveal a marked phenotype [25].

\section{Voltage-gated sodium channels}

In the Nav family, homologous mammalian genes encode nine members, Nav1.1 to Nav1.9. The TTX-sensitive (TTX-S) Nav1.7, and the TTX-resistant (TTX-R) Nav1.8 and Nav1.9 channels, largely expressed in sensory neurons, are recognized as the most important contributors to the control of nociceptive responses in rodents and humans [46-49]. Mutations in human genes, encoding the $\alpha$-subunit of Nav1.7, Nav1.8 and Nav1.9, were found to be responsible for congenital pain insensitivity (loss of function), erythromelalgia (gain of function) and paroxysmal extreme pain disorders, different peripheral neuropathies [50-52].

The TTX-S Nav1.1, Navl.3 and Navl.6 were recently implicated in pain. Nav1.1 channels are related to mechanical pain [53], Navl.3 is involved in cold thermosensation and mechanosensation [54] and Nav1.6 contributes to the development and maintenance of neuropathic pain $[55,56]$.

\section{Voltage-gated potassium channels}

In the large family of potassium channels encoded by more than 80 genes, voltage-gated $\mathrm{K}^{+}$channels $(\mathrm{Kv})$ include various members classified into Kv1-Kv12 subfamilies based on their biophysical and pharmacological properties [57]. In the nervous system, some Kv contribute to the shape and frequency of action potentials that modulate axonal conduction [58-60]. The membrane hyperpolarization induced by $\mathrm{K}$ channels openers is able to regulate and stabilize neuron excitability, and may provide antinociceptive effects in sensory pathways. In arachnid venoms, toxins that activate Nav channels and block Kv channels are often found simultaneously, and act synergistically to depolarize excitable membranes permanently and produce neurotoxicity and pain [61]. The Kv4 family, which is targeted by some spider and scorpion toxins, is implicated in the modulation of pain. Specific inhibition of Kv4.2 by a scorpion toxin controls the mechanical nociception [62]. A dysfunction of Kv4.3 in trigeminal ganglion neurons has recently be shown to impact neuropathic pain associated with cold hypersensitivity [63].

\section{Voltage-gated calcium channels}

Cav channels control key functions in excitable cells including transmitter release, hormone secretion, gene expression or muscle contraction [64]. They comprise T-type channels (encoded by Cav3.1 to 3.3 genes), L-type (Cav1.1 to 1.4), N-type (Cav2.2), $\mathrm{P} / \mathrm{Q}$-type (Cav2.1) and R-type (Cav2.3) channels. Cav2.2, which is predominantly expressed in presynaptic terminals in the peripheral and central nervous systems, is essential in neurotransmitter release [65]. It contributes to pain transmission in particular in neuropathic and inflammatory pain [66,67]. The role of Cav2.3 in inflammatory pain [68] and in nociceptive transmission during neuropathic pain [69] was highlighted by knockout studies. Cav3.2 channels, which have a large expression in nociceptors, are important contributors for nociception as shown by knockdown studies in rodents [70].

\section{ASIC channels}

Acid Sensing Ion Channels (ASIC) are voltage-insensitive cation channels activated by extracellular protons, generating mainly transient inward sodium currents [71]. To date, 4 genes encoding 6 isoforms (ASIC1a, ASIC1b, ASIC2a, ASIC2b, ASIC3 and ASIC4) can combine to form homo- or heterotrimers highly expressed in CNS and PNS [72]. Their activation induces neuronal depolarization and is associated with several physiological and physiopathological processes such as neuronal plasticity, neuroprotection, cancer and nociception [73,74]. ASICla contribute to acute, inflammatory and neuropathic pain. Use of specific pharmacological venom peptides in rodent pain models showed that their blockade causes analgesia and their activation elicits acute pain [75-77]. The role of ASIC1 in migraine and the therapeutic potential of ASIC1 inhibitors in this pathology were also recently shown [78].

Heteromultimeric ASIC1a/ASIC2a channels contribute to opioid-independent analgesia in the CNS [77] while ASIC2b combined to ASICla contribute to acute, inflammatory and neuropathic pain [79]. ASIC1b, which are only expressed in the PNS, contribute to the modulation of acute, inflammatory and probably neuropathic pain $[73,77,80]$. In sensory neurons, ASIC3 are important actors for skin and muscle pain $[81,82]$.

\section{Transient receptor potential channels}

Transient receptor potential (TRP) channels are polymodal receptors widely expressed in sensory neurons in mammals, permeable to $\mathrm{Ca}^{2+}$ and $\mathrm{Na}^{+}$. They detect changes in temperature, light, acidity or osmolarity. Different subtypes (TRPV1, TRPV3, TRPV4, TRPA1, TRPM2, TRPM3 and TRPM8) are activated by painful stimuli in various modalities [83]. TRPV1 opens under nociceptive stimuli such as capsaicin, heat and acidity. Mice with TRPV1 gene deletion are less responsive to noxious heat, revealing that the TRPV1 channel is essential for selective modalities of sensation of pain and for tissue injury induced thermal hyperalgesia $[84,85]$. TRPV3 punctual mutations underlined their role in migraine, fibromyalgia and erythromelalgia [86-88]. TRPV4 are related to sensory or motor neuropathies associated with pain [89]. Genetic deletion of TRPV4 in mice also highlighted their role in inflammatory pain.

Cooling agents such as menthol and icilin activate the sub family of TRPM8 channels expressed in sensory neurons. TRPM8 is as a cold sensitive receptor, its pharmacological blockade and 
genetic deletion showed its role in thermoregulation and in cold hypersensitivity in neuropathic pain [90]. TRPM3 is another temperature sensitive channel expressed in heat afferent neurons whose genetic deletion results in reduced response to noxious heat as well as to inflammatory thermal hyperalgesia [91].

TRPA1 channels are activated by various "burning" agents such as mustard, cinnamon, wasabi, which promote the sensation of pain. Their genetic deletion or pharmacological blockade induces a loss of reaction in chemical, mechanical and inflammatory nociceptive pain models [92]. TRPA1 also seems to have a role in the perception of noxious cold responses associated with or without inflammation [93] and is associated to pain during diabetic neuropathy [94].

\section{Purinergic P2X ion channels}

Purinergic P2X ion channels, include seven members (P2X1 to $\mathrm{P} 2 \mathrm{X} 7$ ) permeable to $\mathrm{Ca}^{2+}$ and activated by ATP. Some of these channels expressed in sensory neurons such as P2X 2 and P2X 3 , can associate in heterotrimers, and have a role in the initiation of nociception [95]. Thus, ATP by activating P2X3 receptors can induce mechanical allodynia in rats [96]. Knock out and knock down studies revealed that P2X3 is involved in inflammatory and neuropathic pain in rats [97,98].

Opening of $\mathrm{P} 2 \mathrm{X} 4$ is known to induce allodynia during neuropathic pain situations [99]. In the same way, P2X7 receptors stimulated during microglial inflammation are involved in the development of neuropathic and inflammatory pain [100].

It should be mentioned that arthropod venoms include nucleosides such as ATP, ADP, AMP and adenosine that can activate purinergic receptors and contribute to early pain processing during envenomation.

\section{Serotonin ionotropic receptors}

Serotonin (5-HT), a neurotransmitter widely released in the nervous system, participates to the modulation of pain, sleep and mood. 5-HT, by acting on its receptors, a family including seven members, $5 \mathrm{HT} 1$ to $5 \mathrm{HT} 7$, can promote or suppress pain sensations [101]. In the ionotropic 5-HT3 receptor family, five subtypes 5-HT3A to E are described in both the central and peripheral nervous system, and are permeable to $\mathrm{Ca}^{2+}$ and $\mathrm{Na}^{+}$. Several studies have shown that central injections of the 5-HT3 receptor antagonists have antinociceptive effects on neuropathic pain while activators induce neuronal hyperexcitability and pain hypersensitivity $[102,103]$. Other studies demonstrated opposite results on pain, using 5-HT3 agonist or antagonists, that could be attributed to different pain models, drug concentrations and mode of administration [104]. Serotonin reuptake drugs, developed by pharmaceutical companies, are known to be effective against several pain syndromes, in particular in migraine and neuropathic pain.

\section{Piezo channels}

The Piezo family includes two mechanosensitive cationic channels, Piezo1 and Piezo2, found in the bladder, colon, kidney, lung and skin. They are mainly permeable to $\mathrm{Ca}^{2+}$, less to $\mathrm{Na}^{+}, \mathrm{K}^{+}$and $\mathrm{Mg}^{2+}$, and their function is related to touch and mechanical pain sensations [105]. Piezo2 strongly expressed in DRG sensory neurons seems to contribute to somatosensory mechanotransduction and allodynia during inflammation [106]

\section{Glutamate ionotropic receptors}

The glutamate ionotropic receptors are opened by glutamate, and localized mainly at the postsynaptic level in the nervous system. At the spinal cord level, they control fast sensory transmission and plasticity but also the generation of long-term memory in the cerebral cortex. They are differentiated into NMDA (N-methyl-D-aspartate), AMPA ( $\alpha$-amino-3-hydroxy-5-methyl4-isoxazoleproprionic acid) and kainate (KA) receptors permeable to $\mathrm{Na}^{+}$or to $\mathrm{Ca}^{2+}$ [107]. Glutamate is the major neurotransmitter between primary afferent fibers and dorsal horn neurons in the spinal cord and contributes to the genesis of excitatory postsynaptic currents (EPSCs) that play a role in pain and itch transmission via AMPA, KA and NMDA receptors [108]. Glutamate is important for nociceptive sensitization in the brain where AMPA, KA and NMDA receptors also play an important role in chronic inflammatory and neuropathic pain $[109,110]$.

\section{Scorpion Toxins Interacting with Pain-Related Ion Channels}

During envenomation in humans, a majority of scorpion venom toxins target $\mathrm{Nav}$ and $\mathrm{Kv}$ channels, acting synergistically, to induce neurotoxic symptoms of hyperexcitability (hypertension, cardiac hyperactivity, hypersecretion of neurotransmitters). Toxins that bind to Nav channels are 60 to 70 amino acid peptides with a conserved structural scaffold consisting of an alpha-helix, and three-stranded beta sheets connected by four disulfide bridges in a $\beta \alpha \beta \beta$ topology. Some are more or less selective for insect versus mammalian Nav channels with sub-micromolar affinities, and they are classified into 2 types ( $\alpha$ - and $\beta$-toxins) according to their mode of action on mammalian Nav [111-113].

Toxins from scorpions with known pain-related ion channels and/or pain-related effects are listed in Table 1. Their mode of action on ion channels are indicated in relation to their classification. Classical $\alpha$ - or $\beta$-toxins are highly specific for mammals, whereas $\alpha$ - or $\beta$-like toxins are active on both mammals and insects. Finally, insect $\alpha$ - and insect $\beta$-toxins are specific for insects and not toxic for mammals even at high concentrations. Moreover, $\alpha / \beta$-toxins are those targeting site 3 and 4 , simultaneously affecting fast inactivation and steady state activation of $\mathrm{Na}^{+}$currents. 
Table 1. Scorpion toxins active on ion channels related to pain.

\begin{tabular}{|c|c|c|c|c|c|}
\hline Scorpion species & Toxin & Action mode & Ion channel & $\begin{array}{l}\text { Type of } \\
\text { effect }\end{array}$ & $\begin{array}{c}\text { Pain phenotype } \\
\text { [references] }\end{array}$ \\
\hline Androctonus australis & $\mathrm{AaH} I \mathrm{I}$ & a-toxin & TTX-S Nav (Nav1.7) & Pain & $\begin{array}{l}\text { Acute, mechanical and } \\
\text { thermal pain (ipl) [123] }\end{array}$ \\
\hline \multirow{6}{*}{$\begin{array}{l}\text { Androctonus } \\
\text { mauretanicus }\end{array}$} & Amm VIII & a-toxin & TTX-S Nav Nav1.7 & Pain & $\begin{array}{l}\text { Acute, mechanical and } \\
\text { thermal pain (ipl) [123] }\end{array}$ \\
\hline & anatoxin Amm VIII & a-toxin & Nav1.2 & Analgesia & Thermal (ip) pain [125] \\
\hline & BmK I & a-toxin & $\begin{array}{l}\text { Nav1.6 (pot) } \\
\text { Nav1.8 (pot) }\end{array}$ & Pain & $\begin{array}{c}\text { Acute, inflammatory } \\
\text { thermal pain, mechanical } \\
\text { hyperalgesia (ipl) } \\
{[115,116,118-120]}\end{array}$ \\
\hline & BmK IT2 & $\beta$-toxin & $\begin{array}{c}\text { TTX-R \&TTX-S Nav } \\
\text { (inh) }\end{array}$ & Analgesia & $\begin{array}{l}\text { Acute, inflammatory pain, } \\
\text { thermal hyperalgesia (it, } \\
\text { ipl) }[133-136]\end{array}$ \\
\hline & BmK IT-AP & Excitatory insect $\beta$-toxin & ND & Analgesia & $\begin{array}{c}\text { Visceral pain (iv) } \\
{[138,150]}\end{array}$ \\
\hline & BmK IT AP3 & Depressant insect toxin & ND & Analgesia & Visceral pain (iv) [138] \\
\hline \multirow[t]{8}{*}{ Buthus martensii Karsch } & $\begin{array}{l}\text { BmK AS } \\
\text { BmK AS-1 }\end{array}$ & $\beta$-toxin & $\begin{array}{c}\text { TTX-R \&TTX-S Nav } \\
\text { (inh) }\end{array}$ & Analgesia & $\begin{array}{l}\text { Visceral (ip, iv), thermal(iv), } \\
\text { Inflammatory (it) pain, } \\
\text { mechanical hyperalgesia } \\
\text { (ipl) }[32,131,132]\end{array}$ \\
\hline & BmK AGP-SYPU1\&2 & $a / \beta$-toxin & $\begin{array}{l}\text { Nav1.4; Nav1.5; } \\
\quad \text { Nav1.7 }\end{array}$ & Analgesia & Visceral (ip, iv) pain [339] \\
\hline & BmK AGAP-SYPU1\&2 & $a / \beta$-toxin & ND & Analgesia & $\begin{array}{l}\text { Visceral (ip, iv), thermal } \\
\text { (iv) pain [340] }\end{array}$ \\
\hline & BmK AGAP & $a / \beta$-toxin & $\begin{array}{c}\text { Nav1.4, Nav1.5 } \\
\text { Nav1.7, Nav1.8 (inh) }\end{array}$ & Analgesia & $\begin{array}{c}\text { Visceral (ip), inflammatory } \\
\text { (ipl, iv), thermal (iv) pain } \\
{[146,147]}\end{array}$ \\
\hline & BmK AngM1 & & Nav (inh) & Analgesia & Visceral pain (iv) [148] \\
\hline & BmK AngP1 & Excitatory insect toxin & ND & Analgesia & Visceral pain (iv) [138] \\
\hline & ANEP toxin & $\beta$-toxin & Nav1.7 (inh) & Analgesia & Visceral pain (iv) [33] \\
\hline & BmP01 & & $\begin{array}{l}\text { TRPV1 (act) } \\
\text { Kv1.3 (inh) }\end{array}$ & Pain & Acute pain (ipl) $[160,161]$ \\
\hline $\begin{array}{l}\text { Buthus occitanus } \\
\text { tunetanus }\end{array}$ & Bot AF & $\beta$-like-toxin & ND & Analgesia & $\begin{array}{c}\text { Heat (ip, it), } \\
\text { inflammatory (ipl), } \\
\text { visceral (ip) pain [154] }\end{array}$ \\
\hline Centruroides elegans & Cell8 & $\beta$-toxin & Nav1.7 (inh) & ND & [139] \\
\hline Centruroides vittatus & Cv IV4 & a-toxin & $\begin{array}{c}\text { Nav1.2, Nav1.3, } \\
\text { Nav1.4, Nav1.7 (pot) }\end{array}$ & Pain & Acute pain (ipl) [21] \\
\hline Centruroides noxius & $\mathrm{Cn} 2$ & $\beta$-toxin & Nav1.6 (act) & Pain & $\begin{array}{c}\text { Acute pain, mechanical } \\
\text { cold allodynia (ipl) } \\
{[143,144]}\end{array}$ \\
\hline \multirow{2}{*}{ Leiurus quinquestriatus } & LqqIT2 & Insect $\beta$-toxin & ND & Analgesia & Thermal pain (ip) [125] \\
\hline & LqhIll & a-like toxin & Nav1.7 (pot) & ND & {$[124]$} \\
\hline Odonthobuthus doriae & OD1 & $\begin{array}{l}\text { a-like-toxin } \\
\text { a/ } \beta \text {-toxin }\end{array}$ & $\begin{array}{c}\text { Nav1.7, Nav1.3 } \\
\text { Nav1.4, Nav1.6 (pot) }\end{array}$ & Pain & $\begin{array}{c}\text { Acute pain (ipl) } \\
\text { [126-129] }\end{array}$ \\
\hline Parabuthus transvaalicus & Kurtoxin & a-toxin & $\begin{array}{c}\text { Cav3.1, Cav3.2, } \\
\text { Cav2.2 (inh); Nav1.2 } \\
\text { (pot) }\end{array}$ & ND & {$[155,156]$} \\
\hline Tityus fasciolatus & Tf2 & $\beta$-toxin & Nav1.3 (act) & Pain & Acute pain (ipl) $[140,317]$ \\
\hline
\end{tabular}


Table 1. Cont.

\begin{tabular}{|c|c|c|c|c|c|}
\hline Scorpion species & Toxin & Action mode & Ion channel & $\begin{array}{l}\text { Type of } \\
\text { effect }\end{array}$ & $\begin{array}{l}\text { Pain phenotype } \\
\text { [references] }\end{array}$ \\
\hline \multirow[b]{2}{*}{ Tityus serrulatus } & Ts2 & a-toxin & $\begin{array}{l}\text { Nav1.3, Nav1.6, } \\
\text { Nav1.7 (pot) }\end{array}$ & ND & [142] \\
\hline & TsNTxP & & ND & Analgesia & $\begin{array}{c}\text { Acute, heat, } \\
\text { inflammatory, } \\
\text { neuropathic pain (it) } \\
\text { [153] }\end{array}$ \\
\hline Urodacus manicatus & WaTx & & TRPA1 (act) & Pain & Acute pain (ipl) [163] \\
\hline
\end{tabular}

ANEP: anti-neuroexcitation peptide; BmK AGAP: Buthus martensii Karsch-analgesic-antitumor peptide; pain-related ion channel and other high-affinity channels (in italics) are indicated; inh: inhibition; act: activation; pot: potentialisation; ND: not done. it: intrathecal; ip: intraperitoneal; ipl: intraplantar; iv: intravenous. Pain phenotypes and injection routes experimented in rodents are indicated in brackets.

Scorpion a-toxins, also known as "excitatory toxins", increase the peak and slow down the inactivation kinetics of sodium currents by binding to the site 3 (S4 segment of domain IV voltage sensor) of the TTX-S and TTX-R Nav channels [114]. Among them, neurotoxins possessing nociceptive effects like BmK I, a major peptide isolated from the Chinese Buthus martensii venom that is non-lethal for mammals, have been shown to induce spontaneous pain and hyperalgesia upon subcutaneous injections in rat hind paw $[115,116]$. Its activity involves the TTX-S Nav1.6 and TTX-R Nav1.8 channels which are over-expressed when BmK I is administered to rodents [117]. BmK I potentiates Nav1.6 and Nav1.8 currents revealing an important role for these channels in the modulation of spontaneous pain and mechanical allodynia [118-120]. During the process of hyperalgesia and pain sensitization induced by BmK I, it has been shown that both neuronal 5-HT3AR signaling pathway and microglia, with up-regulation of $\mathrm{P} 2 \mathrm{X} 7$ receptors and interleukin $1 \beta$, are activated [121,122].

The deadly North-African scorpions Androctonus australis and A. mauretanicus also have $\alpha$-toxins (AaH II and Amm VIII) able to induce mechanical and thermal pain hypersensitivity after peripheral injections in mice [123]. These toxins are particularly active on hNav1.7 currents, slowing their inactivation kinetics. Other pain-inducing $a$-toxins such as CvIVA (isolated from Centruroides vittatus) or LqhIII (Leiurus quinquestriatus), slow the fast inactivation of Nav1.7 channels [21,124]. Controversial effects have been shown using peripheral intraperitoneal (ip) injections of Amm VIII in mice that induce analgesic effects on hot plate pain model [125]. In this study, the authors suggest that activation of an opioid-dependent diffuse noxious inhibitory control could be responsible for the pain relief.

The a-toxin OD1, purified from the Iranian scorpion Odonthobuthus doriae venom, is known to inhibit fast inactivation of mammalian Nav1.4, Nav1.6 and Nav1.7 channels with nanomolar $\mathrm{EC}_{50}$ values but it also has a $\beta$-toxin activity on Nav1.4 and Nav1.6 channels [126]. OD1 also affects the inactivation kinetics of insect Nav channels [127,128]. Mutagenesis study using a triple mutant showed that 3 residues (Asp9, Asp10, Lys11) in the reverse turn region (region 8-12) contribute to sodium channel selectivity, the mutant being more selective to Nav1.7 over Nav1.6 [126]. In a recent study, using synthetic analogs of OD1 that are more potent on Nav1.7, it was shown that the effect of OD1 on $\mathrm{Na}^{+}$current inactivation is due to prolonged flickering between open and closed states [129]. OD1 has become a tool classically used to study acute pain behavior after peripheral administration in rodents.

The so-called "depressant scorpion $\beta$-toxins", by binding to the Nav site 4, and specifically on the extracellular loop of segments S3-S4 of domain II, are able to make them hyperactivable by shifting the activation curves of the currents towards negative potentials. Cells then have a long-lasting hyperexcitability [130]. Some of these toxins have analgesic properties. For instance, peripheral intraplantar ( $i p l)$ injections of $\mathrm{BmK}$ AS, isolated from Buthus martensii, display antinociceptive effects in a model of thermal and mechanical hyperalgesia induced by carrageenan in rats $[32,131]$. Moreover, central intrathecal (it) injections of BmK AS suppress spontaneous nociceptive behavior in rat formalin tests [132]. In the same venom, BmK IT2, a depressant insect selective toxin, reduces thermal pain and hyperalgesia after a peripheral injection in normal and inflamed rats $[133,134]$. The two peptides BmK AS and BmK IT2 have been further shown to block TTX-R and TTX-S Na+ conductances in rat sensory neurons, effects correlated with their analgesic effects $[32,132,135,136]$. Mutagenesis studies have proposed that critical aromatic residues (Trp, Tyr, Phe), that compose the hydrophobic active surface of the toxin, are involved in pharmacological blockade and in the analgesic activity of BmK AS [137].

Interestingly, other insect-selective toxins devoid of toxicity to mammals have been purified from Buthus martensii venom, which are also able to induce analgesic effects in mice. BmK IT$\mathrm{AP}$ and $\mathrm{BmK}$ AngP1 are excitatory insect toxins, with analgesic effects on the acidic twisting mice pain model [138]. However, $\mathrm{BmK}$ AngP1 analgesic effect is 5 times weaker than that of $\mathrm{BmK}$ IT-AP, although its toxicity to insects is twice as strong. This means that analgesic effects cannot be correlated with insect toxicity. 
The first $\beta$-toxin blocker of Nav1.7 is CeII8, isolated from the Centruroides elegans venom. It inhibits the peak sodium current, but its activity on pain models has not yet been investigated [139].

Until recently, a few scorpion toxins have been isolated that specifically target one of the nine mammalian Nav channel isoform. Tf2, a $\beta$-toxin that activate hNav1.3 channels involved in epilepsy and pain perception with a high specificity, was purified from the Brazilian scorpion Tityus fasciolatus. Tf2 $(1 \mu \mathrm{M})$ shift hNavl.3 activation voltage to much more negative values, effectively opening the channel at resting membrane potentials [140]. A more recent study reveals that Tf2 is also able to activate a hNav1.9 chimera at $\mu \mathrm{M}$ concentration [141]. Its activity on Navl. 3 is comparable to that of Ts 2 , another $\beta$-toxin isolated from Tityus serrulatus venom, but Ts2 is less specific, as it affects activation or fast inactivation of other pain-related Nav channel isoforms [142]. Peripheral (ipl) injections of Tf2 in mice causes spontaneous flinching and swelling, but this painful behavior is also observed when Navl.3 is inhibited in mice [141]. Moreover, a single mutation on a synthetic analogue of Tf2, Tf2 [S14R], is able to remove the excitatory activity of the toxin, and to be much less active on Nav1.3, while it retains its in vivo pain activity. This means that Navl.3 is not the unique target for pain inducing effects of Tf 2 and suggests an off-target activity [141].

The $\beta$-toxin Cn2 isolated from Centruroides noxius venom is a specific activator of Nav1.6 channels, which play an essential role in pain transmission in peripheral sensory neurons. Cn2 promotes and enhances Nav1.6 current $\left(\mathrm{EC}_{50}=39 \mathrm{nM}\right)$ in large mice DRG neurons and induces a significant increase in the number of evoked action potentials without changing in the resting membrane potential [143]. Cn2 was used as a selective activator of Nav1.6 channels present at peripheral terminals in the skin, to measure primary afferent response to mechanical stimulus in skin-saphenous nerve and colonsplanchnic nerve preparations. Application of $\mathrm{Cn} 2$ at the distal terminals innervating the skin caused increased responses to mechanical stimulation in A-fibers. Peripheral intra plantar injections of $\mathrm{Cn} 2$ in mice induces an immediate painful behavior (characterized by lifts, licks, shakes and flinches of the hind paw) lasting for 30 minutes along with the development of a mechanical allodynia [143]. A model of cold allodynia, induced by ipl oxaliplatin injections in mice shows a crucial functional contribution of Nav1.6. In this model, 4-aminopyridine and Cn2 ipl injections are able to enhance cold allodynia by combining Navl.6 activation and Kv inhibition [144]. A single mutation on $\mathrm{Cn} 2$ (Cn2E15R) was recently introduced to dissociate excitatory and depressant activities, resulting in a Nav1.6 inhibitor able to induce analgesic effects in rodents [145].

In China, Buthus martensii Karsch is widely used in traditional medicine, because its venom contains more than 10 analgesic peptides. BmK AGAP (Antitumor AnalGesic Peptide) another $\alpha$-toxin isolated from Buthus martensii, has analgesic properties in a mice visceral model induced by ip acetic acid injections, and in inflammatory pain induced by peripheral injection of formalin [146]. Single and double cystein mutations, aimed at modifying the four-disulfide bonds in BmK AGAP, revealed that they are necessary for analgesic activity. The "core domain" located between the $\alpha$-helix and two beta sheets is considered to be the analgesic domain of BmK AGAP [147]. Mutation of Trp38, a link between the two active surfaces of the peptide, can critically affect the structural stability of the peptide and also its analgesic properties $[34,147]$. Many other similar peptides (BmK AGP-SYPU1, BmK AGP-SYPU2) but also the insect selective (BmK IT-AP, BmKITAP3), ANEP toxin and BmK AngM1 display analgesic properties $[33,138,148-150]$. The exact interaction of these toxins with Nav remains unclear. Site directed mutagenesis revealed the prominent role of some residues (Tyr5 and Tyr42) in BmK AGP-SYPU1 for its analgesic activity and in particular for its interaction with the Nav1.7 channel $[149,151]$ but also the role of Gly residues at the $\mathrm{C}$-terminal end for analgesic properties of BmK AGP-SYPU2 (Zhang 2010 BMB).

It seems difficult to explain the pro-nociceptive effect of a scorpion venom that contains several types of toxins, some of which have pro-algic effects and others that are analgesic. In the case of Buthus martensii venom, a recent electrophysiological study comparing the successive and simultaneous application of the two toxins BmK I that is algogenic, and BmK IT2 that is rather antinociceptive, shows that $\mathrm{Na}$ currents are increased even in the presence of BmK IT2. This suggests that BmK IT2 increases the pharmacological effect of BmK I, and shows an allosteric interaction between sites 3 and 4 of Nav channels [152].

The toxin TsNTxP, a long peptide isolated from Tityus serrulatus, presenting structural similarities with $\alpha$ - and $\beta$-scorpion neurotoxins, was shown to exert antinociceptive effects in mice thermal and inflammatory pain models. It also shows antiallodynic effects in neuropathic pain models. Although not tested on Nav channels, this peptide reduces the release of glutamate in rodent spinal cord synaptosomes, which is an important neurotransmitter in nociceptive transmission that acts through ionotropic and metabotropic receptors [153].

From the venom of Buthus occitanus, a long peptide, BotAF was isolated, whose structure resembles a $\beta$-like toxin, but has low activity on TTX-S Nav channels from rat DRG. However, BotAF abolishes acute and inflammatory pain in rodents after peripheral or central administration [154]. This suggests a peripheral and spinal mechanism for this peptide activity whose target is yet unknown.

Kurtoxin, a 63-amino acid peptide isolated from the venom of the scorpion Parabuthus transvaalicus is structurally related to the $\alpha$-scorpion Nav toxins. Kurtoxin is a relative selective inhibitor for low threshold Cav3.1 (a1G) and Cav3.2 (a1H) calcium channels expressed in heterologous systems. Kurtoxin binds with high affinity $(\mathrm{Kd}=15 \mathrm{nM})$ on a single site on Cav3 and inhibits almost all the Cav3 current at $350 \mathrm{nM}$ concentration [155]. It acts as a gating modifier by shifting the opening of Cav3 channels to more positive voltages. Kurtoxin induces a slight inhibition, at higher concentrations, on high threshold Cav2.2 currents in the rat sympathetic and thalamic neurons [156]. Kurtoxin, 
also interacts on Nav channels by slowing both activation and inactivation current kinetics, as do a-type scorpion toxins [155]. However, despite its effects on pain-related channels, its activity has not been tested in vivo on pain behavior in animal models.

Inhibition of voltage-gated potassium channels (Kv) contributes to neuronal depolarization increased excitability and action potentials prolongation. Scorpion toxins that block $\mathrm{Kv}$ channels act synergistically with $\mathrm{Nav} \alpha$ - and $\beta$-toxins to promote neuronal hyperactivity. Ts 8 (also called TsK 2 or TsTxK $\beta$ ) is a long 60 amino acid peptide purified from Tityus serrulatus venom able to inhibit selectively Kv4.2 channels $\left(\mathrm{IC}_{50} \sim 300-600 \mathrm{nM}\right.$ ) without activity on other Kv nor Nav channels. Peripheral (ipl) and central (it) injections of Ts8 in mice induces a spontaneous pain behavior and a mechanical hyperalgesia [62]. Kv4.2 channels are expressed in the brain and heart. Their activation mediates transient currents in particular in dorsal horn neurons and contributes to modulate nociceptive responses [157].

The peptide BmP01 purified from the venom of Buthus martensii, is the first scorpion modulator of TRPV1 channels implicated in acute nociception, inflammation, and thermoregulation. BmP01 is a short peptide ( 29 amino acids) with 3 disulfide bonds stabilized in an Inhibitory Cystine Knot (ICK; [158]) structural fold whose solution structure was resolved [159]. This peptide is devoid of toxicity in mammals and insects. BmP01 dose-dependently activates TRPV1 similarly to capsaicin with an $\mathrm{EC}_{50}$ of $132 \mu \mathrm{M}$ [160]. It was also found to modulate the activity of voltage-gated potassium channels $(\mathrm{Kv})$ by inhibiting mKv1.3, hKv1.3, and rKv1.1, but not mKv1.1, thus presenting species specificity. It is interesting to note that injection of BmP01 in an acidic solution potentiates the pain response in mice, a fact that can be correlated with the acidic properties of scorpion venom [161]. Thus, BmP01 displays strong $\mathrm{pH}$-dependent activity (low potency at neutral $\mathrm{pH}$ ) showing that this peptide and protons synergize to enhance TRPV1 currents. Injection of BmP01 in mice evokes acute pain responses that reflects its specific effect on peripheral TRPV1, as this pain sensation disappears in TRPV1-KO mice [160]. In this peptide, a key residue, Lys23, has been shown to interact with Glu649 of TRPV1 [162].

Another peptide active in the same family of TRP channels was isolated recently from the Australian Black Rock scorpion, Urodacus manicatus. The "Wasabi Receptor toxin", WaTx, at low concentration, activates TRPA1 channels by binding to an intracellular site, prolongs its open-state duration, and lowers the calcium permeability, without activity on other TRP channels [163]. Peripheral injection in mice hind paw induces a painful behavior comparable to allyl isothiocyanate, the natural activator of TRPA1, but without neurogenic inflammatory symptoms.

\section{Spider Toxins Interacting with Pain-Related Ion Channels}

Spider venoms that are dangerous to humans have been widely studied over the past 30 years, with some being responsible for bites that trigger immediate and more severe pain than others.
Several genera belonging to mygalomorph (Atrax, Hadronyche, Missulena, Heteroscodra, Psalmopoeus...) and to araneomorph (Phoneutria, Heteropoda) have processed excitatory venoms containing major neurotoxins that modulate the activity of ion channels in sensory fibers (Figure 2). The focus of recent pain research has been on inhibitory toxins and in particular those with pain-relieving properties.

\section{Nociceptive spider venoms and toxins}

Spider bites are generally painful, with varying sensations ranging from immediate localized pain to more general pain that appears later and may persist for several days. Their venoms are a mixture of toxins acting upon both peripheral and central mechanisms. Their neurotoxins can activate peripheral nociceptive receptors (bradykinin B2, 5-HT4, glutamate NMDA and AMPA, tachykinin NK1 and NK2 receptors), or modulate ion channels (TTX-S Nav, TRPV1 and ASIC). Venom components may also activate central receptors (tachykinin, glutamate and CGRP) that are also involved with the production of inflammatory factors such as cytokines IL- $1 \beta$, TNF- $\alpha$ and prostanoids $[26,36]$. A large number of pro-algic spider peptides bind to Nav channels and promote their activation either by slowing down current inactivation kinetics, and/or shifting their voltage dependence properties (Table 2). These toxins interact specifically with paddle motifs that correspond to domains I-III for channel opening and to domain IV for $\mathrm{Na}^{+}$current fast inactivation [164]

Among araneomorph spiders, the Phoneutria species cause the most painful bites in humans, characterized by intense localized pain with inflammatory manifestations (edema, erythema) and hyperalgesia. The South America Phoneutria venoms are rich in peptides (more than 80 have been sequenced and characterized, MW 3500-9000 Da, www.arachnoserver.org) acting synergistically to produce neurotoxicity [165]. Phoneutria venom was shown to induce nociception by the stimulation of sensory fibers containing various pain-related receptors and ion channels such as kinin B2, 5-HT4 receptors, TRPV1, Nav, or ASIC channels [27]. Among nociceptive toxins present in Phoneutria nigriventer venom, PnTx2-6, a 48 amino acid peptide is one of the major lethal peptide following intracerebroventricular (icv) injection in mice, [166]. Central toxicity is characterized by neuronal hyperactivity associating priapism, salivation, convulsions, and spastic paralysis [167]. Peripheral injections of PnTx2-6 are known to be responsible for priapism, and have been extensively characterized [168]. PnTx2-6, injected in rat hind paw, also induces nociceptive response, in particular a mechanical hyperalgesia that can be measured by the paw pressure test [169]. The mode of action of PnTx2-6 is similar and common to that of $\alpha$-and $\beta$-type scorpion toxins on $\mathrm{Nav}$ channels, since the peptide has been shown to slow down the inactivation of neuronal and muscular Nav currents and to shift the voltage dependence of $\mathrm{Na}^{+}$conductance to negative potentials [166,168,170]. Amazingly, the active core of PnTx26 was used to design another 19 amino acid peptide, PnPP-19, 
Table 2. Pro-algic spider toxins, ion channels and pain.

\begin{tabular}{|c|c|c|c|}
\hline Spider species & Toxin & $\begin{array}{l}\text { Ion channel affinity } \\
\left(E C_{50} \text { or } I C_{50}\right)\end{array}$ & $\begin{array}{l}\text { Pain phenotype } \\
\text { [references] }\end{array}$ \\
\hline Atrax robustus & $\delta-H X T X-A r 1 a$ & $\begin{array}{l}\text { Nav1.1: } 30 \text { nM, Nav1.2: } 39 \text { nM, } \\
\text { Nav1.3: } 39 \text { nM, Nav1.6: } 91 \text { nM (tc) }\end{array}$ & Acute pain (ipl) [174] \\
\hline Heteropoda venatoria & $\begin{array}{c}\mathrm{HpTx} 1 \\
\kappa-S R T X-H v 1 a\end{array}$ & $\begin{array}{c}\text { Kv4.2: } 1 \mu \mathrm{M}, \text { Nav1.7: } 0.51 \mu \mathrm{M}, \\
\text { Nav1.9: } 0.47 \mu \mathrm{M}(\mathrm{tc})\end{array}$ & Mechanical hyperalgesia (ipl) [173] \\
\hline Heteroscodra maculata & $\begin{array}{c}\mathrm{Hm} 1 \mathrm{a} \\
\delta-T R T X-H m 1 a\end{array}$ & $\begin{array}{c}\text { hNav1.1: } 38 \text { nM; } \\
\text { hNav1.2; hNav1.3 (io) }\end{array}$ & $\begin{array}{l}\text { Acute and mechanical } \\
\text { pain (ipl) [53] }\end{array}$ \\
\hline Macrothele gigas & $\delta-H X T X-M g 1 a$ & $\begin{array}{c}\text { TTX-S Nav: } 46 \text { nM; } \\
\text { Nav1.1; Nav1.3; Nav1.6 (io) }\end{array}$ & ND [176] \\
\hline Cyriopagopus schmidti & DkTx & TRPV1: $0.2 \mu \mathrm{M}$ (tc) & ND $[75]$ \\
\hline Phoneutria nigriventer & $\operatorname{PnT} \times 2-6$ & Nav1.3: 200 nM (tc) & $\begin{array}{c}\text { Mechanical hyperalgesia (ipl) } \\
{[166,168-170]}\end{array}$ \\
\hline
\end{tabular}

Spider toxin rational nomenclature adopted by the ArachnoServer Spider Toxin Database [341] is given (in italics) as well as common names. Pain-related ion channel and other high-affinity channels (in italics) are indicated with known affinity values. Pain phenotype induced by toxins in rodent models. HXTX: hexatoxin; SRTX: sparatoxin; TRTX: theraphotoxin; io: injected oocytes; tc: transfected cells; ND: not done.

with properties, that can be used for the therapeutic benefit of erectile dysfunction, without toxicity nor immunogenicity but rather analgesic properties [171]. It was recently shown that PnPP-19 induces analgesic effects via a direct $\mu$-opioid receptors activation and an indirect calcium conductance inhibition [172].

In Heteropoda venatoria venom, the peptide HpTx1 was first identified as an inhibitor of Kv4.2 potassium channels. Unexpectedly, HpTx1 was recently shown to inhibit hNav1.7, without effect on rNav1.8 while it can activate hNav1.9 [173]. Submicromolar concentrations of this peptide significantly enhanced hNav1.9 currents and slowed down their inactivation. HpTx1 is able to restore nociception in Nav1.7-KO mice by enhancing the excitability of DRG neurons. The peptide, when injected into the hind paw of mice, triggered nociceptive behaviors and in particular mechanical pain, which did not occur in Nav1.7-KO mice. In brief, HpTx1 causes pain in WT and Nav1.7-KO mice and analgesia in Nav1.9-KO mice, but is ineffective in Nav1.8-KO mice. These contrary effects on channels involved in pain reveal the complexity of pain mechanisms and signaling pathways, which may also vary according to the species under consideration.

The venom of Theraphosids, in particular the famous Australian tarantulas Atrax and Hadronyche (funnel web spiders, Atracidae) contains several $\delta$-hexatoxins $(\delta$-HXTX) responsible for the serious envenomation leading to an excitatory neurotoxic syndrome sometimes fatal in humans. Most of these $\delta$-HXTXs are 42-44 amino acid peptides arranged in an ICK motif and target Nav channels. They all slow the inactivation kinetics of vertebrate TTX-S and insect Nav currents and bind to the voltage sensor domain IV. Recently, $22 \delta$-HXTX sequences from Australian spider species have been identified and their potency against human Nav channels evaluated [174]. A Fluorescent Imaging Plate Reader assay was used to determine the ability of $\delta$-HXTX-Arla, isolated from Atrax robustus, to potentiate heterologously expressed hNav channels. $\delta$-HXTXArla potentiates currents from the pain-related channels Nav1.1, and Nav1.6 but also Nav1.2 and Nav1.3 with nanomolar affinities $\left(\mathrm{EC}_{50}: 30-91 \mathrm{nM}\right)$. Nociception was characterized after the ipl injection of $\delta$-HXTX-Arla $(100 \mathrm{nM}, 20 \mu \mathrm{L})$ in mice that induced acute nocifensive behavior (flinches of the hind paw) for more than 15 minutes. These results strongly support, in addition to their insecticidal predatory function, a defensive role for Atracidae venoms, since all $\delta$-HXTX activate pain-related Nav channels in vertebrates and are thus able to induce algogenic effects during envenomation. $\delta$-HXTXs have slowly evolved from a common ancestry over the past 150-200 million years and today constitute defensive tools able to inflict pain against vertebrate predators with the exception of cats and dogs that are insensitive to Atracidae venoms [174]. Other $\delta$-HXTX isolated from the Australian Missulena bradleyi and from the Japanese Macrothele gigas share sequence homologies. In particular, $\delta$-HXTX-Mgla was shown to slow down TTX-S Nav current inactivation and to specifically activate rat Nav1.1 and Nav1.3 and mouse Nav1.6 [175,176].

Two peptides, Hmla and $\mathrm{Hm} 1 \mathrm{~b}$ (34-35 amino acid), isolated from the Theraphosid Heteroscodra maculata were shown to selectively interact with hNav1.1 by slowing down current inactivation. Hmla significantly prolongs action potential and does not alter the resting membrane potential in rodent central neurons [53]. Chimeric constructs between hNav1.1 and rKv4.1 channels helped to show that Hmla interacts with both S3b-S4 and the S1-S2 loop of domain IV on sodium channels. Moreover, peripheral injections of Hmla in mice elicit rapid and intense nocifensive responses. It also produces a strong bilateral sensitization to mechanical stimulation, revealing the role of Nav1.1 in mechanonociception, in particular inducing irritable bowel syndrome, a model of chronic mechanical hypersensitivity. 
Although a large number of $\delta$-toxin homologous structures are now known and we can predict their effects on Nav channels, these toxins have not been systematically tested on pain channels or in vivo pain models [176]. Other $\delta$-HXTX or $\delta$-TRTX responsible for nocifensive effects are likely to emerge in the coming years.

Vanillotoxins (VaTx1, VaTx2 and VaTx3) are 34-35 amino acid peptides with ICK fold, purified from Psalmopoeus cambridgei venom, able to activate TRPV1 channels with affinities ranging from 0.3 to $12 \mu \mathrm{M}$ [177]. Vanillotoxins seem specific for TRPV1 since they do not activate other pain-related TRPA1 nor TRPM8 channels. They interact with the outer pore region of TRPV1, on important sites within S5-S6 segments [75]. VaTx1 also blocks with the same affinity Kv2.1 channels in a voltage-dependent manner. Intra plantar injection of VaTx 3 , the most potent toxin on TRPV1, produces painful symptoms in mice characterized by licking and flinching, thus reproducing the equivalent behavior as with crude venom injection.

Another spider peptide, DkTx, is able to selectively and irreversibly activate TRPV1, without effect on other pain-related ion channels [75]. DkTx, purified from Cyriopagopus schmidti (former Ornithoctonus huwena) venom, has a very original structure since it is composed of two independently folded ICK peptides connected by a 7 residue linker, which explains the name "double-knot toxin" (DkTx). The single knot peptides, tested alone on TRPV1 were 5 to 50 fold less active. DkTx binds on TRPV1 in an open state, and in particular within the pore domain where several interaction sites in S5-S6 are important for its effects. The structure of DkTx has been solved together with its unusual mechanism of activation on TRPV1. This revealed an important interaction of the toxin within the surrounding lipid membrane that stabilizes the toxin-channel complex [178]. The two ICK knots of DkTx help to prolong the lifetime of the complex, and the toxin has a small protein-protein interface with TRPV1. A disruption of hydrophobic residues behind the selectivity filter leads to the opening of the channel. rTRPV1 channels have been functionally expressed in worms' polymodal nociceptive neurons to confer a specific, robust, and dosedependent avoidance behavior to capsaicin. However, DkTx that also binds to rTRPV1 does not elicit aversive behavior in C. elegans even at high concentrations [179]. DkTx activates rTRPV1 but its effects on nociception are still unknown in rodents and further study will be required.

\section{a-latrotoxin: a particular and unique case}

The black widow spider has become famous throughout the world for the dreaded effects of its venom on humans. Its bite leads to a very painful and long lasting cholinergic syndrome characterized by sustained muscular contractures (with the characteristic facial trismus), nausea, vomiting, dehydration, diarrhea that can lead to dramatic complications such as respiratory paralysis in fragile subjects [180-183]. The toxin responsible for this strong neurotoxicity belongs to a family of 3 proteins of $120-130 \mathrm{kDa}$ called $\alpha$-latrotoxins ( $\alpha$-LTx), each being specific to crustaceans, insects or mammals $[184,185]$.

By binding selectively and almost irreversibly to two types of receptors at the presynaptic nerve endings, $\alpha$-LTx causes membrane depolarization that results in a massive influx of $\mathrm{Ca}^{2+}$ into the cells. The exocytosis of the synaptic vesicles and the subsequent massive release of neurotransmitters cause a slow and long-lasting contracting paralysis in the mammal or insect victim $[185,186]$. A neurexin has been identified as the first receptor at the presynaptic level, it binds $\alpha$-LTx in a calciumdependent manner and interacts intracellularly with the protein synaptotagmin [187]. A second receptor, called CIRL-latrophilin (or CL1) binds $\alpha$-LTx in a calcium-independent way [188]. In a normal situation, synaptotagmin exerts a negative control on the release of neurotransmitters. $\alpha$-LTx, after binding to its receptor, inserts itself into the plasma membrane to form non-selective cation channels [189]. These high conductance channels, which are permanently opened, allow the $\mathrm{Ca}^{2+}$ entry responsible for the fusion of vesicles and the release of neurotransmitters [190]. The mode of action of $\alpha$-LTx would thus be to lift, via its receptor, the inhibitory control of synaptotagmin, thanks to the entry of $\mathrm{Ca}^{2+}$ ions. However, even in the absence of its receptor, it seems that $\alpha$-LTx can form pores in membranes by inserting itself into the lipid bilayer [191]. The three-dimensional structure of $\alpha$-LTx determined by cryo-electron microscopy shows that this protein can exist in two forms: dimeric or tetrameric. The tetrameric form represents the active form of $\alpha$-LTx, able of inserting itself into the lipid bilayer to form cationic channels $[188,192]$. The interaction with the cell surface would be via the $\mathrm{N}$-terminal domain of each monomer.

The $\alpha$-LTx case illustrates the extraordinary capacity and plasticity of neurotoxins to interact, in a specific way and with a wide variety of mechanisms, with neuronal plasma membrane to create ion flows and modulate, or even exacerbate, a physiological response (here the sustained muscle contractions and cramps) contributing to accentuate the pain felt by a prey or an aggressor.

\section{Interaction of spider toxins with ion channels and analgesic properties}

Antinociceptive spider toxins and toxin blocking pain-related ion channels are presented in Table 3. Spider genus and species are listed according to accepted taxonomy (Web Spider Catalog: https://wsc.nmbe.ch/). Spider toxin rational nomenclature adopted by the ArachnoServer Spider Toxin Database [341] is given (in italics) as well as common names. 
Table 3. Spider toxins, ion channels and antinociceptive effects.

\begin{tabular}{|c|c|c|c|}
\hline Spider species & $\begin{array}{l}\text { Toxin rational } \\
\text { nomenclature }\end{array}$ & $\begin{array}{l}\text { Ion channel: affinity } \\
\quad\left(\mathrm{IC}_{50}, \mathrm{EC}_{50}, \mathrm{Kd}\right)\end{array}$ & $\begin{array}{c}\text { Analgesia (phenotype) } \\
\text { [references] }\end{array}$ \\
\hline \multirow{4}{*}{ Agelenopsis aperta } & AG489, AG505 & TRPV1, 300 nM (io) & ND [292] \\
\hline & $\begin{array}{c}\omega-A G T X-A a 2 a \\
\omega-A g a-\| A\end{array}$ & Cav2.1, cCav2.2: 1-14 nM & ND [272] \\
\hline & $\begin{array}{c}\omega-A G T X-A a 3 a \\
\omega-A g a-I I I A\end{array}$ & $\begin{array}{c}\text { Cav2.1: } 0.5 \text { nM (nn), Cav2.2: } 1.5 \text { nM (nn), } \\
\text { Cav1: } 1 \text { nM (nn) }\end{array}$ & ND $[273,342,343]$ \\
\hline & $\begin{array}{l}\omega \text {-AGTX-Aa4a } \\
\omega \text {-aga-IVA }\end{array}$ & Cav2.1: 2-6 nM (nn) & $\begin{array}{c}\text { Mechanical and heat hyperalgesia } \\
\text { in inflammatory pain [268-271] }\end{array}$ \\
\hline $\begin{array}{l}\text { Ceratogyrus marshalli } \\
\text { (cornuatus) }\end{array}$ & $\begin{array}{l}\beta-T R T X-C m 1 a \\
\text { CcoTx1 }\end{array}$ & $\begin{array}{l}\text { Nav1.1: } 500 \text { nM, Nav1.2: } 3 \text { nM, } \\
\text { Nav1.5: } 323 \text { nM, Nav1.8: } 2 \mu M \text { (io) }\end{array}$ & ND [245] \\
\hline \multirow[t]{2}{*}{ Ceratogyrus darlingi } & $\begin{array}{l}\beta-T R T X-C d 1 a \\
\text { Cd1a }\end{array}$ & $\begin{array}{c}\text { hNav1.7: } 16 \text { nM (tc), hNav1.8, } \\
\text { rCav2.2: } 3 \mu \mathrm{M}(\mathrm{tc})\end{array}$ & Acute pain [242] \\
\hline & JZTX-34 & TTX-S Nav: 85 nM, Nav1.7: 610 nM (tc) & $\begin{array}{l}\text { Acute, heat and inflammatory } \\
\text { pain }[211,212]\end{array}$ \\
\hline \multirow[t]{2}{*}{$\begin{array}{l}\text { Chilobrachys } \\
\text { jingzhao }\end{array}$} & $\begin{array}{c}\beta-T R T X-G j 2 a \\
\text { JZTX-V }\end{array}$ & $\begin{array}{l}\text { rNav1.7: } 62 \text { nM (tc), rNav1.4: 5nM (tc), } \\
\text { hNav1.7: } 0.63 \text { nM (tc), Kv4.2: } 604 \text { nM (io) }\end{array}$ & ND [207] \\
\hline & 5Br-Trp24-JZTX-V (AM6120) & $\begin{array}{c}\mathrm{hNav1.7:} 0.8 \mathrm{nM}(\mathrm{tc}), \mathrm{mNav1.7:} 5.4 \mathrm{nM}(\mathrm{tc}) \\
\text { hNav1.4: } 104 \mathrm{nM}(\mathrm{tc})\end{array}$ & Anti-pruritis [210] \\
\hline \multirow{2}{*}{ Cyriopagopus albostriatus } & $\begin{array}{l}\mu-T R T X-C a 1 a \\
\text { Ca1a }\end{array}$ & $\begin{array}{c}\text { Nav1.7: } 378 \text { nM, Nav1.6: } 547 \text { nM, } \\
\text { Nav1.2: } 728 \text { nM (tc) }\end{array}$ & $\begin{array}{l}\text { Acute, heat and inflammatory } \\
\text { pain [215] }\end{array}$ \\
\hline & $\begin{array}{l}\mu-T R T X-C a 2 a \\
\text { Ca2a }\end{array}$ & $\begin{array}{c}\text { Nav1.7: } 98 \text { nM, Nav1.2: } 216 \text { nM, } \\
\text { Nav1.6: } 313 \text { nM, Nav1.3: } 491 \text { nM (tc) }\end{array}$ & $\begin{array}{l}\text { Acute, heat and inflammatory } \\
\text { pain [214] }\end{array}$ \\
\hline \multirow[t]{2}{*}{ Cyriopagopus doriae } & $\begin{array}{l}\mu-T R T X-H d 1 a \\
H d 1 a\end{array}$ & hNav1.7: 111nM (io), hNav1.1 (io) & ND [195] \\
\hline & $\begin{array}{l}\mu-T R T X-H h n 2 a \\
\text { HainanTxIII }\end{array}$ & $\begin{array}{c}\text { Nav TTX-S: } 1 \text { nM (nn), hNav1.7: 211nM, } \\
\text { hNav1.3: 491nM (tc) }\end{array}$ & $\begin{array}{l}\text { Inflammatory, visceral and } \\
\text { neuropathic pain }[231,344]\end{array}$ \\
\hline \multirow[t]{3}{*}{ Cyriopagopus hainanus } & $\begin{array}{l}\mu \text {-TRTX-Hhn1b } \\
\text { HainanTxIV } \\
(\beta-T R T X-H n 2 a)\end{array}$ & $\begin{array}{l}\text { TTX-S Nav: } 45 \text { nM (nn), hNav1.7: } 21 \text { nM, } \\
\text { Nav1.2: } 31 \text { nM, Nav1.3: } 375 \text { nM (tc) }\end{array}$ & $\begin{array}{c}\text { Inflammatory, visceral \& } \\
\text { neuropathic pain }[228,344,345]\end{array}$ \\
\hline & $\begin{array}{c}\mu-T R T X-H s 1 a \\
H s 1 a\end{array}$ & $\begin{array}{c}\text { Nav1.1: } 19.4 \text { nM, Nav1.6: } 19.2 \text { nM, } \\
\text { Nav1.7: } 27 \text { nM (tc) }\end{array}$ & ND [201] \\
\hline & $\begin{array}{c}\mu / \omega-T R T X-H h 1 a \\
\text { HWTX-I }\end{array}$ & Cav2.2: 100 nM (nn), TTX-S Nav: 55nM (nn) & Inflammatory pain $[278,346,347]$ \\
\hline \multirow[t]{3}{*}{ Cyriopagopus schmidti } & $\mu-T R T X-H h 2 a$ HWTX-IV & $\begin{array}{c}\text { hNav1.7: 17-100 nM (tc), hNav1.6: } 52 \text { nM (tc), } \\
\text { hNav1.2: 44-150 nM (tc), hNav1.1: } 41 \text { nM (tc), } \\
\text { hNav1.3: } 350 \text { nM (tc) }\end{array}$ & $\begin{array}{l}\text { Inflammatory, visceral } \\
\text { and neuropathic pain } \\
{[221,222,227,236,348]}\end{array}$ \\
\hline & $\begin{array}{c}\omega-T R T X-C s-10 \\
\text { HWTX-X }\end{array}$ & Cav2.2: 40 nM (nn) & ND [280] \\
\hline & $\begin{array}{c}\omega-T R T X-C s-16 \\
\text { HWTX-XVI }\end{array}$ & Cav2.2: 60nM (nn) & $\begin{array}{l}\text { Heat, inflammatory and post- } \\
\text { operative pain [281] }\end{array}$ \\
\hline Cyriopagopus lividus & $\begin{array}{c}\mu-T R T X-H I 1 a \\
\text { HI1a }\end{array}$ & Nav1.8: $2 \mu M(t c)$ & $\begin{array}{l}\text { Inflammatory, visceral and } \\
\text { neuropathic pain [244] }\end{array}$ \\
\hline Cyriopagopus schioedtei & $\begin{array}{l}\mu-T R T X-C s 1 a \\
\text { Cyriotoxin1a }\end{array}$ & $\begin{array}{c}\text { TTX-S Nav: } 170 \text { nM, hNav1.1: } 72 \text { nM, } \\
\text { hNav1.2: } 76 \text { nM, hNav1.6: } 115 \text { nM, } \\
\text { hNav1.7: } 130 \text { nM (tc) }\end{array}$ & Heat and mechanical pain [213] \\
\hline $\begin{array}{l}\text { Cyriopagopus sp. } \\
\text { (Phlogiellus) }\end{array}$ & $\begin{array}{l}\mu-T R T X-P h l o 1 a \\
\text { PhITx1 }\end{array}$ & hNav1.7: 39-260 nM (tc-io) & $\begin{array}{l}\text { Acute and inflammatory } \\
\text { pain }[204,232]\end{array}$ \\
\hline Davus fasciatus & $\begin{array}{c}\mu-T R T X-D f 1 a \\
\text { Df1a }\end{array}$ & $\begin{array}{l}\text { hNav1.7: } 2 \text { nM, hNav1.3: } 3 \text { nM, } \\
\text { hNav1.6: } 8 \text { nM, hNav1.1: } 14 \text { nM, } \\
\text { hCav3.2: } 253 \text { nM (tc) }\end{array}$ & Acute pain [241] \\
\hline Geolycosa sp. & Purotoxin (PT1) & P2X3: 12 nM (nn) & $\begin{array}{l}\text { Heat hyperalgesia in } \\
\text { inflammatory pain [301] }\end{array}$ \\
\hline
\end{tabular}


Table 3. Cont.

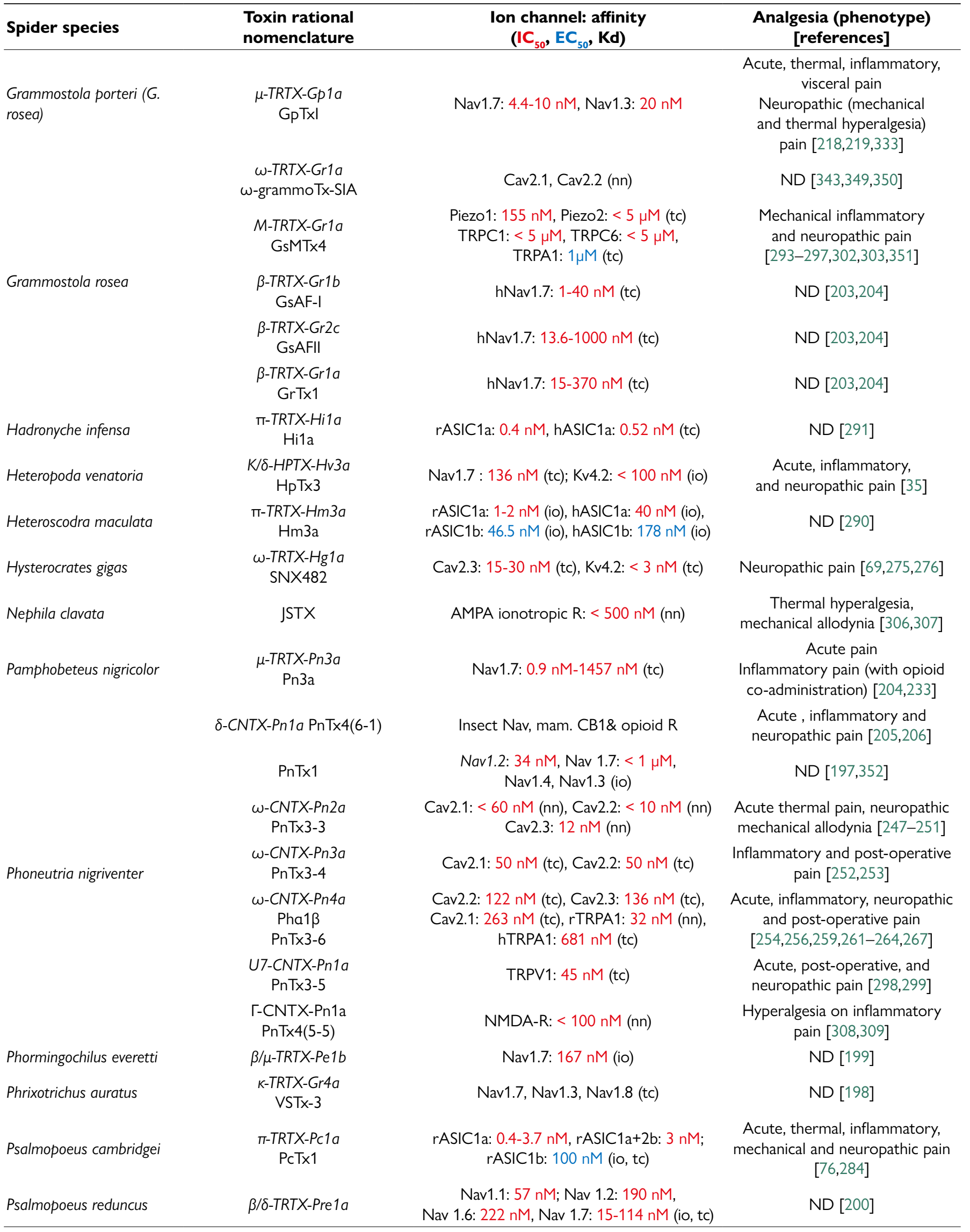


Table 3. Cont.

\begin{tabular}{|c|c|c|c|}
\hline Spider species & $\begin{array}{l}\text { Toxin rational } \\
\text { nomenclature }\end{array}$ & $\begin{array}{c}\text { Ion channel: affinity } \\
\left(I C_{50}, E C_{50}, K d\right)\end{array}$ & $\begin{array}{c}\text { Analgesia (phenotype) } \\
\text { [references] }\end{array}$ \\
\hline \multirow[t]{2}{*}{ Theraphosa apophysis } & $\begin{array}{l}\text { TRTX-Tap1a } \\
\text { Tap1a }\end{array}$ & $\begin{array}{l}\text { hNav1.1: } 301 \text { nM, hNav1.2: } 95 \text { nM, } \\
\text { hNav1.3: } 179 \text { nM, hNav1.6: } 191 \text { nM, } \\
\text { Nav1.7: } 80 \text { nM, Cav3.2: 1.23 } \mu \text { M (tc) }\end{array}$ & $\begin{array}{l}\text { Mechanical hyperalgesia } \\
\text { in visceral pain [243] }\end{array}$ \\
\hline & $\begin{array}{l}\beta / \omega-T R T X-T p 1 a \\
\quad \text { ProTx-I }\end{array}$ & $\begin{array}{c}\text { Nav1.2: } 104 \text { nM; Nav1.6: } 21 \text { nM, } \\
\text { Nav1.7: 51-95 nM, Nav1.8, } \\
\text { Nav1.5: } 20 \text {-358 nM } \\
\text { rCav3.1: } 50 \text { nM, hCav3.1: } 640 \text { nM (tc), } \\
\text { Kv2.1: } 411 \text { nM, hTRPA1: } 389 \text { nM (tc) }\end{array}$ & ND [199,234,235,300,353] \\
\hline Trixopelma pruriens & $\begin{array}{l}\beta / \omega-T R T X-T p 2 a \\
\quad \text { ProTx-II }\end{array}$ & $\begin{array}{c}\text { Nav1.7: 0.3-72 nM, hNav1.1: } 16 \text { nM, } \\
\text { hNav1.3: } 25 \text { nM, Nav1.5: 19-400 nM, } \\
\text { hNav1.6: } 31 \text { nM, Cav3.1: } 150 \text { nM, } \\
\text { hCav3.2: > } 1 \mu M \text { (tc) }\end{array}$ & $\begin{array}{c}\text { Acute and inflammatory pain } \\
{[37,234,235,237,238,353]}\end{array}$ \\
\hline
\end{tabular}

AGTX: agelenatoxin; CNTX: ctenitoxin; TRTX: theraphotoxin, HPTX: heteropodatoxin. Pain-related ion channel and other high-affinity channels (in italics) are indicated with known affinity values ( $\left.\mathrm{IC}_{50}, \mathrm{EC}_{50}, \mathrm{Kd}\right)$. lo: injected oocytes; tc: transfected cells; nn: native neuronal currents; fi: fluorescent imaging; ND: not done. Type of analgesia induced by toxins and reported from rodent model experiments. Cyriopagopus (former Haplopelma) doriae; Cyriopagopus hainanus (Ornithoctonus or Haplopelma or Selenocosmia hainana); Cyriopagopus schmidti (former Haplopelma or Ornithoctonus huwena); Chilobrachys jingzhao (former C. guangxiensis); Grammostola rosea (former G. spatulata); Phrixotrichus auratus (former Paraphysa scrofa).

\section{Inhibition of Nav channels}

Curiously, while spider bites are quite painful, a very large number of analgesic toxins were identified, which block the activity of Nav involved in pain. The search for specific inhibitors of the Nav1.7 channel, one of the major actors in the transmission of pain in the PNS, has led to the identification from tarantula venoms of more than 20 peptides having between 26 and 35 amino acids and belonging to different structural families. Off-targets activities, especially on the skeletal muscle isoform Nav1.4, on the cardiac isoform Nav1.5, but also on neuronal isoforms Nav1.2 and Nav1.6, could impact the therapeutic window and cause dose-limiting adverse effects [193].

Twelve families of peptides that target Nav and called "NaSpTx" (for voltage-gated sodium channel spider toxin) families 1-12, have been defined based on their activity or sequence similarity [194]. Families NaSpTx1-3 include toxins that are more or less potent and selective for pain-related Nav channels. In the NaSpTx family 1 , all peptides were isolated from the venom of tarantulas (Theraphosidae), and consist of 33-35 amino acid residues with 3 disulfide bridges that form an ICK motif. They bind to the S1-S2 and S3-S4 linkers of Nav domain II (neurotoxin site 4). In the NaSpTx2 family, more than 30 peptides with 33-41 residues and ICK motif inhibit Nav, Cav or Kv channels. They bind to S3-S4 linker of Nav domain IV (site 3). NaSpTx3 family includes peptides with 29-32 residues, 3 disulfide bonds, ICK motif, which act as gating modifiers by binding to the voltage sensor region (S3-S4 linker) of channel domain II (site 4).

Some peptides block pain-related Nav but have not yet been tested on nociceptive models, which does not allow their analgesic function to be asserted. This is the case for several theraphosids peptides, such as $\mu$-TRTX-Hdla from Cyriopagopus (former Haplopelma) doriae, $\mu$-TRTX-Ccyla, -1b from Chromatopelma cyaneopubescens, $\mu$-TRTX-Osp1a, -1b from Orphnaecus sp., $\mu$-TRTX-Epla from Cyclosternum (former Euathlus) pulcherrimaklaasi, $\mu$-TRTX-Phlola, -Phlolb, from Cyriopagopus sp. (former Phlogius), and $\mu$-TRTX-Sela from Selenocosmia effera venoms, which inhibit human Nav1.7. All have 32-35 amino acids, an ICK structure, and are members of NaSpTx-F1-F2 or -F3 [195-197]. A high level of selectivity was found for $\mu$-TRTX-Hdla, which inhibits hNav1.7 with a good affinity (IC ${ }_{50} 111 \mathrm{nM}$ ) but also Nav1.1 [195].

Many other spider peptides can be listed with such inhibitory effects on pain-related Nav channels. The voltage sensor toxin 3 (VSTx-3 or $\kappa-T R T X-G r 4 a)$, a 34 amino acid peptide purified from Grammostola rosea venom, is a Cav and Kv blocker but also an inhibitor of TTX-S hNav1.3, hNav1.7 and Nav1.8. [198]. From the same venom, GTx1-15 peptide potently inhibits hNav1.7 (IC $_{50}$ $7 \mathrm{nM}$ ) and Nav1.3 with minor effects on TTX-R channels. The two peptides (34 residues) $\beta / \mu$-TRTX-Pela and $\beta / \mu$-TRTX-Pelb from the arboreal tarantula Phormingochilus everetti are Nav1.7 inhibitors. The recombinant Pelb peptide shows potent and relative selective inhibition $\left(\mathrm{IC}_{50} 167 \mathrm{nM}\right.$ ) on Nav1.7 compared to other Nav isoforms such as Nav1.6, Nav1.5 and Nav1.2 [199].

The $\beta / \delta$-TRTX-Prela is a 35 residue peptide, isolated from the tarantula Psalmopoeus reduncus, which inhibits activation of hNav1.2, hNav1.6, and hNav1.7, and both activation and inactivation of Nav1.1. The $\beta / \delta$-TRTX-Prela interact with the S3$S 4$ loops in DII and DIV Nav channels voltage sensors and with some residues in the S1-S2 loops that are critical for imparting isoform selectivity [200].

The Hsla peptide isolated from the Chinese tarantula Cyriopagopus (former Haplopelma) schmidti is a potent blocker of the pain-related channels hNav1.1, hNavl.6, and hNav1.7 and others such as hNav1.2 and hNav1.3. A fluorescent recombinant 
peptide, Hsla-FL was designed as a vector for delivering an optical sensor to target Nav1.7 in the peripheral nerves of mice in vivo [201]. HS1a-FL was hence developed as a near-infrared imaging agent used to visualize the limits of an operating area during surgery around nerves and to avoid nerve damage with serious or irreversible consequences.

PnTx1 is a longer peptide with 78 residues, isolated from the Ctenidae Phoneutria nigriventer, which inhibits rat Nav1.7 but also Nav1.2, Nav1.3 and Nav1.4 with comparable affinities and has no effect on hNav1.5 nor insect Nav [197]. It is known to induce neurotoxicity after icv injection in mice but its peripheral effects have not been yet described.

For most of these peptides, effects on rodent pain model have not yet been investigated, probably because of a lack of selectivity on pain-related channels. Another limiting factor in the search for new analgesics is the target promiscuity of spider peptides. Studies showed that several Grammostola toxins are active on $\mathrm{Kv}, \mathrm{Cav}$ and Nav channels, and some of them can act both as pore-blockers and gating-modifiers on different ion channels [202]. As an example, the peptide GsAFI has inhibitory effects on several Nav channels ( $\mathrm{IC}_{50} 1-40 \mathrm{nM}$ on Nav1.7) but also on the cardiac potassium channel hERG1 at higher concentrations that makes it unusable for the design of pain medication [203,204].

\section{Analgesic peptides that target Nav channels}

One of the most painful venoms among araneomorph spiders is that of the Phoneutria species, which is however composed of several analgesic peptide toxins. The $\delta$-CNTX-Pnla (PnTx4(6-1) is a 48 amino acid peptide presenting high toxicity to insects but not to rodents after central injections. This $\alpha$-like toxin targets insect Nav without affecting mammalian Nav channels[205]. $\delta$-CNTX-Pnla $(5 \mu \mathrm{g}, i p l)$ induces analgesic effects in several pain models in rats including carrageenan-induced inflammatory hyperalgesia [206]. In a neuropathic (SNI) pain model, $\delta$-CNTXPnla $(0.5 \mu \mathrm{g}, i t)$ rapidly reverses hyperalgesia induced by sciatic nerve constriction. $\delta$-CNTX-Pn $1 \mathrm{a}(0.5 \mu \mathrm{g}$, it $)$ also induces antinociceptive effects on an acute pain model (prostaglandin E2, ipl). Although the direct involvement of ion channels in this analgesic effect is not known, it was shown that other receptors are involved in the opioid and cannabinoid endogenous systems [206]. Broader research would make it possible to identify more specific targets among other mammalian ion channels.

The venom from the large araneomorph Heteropoda venatoria contains the HpTx3 peptide, a Kv4.2 potassium channel inhibitor, which was recently found to be a potent and selective hNav1.7 blocker $\left(\mathrm{IC}_{50} 136 \mathrm{nM}\right.$ ) [35]. Its interaction in S3-S4 loop in domains II and IV of $\mathrm{Nav}$ is representative of a mixt pore blocking and gating modifier effect. When HpTx3 $(0.2-5 \mathrm{mg} / \mathrm{kg})$ is peripherally injected in mice, analgesic effects are observed in acute (acetic acid, hot plate), inflammatory (formalin, CFA) and neuropathic (SNI) pain models [35].

Two analgesic peptides have been isolated from the Chinese earth tiger Chilobrachys jingzhao venom: JZTX-V, 29 residues, which inhibits TTX-R and TTX-S Nav with potent affinities $\left(\mathrm{IC}_{50}\right.$ around $30 \mathrm{nM}$ ) in rat sensory neurons [207]. It alters the gating properties of channels, by shifting $\mathrm{Na}^{+}$current activation and inactivation curves. A complete blockade of the skeletal muscle rNav1.4 is observed with JZTX-V, while the inhibition of hNav1.7 is incomplete, which could lead to adverse effects [208]. The search for selective inhibitors for Nav1.7 led to the mutation of a key residue, Ile28, which contributes to the affinity of JZTX-V for Nav1.4. Several analogues, with the Ile28Glu mutation, present a higher affinity and selectivity for TTX-S Nav over TTX-R Nav in DRG neurons and inhibit Nav1.7 with sub-nanomolar affinities [209]. Other mutations leading to 5Br-Trp24-AM-6120 peptide provide optimization of selectivity and potency for hNav1.7 and mNav1.7. This latter mutant also showed analgesic properties following $2 \mathrm{mg} / \mathrm{kg} s c$ injections, on a mice pruritis model induced by histamine [210]. In the same venom, the peptide JZTX-34, blocks TTX-S Nav ( $\mathrm{IC}_{50} 85 \mathrm{nM}$ ) in rat DRG neurons and shifts the steady state inactivation curve, without effect on TTX-R Nav [211]. JZTX-34 preferentially blocks Nav1.7 (IC $610 \mathrm{nM}$ ) compared to other Nav1 isoforms, by binding to the S3-S4 linker on domain II voltage sensor, in particular on a critical residue (D816) and trapping domain II S4 in a resting state [212]. JZTX$34(0.5$ to $2 \mathrm{mg} / \mathrm{kg}$, ip) dose-dependently reverses acute and inflammatory pain in the formalin test in mice. JZTX-34 also reduces abdominal contractions and hind limb movements in the acetic acid-induced writhing test. In the hot plate test, JZTX-34 (ip) increases the latency time for escaping [212].

The venom of the Malaysian earth tiger Cyriopagopus species contains analgesic peptides like Cyriotoxin 1a (CyrTx-1a, 33 amino acids, NaSpTx1 family) isolated from C. schioedtei. CyrTx-1a inhibits human Nav1.1, Nav1.3, Nav1.6 and Nav1.7 with nanomolar affinities and minor effects on Cav or Kv channels. The peptide was selected, after a high throughput screening of 117 venoms tested on functional automated patch-clamp assays, for their ability to block hNavl.7 with high potency and selectivity [213]. CyrTx-1a also inhibits TTX-S Nav currents in mouse DRG neurons ( $\mathrm{IC}_{50} 170 \mathrm{nM}$ ) with a good selectivity over TTX-R Nav. Despites its effects on Nav1.6, ipl injections of the peptide does not impair mice skeletal neuromuscular excitability. Analgesic properties of CyrTx-1a (102 nmol/kg, ipl) were evaluated on a hot plate model. It is important to note that in vivo toxicity (50\% death) was seen using quite the same concentrations $(144 \mathrm{nmol} / \mathrm{kg})$, but after intra muscular injections.

Cyriopagopus albostriatus venom contains two peptides, $\mu$-TRTX-Cala and $\mu$-TRTX-Ca2a, 38 and 35 amino acid respectively, which are more selective for hNav1.7 and do not alter its voltage-dependent properties [214,215]. Cala (100-500 $\mu \mathrm{g} / \mathrm{kg}, i p l)$ and $\mathrm{Ca} 2 \mathrm{a}(50-200 \mu \mathrm{g} / \mathrm{kg}$, ip or ipl) show analgesic properties in acute (acid acetic-induced writhing), inflammatory (formalin test) and heat (hot plate) pain models in mice, dosedependently attenuating pain behaviors [214,215].

In Grammostola porteri venom, GpTx1 (also called Gtx1-15; 34 residues, NaSpTx1 family [198]), has a potent inhibitory activity on Nav1.7 ( $\mathrm{IC}_{50} 10 \mathrm{nM}$ ) and a good selectivity over Nav subtypes [216]. Different amino acid substitutions (Ala, Glu, Arg and Lys scans) were designed to obtain mutant peptides with single digit 
nanomolar potency on Nav1.7 and more selectivity against Nav1.4 and Nav1.5 [216,217]. The co-injection of GpTx1 (30-300 nM, $i p l)$ with the painful scorpion peptide OD1, dose-dependently reduces spontaneous pain behavior in mice. However, a systemic injection ( $i p$ ) of GpTx1 is unable to reverse OD1 effects even at a high concentration $(0.1 \mathrm{mg} / \mathrm{kg})$ [218] and induces motor deficits (ataxia) at higher doses $(0.3 \mathrm{mg} / \mathrm{kg})$, which is probably due to its inhibitory effect on Nav1.6. A higher selectivity for Nav1.7 over Nav1.6 seems necessary to get an acceptable therapeutic window for systemic use of analgesic peptides. In other pain models, the central (it) injection of GpTx1 induces antinociception involving the opioid system but without tolerance nor motor side effects [219]. GpTx1 (0.05-5 pmol, it) dose-dependently produces analgesia in the tail flick test and in the acetic acid-induced visceral pain. Gptx1 (0.1-5 pmol, it) also prevents mechanical allodynia in carrageenan-induced inflammatory pain, and thermal hyperalgesia in CCI-induced neuropathic pain [219]. Moreover, GpTx1 (0.1-10 pmol, it) reduces the nociceptive acute and inflammatory responses induced by formalin injection.

Venoms from the Chinese bird-eating Cyriopagopus sp. (formerly Ornithoctonus or Selenocosmia or Haplopelma) are rich in peptides modulating Nav channels. Huwentoxin IV (HWTXIV, 35 amino acid, NaSpTx1 family) a peptide isolated from Cyriopagopus schmidti specifically inhibits TTX-S Na ${ }^{+}$currents without effect on TTX-R Na+ currents in rat DRG neurons [220]. HWTX-IV potently inhibits hNav1.7, rNav1.2, rNav1.3 and hNav1.6 [221,222]. It has no effects on skeletal muscle rNav1.4 and cardiac hNav1.5. HWTX-IV binds to site 4, in particular with 5 residues that are crucial to impair activation of Nav1.7, trapping the domain II sensor in a closed state [223]. A docking model of the toxin on Nav1.7 has been proposed showing that several key molecular determinants forming a hydrophobic patch are important for its interaction [224,225]. In order to find new powerful analgesics, several HWTX-IV analogs were synthesized showing an increased potency and/or selectivity on hNav1.7 over other Nav isoforms [221,226]. HWTX-IV induces analgesic effects in inflammatory and neuropathic pain models in rodents [227]. Injection of HWTX-IV $(100 \mu \mathrm{g} /$ $\mathrm{kg}$ ) in rats produces an efficient reversal of formalin-induced hyperalgesia and a protective effect after acetic acid injection. Moreover, HWTX-IV induces antiallodynic effects on a spinal nerve model of chronic neuropathy. However, the interaction of HWTX-IV with Nav1.6 may suggest in vivo motor side effects that could impair its use as a therapeutic analgesic drug [222].

The venom of the tarantula Cyriopagopus (former Haplopelma) hainana contains two main peptides, Hainantoxin-III and -IV, presenting sequence homologies with HWTX-IV. HNTX-III and HNTX-IV inhibit TTX-S Nav currents in rat DRG ( IC $_{50} 1.1$ and $44.6 \mathrm{nM}$ respectively) and do not affect Cav nor $\mathrm{Kv}$ channels [228]. These peptides shift the $\mathrm{Na}^{+}$current inactivation curve in the hyperpolarizing direction without affecting activation and inactivation kinetics. In particular, they inhibit hNav1.7 current activation in a manner similar to HWTX-IV, trapping the voltage sensor in the closed state [229]. HNTX-III and HNTX-
IV bind to site 4, located on the extracellular S3-S4 linker of hNav1.7 domain II [230]. Both peptides (50 to $200 \mu \mathrm{g} / \mathrm{kg}$, ip pretreatment) produce analgesia in inflammatory (CFA, formalin), acute visceral (acetic acid injections) and neuropathic (SNI) pain models in rodent, by reversion of mechanical hyperalgesia, without CNS side effects [227,231].

Phlotoxin-1 (PhlTx1, a 34 amino acid) isolated from Cyriopagopus (former Phlogiellus) sp., presents low sequence homologies with the other identified peptides in the NaSpTx1 family. PhlTxl inhibits hNav1.7 with potent affinity $\left(\mathrm{IC}_{50} 39 \mathrm{nM}\right)$ and selectivity, with almost irreversible effects. It slightly inhibits hNav1.4 and hNav1.6 at high $(1 \mu \mathrm{M})$ concentration [204,232]. The blocking efficiency of PhlTxl was compared with that of 10 leading spider toxins, belonging to NaSpTx1-3 families, known to inhibit Nav1.7, in the same experimental conditions [204]. The most potent hNav1.7 inhibitor peptides in this study are HNTXIV, HWTX-IV, HWTX-I, ProTx-I, ProTx-II, GsAFI, GsAFII, GrTxl and PhlTxl with $\mathrm{IC}_{50}$ below $50 \mathrm{nM}$. Injections of PhlTx1 $(0.47 \mu \mathrm{g}, i t)$ reduces acute and inflammatory pain in the OD1 and formalin models in mice without neurotoxic effects [232].

The peptide $\mu$-TRTX-Pn3a (Pn3a, 35 amino acids) isolated from Pamphobeteus nigricolor potently inhibits hNav1.7 $\left(\mathrm{IC}_{50}\right.$ $0.9 \mathrm{nM}$ ) with an exquisite selectivity over all hNav isoforms, $\mathrm{Kv}$, Cav channels and nicotinic acetylcholine receptors [233]. Pn3a is a gating modifier toxin that shifts the voltage dependence of Nav1.7 activation to more depolarized membrane potentials. It binds to S3-S4 linkers in the voltage sensing DII and DIV domains of Nav1.7. Pn $3 \mathrm{a}$ at the highest dose tested $(3 \mathrm{mg} / \mathrm{kg}$, $i p)$, induces a sustained analgesic activity, on acute (OD1, ipl) spontaneous pain model. Curiously, no attenuation of noxious heat pain was observed on the hot plate model. Moreover, the peptide was devoid of anti-allodynic activity in inflammatory pain models in rodents when administered systemically except when it was co-injected with subtherapeutic doses of opioids [233]. More recent studies have shown that $\mathrm{Pn3a}$ is a poor inhibitor for hNav1.7 $\left(\mathrm{IC}_{50}>1 \mu \mathrm{M}\right)$ in mammalian transfected cells that raises the question of its real affinity for Nav1.7 [204].

The protoxins, ProTx-I (35 amino acids, NaSpTx2 family) and ProTx-II (30 amino acids, NaSpTx3 family) are ICK peptides isolated from Trixopelma pruriens venom. They are the first inhibitors for the TTX-R Nav, by blocking hNav1.5 and rNav1.8 currents with a similar potency $\left(\mathrm{IC}_{50} 20-30 \mathrm{nM}\right.$ ), acting like gating modifiers $[234,235]$. They are also potent inhibitors of the TTX-S Nav1.2, Nav1.6, and Nav1.7. ProTx-II is more potent on Nav1.7 than on Nav1.5, and inhibits the fast inactivation of hNav1.7 by trapping the domain IV voltage sensor in the resting conformation [236]. ProTx-I and -II also shift the voltage dependence of activation of Cav3.1 [234,235]. Moreover, submicromolar concentration of ProTx-I inhibits the potassium Kv2.1 channel and TRPA1 that represent an important off target impact. On skin-nerve preparation, ProTx-II $(0.3-10 \mu \mathrm{M})$ is able to reduce the amplitude of $C$-fiber action potential with weaker effects on A $\beta$-fibers, only on desheathed sensory nerves [237]. The maximum tolerated dose is $2 \mu \mathrm{g}(i t)$ in rats, since higher doses 
induce weakness, hind and forelimbs paralysis, and death. The motor effects probably result from the inhibition of other Nav isoforms such as Nav1.1 and Nav1.6. However, weak doses of ProTx-II (1-2 $\mu \mathrm{g})$ induce analgesic effects in thermal pain models as well as in the formalin-induced acute and inflammatory pain [37]. ProTx-II was also shown to control pain in burn injury by reducing the frequency of excitatory post synaptic currents in spinal dorsal horn neurons [238].

ProTx-III, also called Tpla (33 amino acids), isolated from Trixopelma pruriens, preferentially inhibits the hNav1.7, hNavl.6, hNavl.1 and hNav1.3 isoforms [239]. ProTx-III potently inhibits Nav1.7 $\left(\mathrm{IC}_{50} 2 \mathrm{nM}\right)$ and does not affect other Cav channels involved in pain pathways. The antinociceptive effect of ProTx-III (12 and $40 \mathrm{pmol}, s c$ ) was observed by reduced flinching behavior in a model of spontaneous pain induced by OD1 in mice [239].

ProTx analogues were designed to improve selectivity for Navl.7 based on peptide pharmacophore and channel interaction [199]. Several mutants, with modified C terminus (ProTx-I$\mathrm{NH} 2$ and ProTx-II-NHCH3), have increased activity on both Nav1.2 and Nav1.7 and a decreased activity on Navl.5 and Nav1.6 [240]. It seems that point modifications of amino acids on similar pharmacophores including the C-term residue, can affect the affinities of toxins for Nav channels. This shows the real difficulty in obtaining a selective toxin for Nav1.7 without affecting its effect on other Nav channels.

ProTx-II was used as a scaffold to design JNJ63955918, a longer peptide with two mutations (W7Q, W30L) providing improved Nav1.7 selectivity and in-vivo tolerability [37]. This mutant binds to the closed state of Nav1.7 and prevents its activation in a voltage insensitive manner. JNJ63955918 induces an insensitivity to pain, in rat models of thermal and chemical nociception, lasting for $6 \mathrm{~h}$ after it injection. Doses up to $5 \mu \mathrm{g} / 10$ $\mu \mathrm{L}$ are well tolerated with no detectable severe adverse effects except itching behavior. The analgesic properties of JNJ63955918 were also proved in tail flick and hotplate pain models, by a continuous it infusion $(0.5 \mu \mathrm{g} / \mathrm{h})$ in rats during 14 days without serious adverse effects. JNJ63955918 has analgesic effects on inflammatory pain tested on rats made tolerant to morphine and after peri-sciatic administration on Hargreaves thermal pain. This case illustrates that a high selectivity (more than 100x) and potent inhibition of Navl.7 over other Nav isoforms seems to be required for safety treatment of pain.

Several other peptides are potent inhibitors of Nav1.7 but they also block other pain-related channels. A peptide isolated from Davus fasciatus, Dfla ( $\mu$-TRTX-Df1a, 34 amino acids), with analgesic properties on acute pain, potently inhibits several hNav subtypes ( $\left.\mathrm{IC}_{50} 2-14 \mathrm{nM}\right)$ and all hCav3 isoforms with more potent effects on hCav3.1 and hCav3.3 [241].

$\beta$-TRTX-Cdla (33 amino acids) extracted from the African rear-horned baboon tarantula Ceratogyrus darlingi $\left(\mathrm{IC}_{50} 16 \mathrm{nM}\right.$ on hNav1.7 and $3 \mu \mathrm{M}$ on Cav2.2), produces antinociceptive effects $(0.1-10 \mu \mathrm{M} ; 40 \mu \mathrm{L} i p l)$ on acute pain induced by the scorpion peptide OD1 [242]. Two peptides, Tap1a and Tap2a, recently purified from the venom of the Venezuelan Pinkfoot Goliath tarantula, Theraphosa apophysis block pain related Nav and Cav channels. Intracolonic administration of Tpla, the most potent inhibitory peptide, almost completely reduced mechanical hyperalgesia in a model of chronic visceral pain in mice [243].

The peptide $\mu$-TRTX-Hlla, purified from Cyriopagopus lividus (former Haplopelma lividum) venom, is one of the only selective peptides for the TTX-R Nav1.8 channel. Hlla, which does not belong to any NaSpTx family, inhibits Navl.8 with a rather low affinity $\left(\mathrm{IC}_{50} 2 \mu \mathrm{M}\right)$ but shows antinociceptive effects in inflammatory, visceral and neuropathic pain models in mice [244]. Others less selective peptides such as CcoTx1 ( $\beta$-TRTXCm1a) and CcoTx2 ( $\beta$-TRTX-Cm1b), isolated from Ceratogyrus marshalli (former C. cornuatus), are known to block Nav1.8 or Navl.1 with similar affinities [245].

\section{Inhibition of Cav channels}

Spiders have developed essentially paralyzing venoms to capture their prey, mainly invertebrates, with toxins that block the entry of calcium into cells by binding to Cav channels. These toxins contribute to inhibit the release of neurotransmitters at the neuromuscular junctions leading to flaccid paralysis in the insect. Some spider toxins are also effective on mammalian Cav including those, such as Cav2.2, Cav2.3 and Cav3.2 that are involved in the transmission of pain.

Several peptides from Phoneutria nigriventer venom have been isolated from the third chromatographic fraction (PhTx3). Three sub-fractions inhibit neuronal Cav and induce analgesia in different pain models in rodents $[36,165]$.

Pn2a ( $\omega$-CNTX-Pn2a or PnTx3-3, 76 amino acids) one of the most toxic peptide, produces a flaccid paralysis after injection into mice [246]. Pn2a inhibits high voltage-activated Cav with the following order of efficacy Cav2.1>Cav2.3>Cav1.4>Cav2.2. It has a potent affinity for Cav2.3 and Cav2.1 ( $\mathrm{IC}_{50} 12-16 \mathrm{nM}$ ) but also irreversibly blocks (Kd=0.7 nM) Cav2.2 channels [247-249]. Central supraspinal (icv) and spinal (it) injections of Pn2a (30 pmol) in rodents induce short analgesic effects in acute thermal (tail flick) pain models without motor dysfunction [250,251]. Spinal injection of Pn2a also induces long-lasting antinociceptive effects in mechanical allodynia produced in neuropathic pain models without impairing functions at higher doses. However, the same injection of Pn2a does not alter mechanical sensitivity in non-neuropathic pain models. Moreover, spinal (it) injection of Pn2a does not prevent or reverse mechanical allodynia in inflammatory models, revealing that Cav2.1 and Cav2.3 channels are probably not involved in this inflammatory pain whereas they are involved in neuropathic pain. In addition, the inhibition of glutamate release linked to Cav2.1 and Cav2.3 blockade could be an explanation for the antinociceptive effect of Pn2a by both supraspinal and spinal injections $[250,251]$.

In the same way, Pn3a ( $\omega$-CNTX-Pn3a or Tx3-4), another peptide isolated from Phoneutria venom, and known to block Cav2 channels, inhibits capsaicin-stimulated release of glutamate in $\mathrm{Ca}^{2+}$ dependent and independent ways [252]. Spinal injection of Pn3a (30 pmol/site, it) seems to have no effect on acute 
nociceptive pain in hotplate test. However, Pn3a (until 100 $\mathrm{pmol} / \mathrm{site}$, pre- or post-administered $i t$ ) reversed nociception of the second inflammatory phase in a formalin pain model in mice without motor side effects [253]. Spinal Pn3a injection ( $3 \mathrm{pmol} / \mathrm{site}$ ) also improves pain recovery in a post-operative model tested by mechanical hypersensitivity.

The third Cav blocker purified from Phoneutria nigriventer venom is Pn4a ( $\omega$-CNTX-Pn4a also called Pha1 $\beta$ or PnTx3-6) (55 amino acids) the most abundant peptide. Pn4a blocks Cav1.2, Cav2.1, Cav2.2 and Cav2.3 channels with a relative selectivity for Cav2.2 ( $\mathrm{IC}_{50} 136 \mathrm{nM}$ ) [254]. Pn4a (it injections in rats) reduces pain behaviors in inflammatory pain models (formalin and CFA tests), where the contribution of glial cells in the dorsal horn of spinal cord to allodynia has been shown [255]. During inflammation, Pn4a also have analgesic effects in irritating pain induced by capsaicin [256-258] where it reduces spontaneous and mechanical allodynia [259]. Pn4a induces a long lasting analgesia in postoperative pain with a reduction of mechanical allodynia $[260,261]$. In neuropathic pain (ligation of the sciatic nerve and drug-induced fibromyalgia), Pn4a (200-300 pmol, it) reduces the mechanical hyperalgesia [256,258,262-264]. Pn4a (100 pmol/ site) has also analgesic effects in visceral pain (ip injections of acetic acid, intracolonic injection of capsaicin) [259]. In these studies, the analgesic effect of Pn4a was compared with that of $\omega$-conotoxin MVIIA (ziconotide, PRIALT ${ }^{*}$ ), a cone snail peptide known to block Cav2.2, and used as a medication in clinics to treat severe chronic pain in humans [265]. Ziconotide is however known to have narrow therapeutic windows and to induce serious side effects [266]. Pn4a has a wider therapeutic index than $\omega$-conotoxin MVIIA, making this peptide an interesting therapeutic approach due also to its long duration of action and the absence of toxic side effects [263,267].

The $\omega$-agatoxin-IVA ( $\omega$-Aga-IVA or $\omega$-AGTX-Aa4a; 48 amino acid) is a selective and high affinity Cav2.1 blocker extracted from the venom of Agenelopsis aperta. $\omega$-Aga-IVA acts in a voltage-dependent manner, and bind to a region near the voltage sensor domain IV [268]. The peptide was tested in a model of inflammation induced by injection of kaolin and carrageenan into rat knee joints where sensory neuron responses were recorded. The application of $\omega$-Aga-IVA ( 0.1 $\mu \mathrm{M})$ on the spinal cord prevented the responses to innocuous and noxious pressure onto the knee. This suggests that P-type calcium channels (Cav2.1) are involved in the generation of inflammation-evoked hyperexcitability of spinal cord neurons $[269,270]$. In a test measuring heat hyperalgesia on the same model of inflammation, application of $\omega$-Aga-IVA before the induction of inflammation is only effective on secondary heat hyperalgesia [271]. This supports the thesis that spinal Cav2.1 channels are engaged in responses to noxious stimuli once, and only if, the central sensitization is established.

Group II $\omega$-agatoxins are blockers of other pain-related Cav, i.e. Cav2.2 for $\omega$-Aga-IIA and $\omega$-Aga-IIB, whereas group III $\omega$-agatoxins ( $\omega$-Aga-IIIA, -IIIB, -IIIC and-IIID) are less specific since they block Cav2.2 and Cav2.1 [272]. The $\omega$-Aga-IIIA, a
76 amino acid peptide has potent effects on Cav2.1 and Cav2.2 but also on neuronal and cardiac Cav with nanomolar affinity $[272,273]$. Inhibition of Cav2.1 and Cav2.2 currents by $\omega$-AgaIIIA is partial (70\%), revealing a voltage-dependence mechanism and effects are slowly reversible [274]. These peptides that are not specific for pain-related Cav have not been investigated in in vivo pain experiments. More specific and shorter peptides isolated from Conus species, such as $\omega$-conotoxins (-GVIA, -MVIIA, -MVIIB) are extensively used to characterize the role of Cav in pain modalities.

A selective inhibitor for Cav2.3, SNX482, was isolated from the venom of the tarantula Hysterocrates gigas. SNX482 (41 amino acid) blocks Cav2.3 channels ( $\mathrm{IC}_{50} 30 \mathrm{nM}$ ), the so-called "R-type" current in rat central neurons, without effect on other Cav [275]. The antinociceptive effect of SNX482 was demonstrated in a chronic neuropathic SNL model in rats showing the contribution of Cav2.3 in neuropathic pain [69]. Recent work has shown that SNX482 is not so specific among all ion channels since it potently blocks the potassium Kv4.3 channels $\left(\mathrm{IC}_{50}<3 \mathrm{nM}\right)$ [276]. Other spider toxins, like $\omega$-grammotoxin SIA targeting Cav2.1 and Cav2.2, or hanatoxin that blocks Kv2, have promiscuous effects because they share structural sequence homologies and they bind to a highly conserved voltage sensing domain on Cav and Kv channels [202].

The tarantula venom, Cyriopagopus schmidti (former Haplopelma or Ornithoctonus huwena) provided a rich source of toxins active on pain-related calcium channels. HWTX-I $(\mu / \omega-T R T X-H h 1 a)$, the major 33 amino acid peptide, is a selective inhibitor of Cav2.2 ( $\left.\mathrm{IC}_{50} 55-100 \mathrm{nM}\right)$ [277]. In inflammatory pain models (formalin test and rheumatoid arthritis in rats), central injections of HWTX-I ( 0.1 to $0.5 \mu \mathrm{g} / \mathrm{kg}$, it) induces analgesia without other side effects [278,279]. Another shorter peptide, HWTX-X (28 amino acids), sharing some sequence homologies with $\omega$-conotoxins, blocks Cav2.2 channels $\left(\mathrm{IC}_{50} 40 \mathrm{nM}\right)$ [280]. However, the effects of HWTX-X have not yet been tested on pain models. A third peptide, $\omega$-huwentoxin-XVI (HWTX-XVI or $\omega$-TRTX-Cs16a; 39 amino acids), specifically blocks Cav2.2 ( IC $_{50}$ $60 \mathrm{nM}$ ) and induces antinociception in several pain models in rodents. Peripheral injections of $\omega$-HWTX-XVI $(56-112 \mathrm{nmol} /$ $\mathrm{kg}, i p$ ) reduce heat pain (hot plate model) and inflammatory pain (formalin-test) in mice while intramuscular injections reduce mechanical allodynia in a post-operative model in rats [281]. The peptide specificity was checked on TTX-S and TTX-R Nav channels in rat DRG, and on several $\mathrm{Kv}$ channels that are all insensitive to HWTX-XVI.

\section{Inhibition of ASICs}

Evidences on the physiological and physiopathological roles of ASIC channels were obtained by combining genetic studies with pharmacological approaches. Small molecules that are poorly specific ASIC blockers, like amiloride, benzamil or A-317567, induce analgesic effects after in vivo administration in rodent pain models and in some rare small clinical studies in humans [282]. But more specific ASIC antagonists like animal venom 
peptides allowed to demonstrate the role of ASICs in different models of acute, inflammatory, post-operative and neuropathic pain $[73,77,78,283]$.

The first pharmacological tool, PcTx1 ( $\pi$-TRTX-Pcla, 40 amino acids), is a minor component isolated from Psalmopoeus cambridgei venom, and shares no more than $28 \%$ sequence identities with other known spider toxins that target Nav, Cav or Kv channels [284]. PcTx1 blocks ASICla-containing channels with a potent affinity and selectivity [283]. At physiological $\mathrm{pH}, \mathrm{PcTx} 1$ is able to be an agonist of rASIC1b and of chicken ASIC1a [285,286]. PcTx1 is a state-dependent modulator, involving the $\mathrm{pH}$-dependent properties of ASIC channels but also the $\mathrm{pH}$ at which the toxin is applied [287]. PcTx1 binds into the acidic pocked (the $\mathrm{pH}$-sensor) of ASICla and induces a stabilization of the inactivated state of the channel by shifting its inactivation curve towards alkaline $\mathrm{pH}[286,287]$. The regulation of inactivation of ASICla by PcTx1 occurs through the Palm and $\beta$-ball domains of ASIC1 channel, which are part of the large extracellular loop [288]. Central (it and icv) injections of PcTx1 induce potent analgesic effects in acute pain as well as in inflammatory and neuropathic pain models [76] through blockade of ASICla homomeric channels, and probably also ASICla2b heteromers [79]. These analgesic effects involve the activation of the endogenous enkephalin pathway. PcTx1 (it) also prevents chronic abdominal pain in a rat model of irritable bowel syndrome induced by butyrate [289].

A shorter peptide, Hm3a ( $\pi$-TRTX-Hmla), isolated from the tarantula Heteroscodra maculata presents high sequence identities (82\%) with Pctx1 and similar effects, i.e., a potent $\mathrm{pH}$-dependent inhibition of ASICla and potentiation of ASIC1b [290]. Hm3a has the advantage of very high biological stability that will allow the study and development of interesting tools targeting ASICs for the study of pain.

The third spider toxin active on ASIC channels is an atypical one, Hila ( $\pi$-TRTX-Hila), composed of two peptides with a short linker, presenting ICK structure and sequence identities (50 and $62 \%$ for each peptide) with PcTx1. Hila partially inhibits rASICla and hASICla with high affinity in a $\mathrm{pH}$-independent manner and slow off-rate without effects on ASIC1b [291]. Its mode of action is different from that of PcTx1, since it binds to and stabilizes the closed state of ASICla. Hila was not tested in vivo on pain but in a model of stroke induction in rats, where it strongly attenuates brain damage. Hila could be considered as a lead for development of neuroprotective agents against brain ischemic injury.

\section{Interaction with TRP channels}

While TRP channels are widely distributed at peripheral nerve endings and in particular on nociceptive fibers, a few animal toxins modulate them.

The acylpolyamines AG489 and AG505, isolated from Agelenopsis aperta venom, were the first animal toxins described to block TRPV1 [292]. AG489 and AG505 (1-10 $\mu \mathrm{M})$ dosedependently inhibit TRPV1 current activated by capsaicin in a voltage-dependent manner and through a pore-blocking mechanism. Their putative analgesic effects on thermal local pain in rodents have not yet been investigated.

The 34 amino acids peptide GsMTx-4 (M-TRTX-Grla) isolated from Grammostola spatulata (G. rosea) blocks TRPC6, a sensor of mechanically and osmotically induced membrane stretch, which is predominantly expressed in smooth muscles but also in other cells [293]. A functional interaction between TRPC6 and TRPC1 with TRPV4, which are coexpressed in DRG neurons, contributes to the mechanism mediating primary afferent nociceptor sensitization and mechanical hyperalgesia [294]. GsMTx4 likely acts by inserting in the outer leaflet of the membrane and modifying the channel boundary lipids to favor the closed state [293,295]. Conversely, other TRP channels like TRPA1 can be activated by the toxin at $1 \mu \mathrm{M}$ according to a mechanism similar to trinitrophenol, a membrane crenator [296]. GsMTx-4 is also a modulator of stretch-activated channels (SACs), the molecular sensors for mechanotransduction, i.e., for touch, pressure, proprioception, and pain [295]. Intradermal injection of GsMTx-4 (up to $1 \mu \mathrm{g}$ ) in rat hind paw, reverses hyperalgesia to mechanical and hypotonic stimuli in inflammatory and neuropathic pain models [294,297]. Mechanical pain, often caused by surgery, burns, inflammation, neuropathies, requires specific treatments not available yet in clinic, and GsMTx4, via peripheral administration, offers a new hope to alleviate this type of pain in patients.

The Phoneutria nigriventer venom peptide Pn4a (Pha1 $\beta)$ known to inhibit pain-related Cav channels is also a blocker of TRPA1 with a large difference in affinity for the rat and human isoforms [264]. In this study, authors report that central (it) and peripheral (ip) injections of low doses of the Pn $4 \mathrm{a}(<300 \mathrm{pmol})$ reduce acute nociception, mechanical and cold hyperalgesia induced by allyl isothiocyanate and the neuropathic pain evoked by the chemotherapeutic drug bortezomib.

Another Phoneutria peptide, Tx3-5 (U7-CNTX-Pn1a) was recently characterized as a specific and potent inhibitor of TRPV1 channels without effect on TRPA1 [298]. Tx3-5 presents interesting analgesic properties in various mouse pain models. First, local injection of Tx3-5 (100 fmol, id ) prevents the nociceptive behavior induced by capsaicin injection into a rat left vibrissa in an orofacial test [298]. This local antinociceptive effect can be easily attributed to its blocking effect on TRPV1. Other analgesic effects are described after central injection (3-300 fmol, it) of Tx3-5 to mice that can prevent or reverse post-operative nociception in a dose-dependent manner [299]. Low doses (30 fmol) of Tx3-5 also induces a partial analgesia in neuropathic pain model but also in a cancer model of nociception, as potently as morphine and without adverse effects [299].

The ProTx-I peptide that block pain-related Nav channels also inhibits TRPA1 currents with an affinity of $390 \mathrm{nM}$ without affecting TRPV1. Its high affinity for Navl.2 was used to conduct structure-function studies with chimeric channels and ProTx-I variants. It reveals that ProTx-I inhibits both Nav and TRPA1 by binding to their S1-S4 gating domains and stabilization of the 
closed conformation [300]. Interestingly, mutagenesis yielded two ProTx-I variants that acquire selectivity and are only active either on TRPA1 (variant W5A) or on Nav1.2 (variant S22A) [300].

\section{Spider toxins and other pain-related channels}

Purotoxin-1 (PT1) (35 amino acids, ICK structure) isolated from a Geolycosa sp. spider, potently ( $\mathrm{IC}_{50} 12 \mathrm{nM}$ ) and selectively blocks P2X3 ionotropic receptors in their desensitized state in rat DRG neurons. PT1 is active on homomeric forms of P2X3, and has no effect on other ion channels like TRPV1. When PT1 is injected $(0.5 \mathrm{nmol}, i p l)$ in rat hind paw, it reduces the thermal hyperalgesia triggered by inflammatory drugs such as CFA and carrageenan. It also reduces the nociceptive behavior induced by formalin in the second phase and after capsaicin injection [301].

The peptide GsMTx4, already known for its effects on TRP channels, blocks Piezol channels in its closed state, with a binding affinity of $155 \mathrm{nM}$ [302]. It also inhibits human Piezo2 response to mechanical force in transfected cells and the native Piezo-like current recorded in enterochromaffin cells in gastrointestinal epithelium $[303,304]$. GsMTx4 acts as a gating modifier inducing a rightward shift in the pressure-gating curve, and inserts in lipids that surround the channel to favor its closed conformation [302]. The ability for many spider gating-modifiers toxins to partition into membranes appears to be an essential feature for their pharmacological activity. GsMTx- 4 has the ICK motif and is amphipathic, with a hydrophobic surface, surrounded by charged residues, able to bind and penetrate the lipid bilayer, being a key to its mechanism of action on ion channels. GsMTx4 antinociceptive effects, described during inflammation-induced mechanical hyperalgesia, could be linked to its activity on Piezo channels [297].

Glutamate ionotropic receptors are permeable to cations and blocked by various polyamines isolated from spiders [305]. The AMPA type, localized on GABA neurons in spinal cord, are blocked by JSTX, a polyamine toxin isolated from the Joro spider Nephila clavata [306]. In a model of secondary hyperalgesia generated by a first-degree burn on rat heel, central administration of JSTX $(5 \mu \mathrm{g}, i t)$, before the burn, blocks mechanical allodynia measured on the plantar surface of the paw. JSTX also blocks induction of thermal hyperalgesia and mechanical allodynia on an inflammatory model induced by carrageenan, but has no effect in the formalin test [307]. These data show the important role of AMPA receptors in the regulation of hyperalgesia induced by tissue injury and inflammation.

The toxin PnTx4(5-5) ( $\Gamma$-ctenitoxin-Pn1a, 47 amino acids) isolated from Phoneutria nigriventer venom has a high insecticidal activity but no toxicity after icv injections in mice. PnTx4(5-5) $(100 \mathrm{nM})$ blocks NMDA evoked currents, reducing EPSCs in rat hippocampal slices, thus showing neuroprotective effects against glutamate-mediated excitotoxic neuronal cell death [308]. The peptide does not affect GABA, kainic acid or AMPA receptors. In a more recent study [309], local injections of PnTx4(5-5) $(5 \mu \mathrm{g}, s c)$ were shown to reduce hyperalgesia induced by PGE2 or carrageenan in rats, in a dose-dependent manner. PnTx4(5-5) also reverses glutamate-induced hyperalgesic effects, showing a clear relation between analgesia and its effects on glutamatergic system [309].

\section{Interaction of Toxins with Phospholipids}

Experimental evidence suggests that voltage-gated ion channels are located in the cell membrane within raft domains, regions that are very rich in cholesterol and sphingomyelin and display unique physical properties. This location is considered to be important for the pharmacological sensitivity of ion channels for toxins. More and more toxins are identified in which the interaction with lipids promotes the binding, selectivity and affinity for ion channels.

Several spider peptides acting as gating modifiers have an amphipathic nature and present an ability to bind to lipid membranes, correlated to their affinity for the targeted ion channel [310]. Studies have proposed that they form a trimolecular interaction with lipids and voltage-gated ion channels. Spider toxins active surface is generally composed of a conserved hydrophobic patch surrounded by a charged ring of amino acids. This active surface promotes not only the interaction with ion channels but also with membrane lipids via hydrophobic interactions. The charged ring generates electrostatic interactions with the phospholipid headgroups. In a study set out to determine whether lipids interact with the voltage-sensing S1-S4 domains in $\mathrm{Kv}$ channels, it was shown that sphingomyelin interacts within a particular motif within voltage sensors [311]. In particular, the S3b-S4 paddle motif determines the sensitivity of the channel to lipid modification. Thus, both lipids and spider toxins interact with the paddle motif, thus defining a triangular interaction. As evidenced, the lipid modifications, by exposure to sphingomyelinase $\mathrm{D}$, alters voltage sensor pharmacology to spider toxin and mutations in the paddle motif alters toxin affinity.

Spider ICK peptides like GsMTx4, or the Kv blockers SGTx1 and $\mathrm{HpTx} 2$ that act as gating modifiers interact with different mode on lipid bilayer $[312,313]$. GsMTx4, which is amphipathic, makes hydrophobic and electrostatic interactions with lipids. GsMTx4 alters bilayer mechanical properties so that it may disturb the lipid packing adjacent to the channel. Thus, GsMTx4 can selectively inhibit the gating of cation selective SACs by increasing the membrane tension required for activation [314].

Other examples are given with spider ICK toxins acting on pain-related-Nav channels, such as ProTx-II, which has a potent affinity for hNav1.7 $\left(\mathrm{IC}_{50} 0.3 \mathrm{nM}\right)$ and good lipid membranesbinding properties [315]. It has been shown that there is a direct correlation between ProTx-II membrane binding affinity (to the water-lipid interface) and its potency as a hNavl.7 channel inhibitor. ProTx-II analogues, with substitution of hydrophobic aromatic Trp residues by nonaromatic amino acid residues, possess a lower tendency to bind/insert into the membrane, thus showing reduced binding affinity for lipid membranes in relation to a decreased inhibition potency for $\mathrm{hNav1.7}$. This indicates that each of the Trp and Lys residues are important for the membrane-binding properties of ProTx-II. In addition, 
an increase in overall positive charge enhances the membrane binding affinity of ProTx-II for membranes, probably due to increased electrostatic attractions for the phosphate groups in the phospholipid headgroups [315].

In contrast to ProTx-II, HWTX-IV lacked the ability to partition into phospholipid bilayer of artificial membranes. However, the synthesis of a HWTX-IV analogue (gHwTx-IV), with only 4 amino acid substitutions in $\mathrm{N}$ - and C-terminal positions, increased its ability to bind to lipid membranes and also improved inhibitory potency at hNav1.7 [316,317]. The mutant gHwTx-IV has more positive charges on the face possessing the four mutations that allows electrostatic interactions with the membrane. The mutant also has a notable increase in the hydrophobic area due to the presence of Gly and Trp substitutions allowing additional hydrogen bonding and hydrophobic interactions of gHwTx-IV, compared to the native HwTx-IV, with hNav1.7.

The 33 amino acid peptide $\mu$-TRTX-Hhn2b (HNTX-I), isolated from Cyriopagopus (former Haemadipsa or Ornithoctonus) hainanus venom is inactive on TTX-S and TTX-R mammalian Nav, but the production of a double mutant of this peptide (G7W; $\mathrm{N} 24$ S), which creates subtle displacements of the side chains of key pharmacophore residues, allows a potent inhibition of hNav1.7. In particular, one of these substitutions (G7W) creates a selective binding to anionic lipids [318]. Other substitutions that reduce negative charges, and enhance positive charges surface but also strengthened hydrophobic interactions, result in a clear increase of activity on Nav1.7 channels [319]. Some mutation studies show that critical residues represented by the motif X1X2SWCKX3 are required for the activity on Nav1.7, X representing a hydrophobic residue and $\mathrm{S}$ required to position $\mathrm{W}$ and K correctly on the active surface of spider peptides [320,321].

\section{Toxins as a Basis for Developing New Pain Treatments}

Pain is one of the first reasons for consulting a general practitioner. Acute pain is a protective signal while chronic pain, if it lasts more than 3 months, becomes a real pathology. This is the case of neuropathic pain resulting from internal nerve damage in cases of trauma or during inflammatory, infectious, or metabolic diseases [322]. It also occurs during cancer treatment with chemotherapy. Whatever its duration, intensity and etiology, pain deserves an adapted treatment with tolerance and the minimum of undesirable side effects [323].

Among the treatments currently used, acetaminophen, nonsteroidal anti-inflammatory drugs, serotonin-noradrenaline reuptake inhibitors, tricyclic antidepressants, antiepileptics are often used as first-line drugs. Weak opioids are prescribed as second line, then strong opioids as last line drugs [324]. These analgesics have found application for various types of pain but all have uncomfortable side effects in patients, related to their impact up peripheral and central nervous systems [325]. During treatment of neuropathic pain, many patients remain refractory to, or intolerant of the existing pharmacology, and some drugs also have narrow therapeutic window [326,327]. New families of drugs as well as new targets involved in pain could provide therapeutic leads for the synthesis of antinociceptive drugs.

Cav2.2 channels that are expressed in peripheral neurons have been validated as pain target with, in particular, the feedback from the use of ziconotide in clinical trials [265]. Ziconotide is the only drug, based on animal toxin, used in clinics to treat severe intractable pain. Ziconotide has analgesic properties as potent as morphine and needs to be administered at the spinal level in patients. However, due to its narrow therapeutic index, it can cause undesirable side effects such as motor disturbances, dizziness, somnolence, amnesia, hallucinations, and nausea, but is neither addictive nor induces tolerance, unlike morphine [266]. The numerous Phoneutria and Cyriopagopus $\omega$-toxins targeting Cav2. 2 could also be used as a basis for the development of new pain medications.

In recent years, Nav1.7 has been the focus of interest and validated as a pain target based on observations of human genetic loss of function, showing inability to sense pain and only minor sensory impairment in individuals with this channelopathy [50]. Its preferential expression in peripheral sensory and sympathetic neurons makes it an ideal target for analgesics [193].

Spider venoms are rich in modulators for pain targets, so it is not surprising that recent research has aimed to modify and develop new toxin structures to improve the specificity and affinity of their interactions with ion channels of interest. Spider toxins that inhibit Nav channels involved in pain also offer the advantage of being shorter than those of scorpion venoms that have the same targets. Although scorpion toxins, such as those from Buthus martensii, have real potential to overcome pain, particularly for cancer treatments [328,329], spider toxins are also much more specific for subtypes of pain-related ion channels (e.g. Protx, HwTx-IV, GsAF, GpTx-I, Pn3a, PcTx1...) and some have potent in vitro and in vivo effects. Alanine scanning of several spider peptides and their structure -function studies on ion channels revealed that some residues are critical for potent activity, and that substitution of other residues confers more potency and ion channel selectivity [216]. HwTx-IV is a potent blocker of Nav1.7, which also inhibits neuronal Nav1.1, 1.2, 1.3, and 1.6 channels but with a good selectivity against cardiac Nav1.5 channel. A triple mutant of HwTx-IV (m3-HwTx-IV), showed an increased potency for Nav1.7, without major structural modifications, widening the gap with its effects on the muscle Nav1.4 and no effect on cardiac Nav1.5 channels [330]. The mutant peptide also provides analgesia in a mouse model of acute pain confirming the same in vivo activity as the wild type peptide. Such mutations were done on several spider toxins allowing more selective and potent Nav1.7 antagonists [331].

In vivo stability of peptide toxins can be impaired by enzymatic degradation that make them unsuitable for oral therapeutic administration and requires intrathecal injections. Their disulfide bonds are susceptible to reduction by isomerases, leading to chain unfolding and oxidative refolding with consequent loss 
of biological activity. Replacement of disulfide bonds results in analogues with comparable potency. This type of modification was done with ProTx-II, where replacement of cysteine by lanthionine results in a thioether side-chain bridge that cannot be cleaved in vivo [332]. However, this approach was not successful in delivering potent or selective Nav1.7 channel blockers based on ProTx-II.

The compact, folded structure of disulfide rich peptides often protects them from proteolysis, but they still present risks to have a short in vivo half-life due to a rapid renal filtration. To avoid too rapid elimination, coupling with large proteins increasing their half-life and improving their bio-availability in vivo has been considered. Some examples of these approaches have been described with modified natural toxins from spiders. PEGylation, consists to add a hydrophilic polymer to the peptide of interest, without affecting its potency on ion channels. PEGylation on several residues of GpTx1, whose position is not crucial for its function on Nav1.7, showed the same potency and selectivity as compared to the native GpTx1 [333]. Another approach using multivalent peptides has been shown, in some cases, to have increased binding affinity for their targets. The explanation could be that a dimeric peptide can simultaneously bind to different sites on the target or that each peptide bridges two different channels in close proximity in the cell membrane. Improvement of bio-availability has been achieved using GpTxl as a homodimer constituted by two peptides linked by a hydrophilic polymer (long chain PEG) that also improved the affinity and binding properties to Nav1.7 [333]. Another double knotting peptide was produced, using a chemoenzymatic ligation with sortase A, creating an amino acid link between two spider toxins [334]. CcoTx-I, CcoTx-II, HxTx-IV and their analogues known to inhibit Nav1.7 were used either in homo or hetero dimers to compare their activity and binding on Nav1.7. All dimers were active, some peptide combinations resulted in an equivalent potency compared to the individually peptide application, others resulted in intermediate potency and a more cooperative binding. Some others showed that peptides need a longer incubation time with Nav1.7 to achieve binding equilibrium [334]. The benefits of modulating Nav channels with bivalent knottins could be that peptides would stay longer at the channel binding site, leading to a sustained inhibitory effect. This would also allow an ability to modulate inhibitory potency with varied PEG linkers. Combining a ligand that binds to a voltage-sensor domain with one that binds to the pore domain has also been tried using a conotoxin (for pore occlusion) and a spider peptide, which allosterically modulates the Nav1.4 channel gating [335]. This generated a heterobivalent ligand with a higher potency and with a slower dissociation rate.

The design of cyclic peptide inhibitors is another approach for the development of promising therapeutic drugs. Using a common pharmacophore deduced from a conotoxin and a spider peptide active on two pain-related Nav1.7 and Nav1.9 channels, a short ten residue cyclic peptide was designed. Cyclization was obtained via a disulfide bond. The cyclic mutant presented not only increased inhibitory activity on Nav1.7 and Navl.9 channels, but it also has a better serum stability [336].
Peptide-antibody conjugates are also used and confer improvements, due to the large size and hydrodynamic properties of the antibody. Their interaction with specific receptors $(\mathrm{FcRn})$ decreases renal filtration and recycling. An analogue of JzTx-V, potent inhibitor of Nav1.7, was designed in this intention resulting in a JzTx-V-antibody conjugate with 100 -fold improved in vitro potency but a reduced half-time in vivo. The reduction of net positive charges on the peptide helps to improve plasma exposure in rodents, ultimately resulting in a compound with moderate activity on Nav1.7 [337].

Another example was found using GpTxI that also inhibits Nav1.7. GpTxI analogues with amino acid substitutions improving selectivity against cardiac and muscle Nav channels, were developed, and linked using a PEG linker on a carrier monoclonal antibody [338]. These modifications confer an extended half-life but only moderate in vitro activity and exhibited no activity in a mouse histamine-induced pruritis model. The potency of the peptide-antibody conjugates was dependent on the conjugation site within the antibody, the length of the linker, and the peptide loading.

\section{Conclusion}

Scorpion and spider venoms offer a huge amount of toxins that can explain their neurotoxicity and pain-inducing effects. Toxins able to modulate specific ion channels implicated in pain are certainly important actors for pain perception and integration in mammals during envenomation, even if other components - i.e. small molecules like histamine, serotonin, or ATP -also contribute to nociception.

In recent years, an increasing number of toxins have been discovered that modulate pain-related channels, which help us to better understand their biophysical properties and roles. However, in the search for new analgesics careful attention must be given, since the same venom peptide can target several channels in the same family, thus inducing in vivo undesirable effects. The same toxin can act differently on ion channels of different animal species (i.e. insects or vertebrates), which precludes foreseeing effects in humans. The case of $\delta$-hexatoxins that are toxic to humans and primates but not to other vertebrates (cats and dogs) is an example. The same toxin can also act in opposite mechanisms in the same family of ion channels, as illustrated by HpTx1 on Nav1.7 and Nav1.9 channels. With the same venom, several toxins can also act on different ion channels in the same way, that means synergizing their in vivo effects, or in an opposite manner, as it has been shown for PcTxl and VaTx peptides isolated from Psalmopoeus cambridgei. Then, the question about the role of these toxins in the predation or defense for spiders remains elusive.

The presence of a minority of peptides having opposite effects compared to other majority of venom peptides could suggest that the less abundant ones are traces of ancestral toxins that have disappeared in the course of evolution in order for the animal to adapt to its environment, its prey as well as its aggressors. The way of venom or toxin injection is also determinant for 
toxic effects. Usually, stings or bites in vertebrates primarily affect the peripheral nervous system and it is not well known whether long toxins are able to cross the blood-brain barrier. When spiders hunt their prey, they seek to bite the insect at the nerve centers, which they locate perfectly, for a lightning action, or elsewhere if they want to keep their prey alive. In the latter case, analgesic toxins may help the spider (or scorpion) to calm and control its prey for easier feeding.

Pain is the most frequent symptom during scorpion and spider envenomation, but curiously, various toxins with the opposite effect, rather promoting antinociceptive action, have been found in venoms. More and more peptides with analgesic properties are actually used as molecular templates with structural modifications to improve their pharmacological profile, with higher selectivity and affinity, and their in vivo bio-availability to propose new analgesic drugs to human medicine. Some clinical trials with selective drugs for pain-related channels are in progress with promising results.

\section{Abbreviations}

ASIC: acid sensing ion channels; Cav: voltage-gated calcium channel; CNS: central nervous system; DRG: dorsal root ganglia; EPSC: excitatory post-synaptic currents; h: human; $i c v$ : intra cerebro ventricular; id: intradermal; ip: intraperitoneal; $i p l$ : intraplantar; it: intrathecal; $i v$ : intravenous; $\mathrm{IC}_{50}$ : toxin concentration necessary to inhibit $50 \%$ of the response; ICK: inhibitory cystine knot; KO: knockout; Kv: voltage-gated potassium channel; NaSpTx: voltage-gated sodium channel spider toxin; Nav: voltage-gated sodium channel; NMDA: N-methyl-D-aspartate; PNS: peripheral nervous system; r: rat; TTX: tetrodotoxin; TTX-R: resistant to tetrodotoxin; TTX-S: sensitive to tetrodotoxin.

\section{Acknowledgments}

The author is very grateful to F. Aguila for the technical infographic assistance, to M. L. Célérier and M. Salinas for the helpful discussions and to $\mathrm{P}$. Parris for the careful reading of the manuscript.

\section{Availability of data and materials}

Not applicable.

\section{Funding}

A part of this work on ASIC was done with support from LabEx Ion Channel Science and Therapeutics, and FHU InovPain, Université Côte d'Azur, Nice, France.

\section{Competing interests}

The author declares that she has no competing interests.

\section{Ethics approval}

Not applicable.

\section{Consent for publication}

Not applicable.

\section{References}

1. Goyffon M, Tournier JN. Scorpions: a presentation. Toxins (Basel). 2014 Jul;6(7):2137-48.

2. da Silva PH, da Silveira RB, Appel MH, Mangili OC, Gremski W, Veiga, SS. Brown spiders and loxoscelism. Toxicon. 2004 Dec 1;44(7):693-709.

3. Estrada G, Villegas E, Corzo G. Spider venoms: a rich source of acylpolyamines and peptides as new leads for CNS drugs. Nat Prod Rep. 2007 Feb;24(1):145-61.

4. Yan S, Wang X. Recent Advances in Research on Widow Spider Venoms and Toxins. Toxins (Basel). 2015 Dec;7(12):5055-67.

5. Chippaux JP, Goyffon M. Epidemiology of scorpionism: a global appraisal. Acta Trop. 2008 Aug;107(2):71-9.

6. Santos MS, Silva CG, Neto BS, Grangeiro Junior CR, Lopes VH, Teixeira Junior AG, Bezerra DA, Luna JV, Cordeiro JB, Junior JG, Lima MA. Clinical and Epidemiological Aspects of Scorpionism in the World: A Systematic Review. Wilderness Environ Med. 2016 Dec;27(4):504-18.

7. Albuquerque P, Magalhaes KDN, Sales TC, Paiva J, Daher EF, Silva Junior GBD. Acute kidney injury and pancreatitis due to scorpion sting: case report and literature review. Rev Inst Med Trop S Paulo. 2018;60:e30.

8. Ismail M. The scorpion envenoming syndrome. Toxicon. 1995 Jul;33(7):8258.

9. Sofer S, Shahak E, Gueron M. Scorpion envenomation and antivenom therapy. J Pediatr. 1994 Jun;124(6):973-8.

10. Isbister GK, Fan HW. Spider bite. Lancet. 2011 Dec 10;378(9808):2039-47.

11. Vetter RS, Isbister GK. Medical aspects of spider bites. Annu Rev Entomol. 2008;53:409-29.

12. Swanson DL, Vetter RS. Loxoscelism. Clin Dermatol. 2006 MayJun;24(3):213-21.

13. Bucaretchi F, Mello SM, Vieira RJ, Mamoni RL, Blotta MH, Antunes E, Hyslop S. Systemic envenomation caused by the wandering spider Phoneutria nigriventer, with quantification of circulating venom. Clin Toxicol (Phila). 2008 Nov;46(9):885-9.

14. Isbister GK, Gray MR. Bites by Australian mygalomorph spiders (Araneae, Mygalomorphae), including funnel-web spiders (Atracinae) and mouse spiders (Actinopodidae: Missulena spp). Toxicon. 2004 Feb;43(2):133-40.

15. Isbister GK, Gray MR. Latrodectism: a prospective cohort study of bites by formally identified redback spiders. Med J Aust. 2003 Jul 21;179(2):88-91.

16. Young AR, Pincus SJ. Comparison of enzymatic activity from three species of necrotising arachnids in Australia: Loxosceles rufescens, Badumna insignis and Lampona cylindrata. Toxicon. 2001 Feb-Mar;39(2-3):391-400.

17. Lajoie DM, Roberts SA, Zobel-Thropp PA, Delahaye JL, Bandarian V, Binford G], Cordes MH. Variable Substrate Preference among Phospholipase D Toxins from Sicariid Spiders. J Biol Chem. 2015 Apr 24;290(17):10994-11007.

18. Chen B, Wang C, Ji Y. Scorpion BmK venom induces nociceptive response of rats by plantar injection. Neurotoxicol Teratol. 2001 Nov-Dec;23(6):675-9.

19. Goyffon $M$, Vachon M, Broglio N. Epidemiological and clinical characteristics of the scorpion envenomation in Tunisia. Toxicon. 1982;20(1):337-44.

20. Freire-Maia L, Campos JA, Amaral CF. Approaches to the treatment of scorpion envenoming. Toxicon. 1994 Sep;32(9):1009-14.

21. Rowe $A H$, Xiao Y, Scales J, Linse KD, Rowe MP, Cummins TR, Zakon HH. Isolation and characterization of CvIV4: a pain inducing alpha-scorpion toxin. PLoS One. 2011;6(8):e23520.

22. Bai ZT, Liu T, Chai ZF, Pang XY, Ji YH. Rat pain-related responses induced by experimental scorpion BmK sting. Eur J Pharmacol. 2006 Dec 15;552(13):67-77.

23. Nascimento EB, Jr Costa KA, Bertollo CM, Oliveira AC, Rocha LT, Souza AL, Gloria MB, Moraes-Santos T, Coelho MM. Pharmacological investigation of the nociceptive response and edema induced by venom of the scorpion Tityus serrulatus. Toxicon. 2005 Apr;45(5):585-93.

24. White J, Hirst D, Hender E. 36 cases of bites by spiders, including the whitetailed spider, Lampona cylindrata. Med J Aust. 1989 Apr 3;150(7):401-3. 
25. Jami S, Erickson A, Brierley SM, Vetter I. Pain-Causing Venom Peptides: Insights into Sensory Neuron Pharmacology. Toxins (Basel). 2017 Dec 27;10(1):15.

26. Zanchet EM, Longo I, Cury Y. Involvement of spinal neurokinins, excitatory amino acids, proinflammatory cytokines, nitric oxide and prostanoids in pain facilitation induced by Phoneutria nigriventer spider venom. Brain Res. 2004 Sep 17;1021(1):101-11.

27. Gewehr C, Oliveira SM, Rossato MF, Trevisan G, Dalmolin GD, Rigo FK, de Castro Junior CJ, Cordeiro MN, Ferreira J, Gomez MV. Mechanisms involved in the nociception triggered by the venom of the armed spider Phoneutria nigriventer. PLoS Negl Trop Dis. 2013 Apr 25;7(4):e2198.

28. Rash LD, King RG, Hodgson WC. Evidence that histamine is the principal pharmacological component of venom from an Australian wolf spider (Lycosa godeffroyi). Toxicon. 1998 Feb;36(2):367-75.

29. Weisel-Eichler A, Libersat F. Venom effects on monoaminergic systems. J Comp Physiol A Neuroethol Sens Neural Behav Physiol. 2004 Sep;190(9):683-90.

30. Chan TK, Geren CR, Howell DE, Odell GV. Adenosine triphosphate in tarantula spider venoms and its synergistic effect with the venom toxin. Toxicon. 1975 Feb;13(1):61-6.

31. Ma H, Xiao-Peng T, Yang SL, Lu QM, Lai R. Protease inhibitor in scorpion (Mesobuthus eupeus) venom prolongs the biological activities of the crude venom. Chin J Nat Med. 2016 Aug;14(8):607-14.

32. Chen J, Feng XH, Shi J, Tan ZY, Bai ZT, Liu T, Ji YH. The anti-nociceptive effect of BmK AS, a scorpion active polypeptide, and the possible mechanism on specifically modulating voltage-gated $\mathrm{Na}+$ currents in primary afferent neurons. Peptides. 2006 Sep;27(9):2182-92.

33. Song Y, Liu Z, Zhang Q, Li C, Jin W, Liu L, Zhang J, Zhang J. Investigation of Binding Modes and Functional Surface of Scorpion Toxins ANEP to Sodium Channels 1.7. Toxins (Basel). 2017 Dec;9(12):387.

34. Cui Y, Guo GL, Ma L, Hu N, Song YB, Liu YF, Wu CF, Zhang JH. Structure and function relationship of toxin from Chinese scorpion Buthus martensii Karsch (BmKAGAP): gaining insight into related sites of analgesic activity. Peptides. 2010 Jun;31(6):995-1000.

35. Wu X, Wang Z, Chen Y, Xu D, Zhang P, Wang X. Newly Discovered Action of HpTx3 from Venom of Heteropoda venatoria on Nav1.7 and Its Pharmacological Implications in Analgesia. Toxins (Basel). 2019 Dec;11(12):680.

36. Lauria PSS, Villarreal CF, Casais ESLL. Pain modulatory properties of Phoneutria nigriventer crude venom and derived peptides: A double-edged sword. Toxicon. 2020 Oct 15;185:120-8.

37. Flinspach M, Xu Q, Piekarz AD, Fellows R, Hagan R, Gibbs A, Liu Y, Neff RA, Freedman J, Eckert WA, Zhou M, Bonesteel R, Pennington MW, Eddinger KA, Yaksh TL, Hunter M, Swanson RV, Wickenden AD. Insensitivity to pain induced by a potent selective closed-state Nav1.7 inhibitor. Sci Rep. 2017 Jan 3;7(39662).

38. Rajendra W, Armugam A, Jeyaseelan K. Toxins in anti-nociception and anti-inflammation. Toxicon. 2004 Jul;44(1):1-17.

39. Trim SA, Trim CM. Venom: the sharp end of pain therapeutics. Br J Pain. 2013 Nov;7(4):179-88.

40. Catterall WA. Forty Years of Sodium Channels: Structure, Function, Pharmacology, and Epilepsy. Neurochem Res. 2017 Sep;42(9):2495-504.

41. Bidaud I, Mezghrani A, Swayne LA, Monteil A, Lory P. Voltage-gated calcium channels in genetic diseases. Biochim Biophys Acta. 2006 Nov;1763(11):1169-74.

42. Pongs $O$. Voltage-gated potassium channels: from hyperexcitability to excitement. FEBS Lett. 1999 Jun;452(1-2):31-5.

43. Catterall WA, Lenaeus MJ, Gamal El-Din TM. Structure and Pharmacology of Voltage-Gated Sodium and Calcium Channels. Annu Rev Pharmacol Toxicol. 2020 Jan 6;60:133-54.

44. Waxman SG, Zamponi GW. Regulating excitability of peripheral afferents: emerging ion channel targets. Nat Neurosci. 2014 Feb;17(2):153-63.

45. Julius D, Basbaum Al. Molecular mechanisms of nociception. Nature. 2001 Sep 13;413(6852):203-10.

46. Hameed S. Nav1.7 and Nav1.8: Role in the pathophysiology of pain. Mol Pain. 2019;15:1744806919858801.
47. Priest BT, Murphy BA, Lindia JA, Diaz C, Abbadie C, Ritter AM, Liberator P, lyer LM, Kash SF, Kohler MG, Kaczorowski GJ, Maclntyre DE, Martin WJ. Contribution of the tetrodotoxin-resistant voltage-gated sodium channel NaV1.9 to sensory transmission and nociceptive behavior. Proc Natl Acad Sci U S A. 2005 Jun 28;102(26):9382-7.

48. Padilla F, Couble ML, Coste B, Maingret F, Clerc N, Crest M, Ritter AM, Magloire H, Delmas P. Expression and localization of the Nav1.9 sodium channel in enteric neurons and in trigeminal sensory endings: implication for intestinal reflex function and orofacial pain. Mol Cell Neurosci. 2007 May;35(1):138-52.

49. Leo S, D'Hooge R, Meert T. Exploring the role of nociceptor-specific sodium channels in pain transmission using Nav1.8 and Nav1.9 knockout mice. Behav Brain Res. 2010 Mar 17;208(1):149-57.

50. Cox JJ, Reimann F, Nicholas AK, Thornton G, Roberts E, Springell K, Karbani G, Jafri H, Mannan J, Raashid Y, Al-Gazali L, Hamamy H, Valente EM, Gorman S, Williams R, McHale DP, Wood JN, Gribble FM, Woods CG. An SCN9A channelopathy causes congenital inability to experience pain. Nature. 2006 Dec 14;444(7121):894-8.

51. Wu MT, Huang PY, Yen CT, Chen CC, Lee MJ. A novel SCN9A mutation responsible for primary erythromelalgia and is resistant to the treatment of sodium channel blockers. PLoS One. 2013;8(1):e55212.

52. Dib-Hajj SD, Estacion M, Jarecki BW, Tyrrell L, Fischer TZ, Lawden M, Cummins TR, Waxman SG. Paroxysmal extreme pain disorder M1627K mutation in human Nav1.7 renders DRG neurons hyperexcitable. Mol Pain. 2008;4:37.

53. Osteen JD, Herzig V, Gilchrist J, Emrick JJ, Zhang C, Wang X, Castro J, Garcia-Caraballo S, Grundy L, Rychkov GY, Weyer AD, Dekan Z, Undheim EA, Alewood P, Stucky CL, Brierley SM, Basbaum AI, Bosmans F, King GF, Julius D. Selective spider toxins reveal a role for the Nav1.1 channel in mechanical pain. Nature. 2016 Jun 23;534(7608):494-9.

54. Minett MS, Falk S, Santana-Varela S, Bogdanov YD, Nassar MA, Heegaard AM, Wood JN. Pain without nociceptors? Nav1.7-independent pain mechanisms. Cell Rep. 2014 Jan 30;6(2):301-12.

55. Chen L, Huang J, Zhao P, Persson AK, Dib-Hajj FB, Cheng X, Tan A, Waxman SG, Dib-Hajj SD. Conditional knockout of NaV1.6 in adult mice ameliorates neuropathic pain. Sci Rep. 2018;8:3845.

56. Xie W, Tan ZY, Barbosa C, Strong JA, Cummins TR, Zhang JM. Upregulation of the sodium channel $\mathrm{NaVbeta} 4$ subunit and its contributions to mechanical hypersensitivity and neuronal hyperexcitability in a rat model of radicular pain induced by local dorsal root ganglion inflammation. Pain. 2016 Apr;157(4):879-91.

57. Gutman GA, Chand KG, Grissmer S, Lazdunski M, McKinnon D, Pardo LA Robertson GA, Rudy B, Sanguinetti MC, Stuhmer W, Wang X. International Union of Pharmacology. LIII. Nomenclature and molecular relationships of voltage-gated potassium channels. Pharmacol Rev. 2005 Dec;57(4):473-508.

58. Jenkinson DH. Potassium channels--multiplicity and challenges. Br J Pharmacol. 2006 Jan;147(Suppl 1):S63-71.

59. Swartz KJ. Towards a structural view of gating in potassium channels. Nat Rev Neurosci. 2004 Dec;5(12):905-16.

60. Dodson PD, Forsythe ID. Presynaptic K+ channels: electrifying regulators of synaptic terminal excitability. Trends Neurosci. 2004 Apr;27(4):210-7.

61. Norton RS, Chandy KG. Venom-derived peptide inhibitors of voltagegated potassium channels. Neuropharmacology. 2017 Dec;127:124-38.

62. Pucca MB, Cerni FA, Cordeiro FA, Peigneur S, Cunha TM, Tytgat J, Arantes EC. Ts8 scorpion toxin inhibits the Kv4.2 channel and produces nociception in vivo. Toxicon. 2016 Sep 1;119:244-52.

63. Kanda H, Ling J, Chang YT, Erol F, Viatchenko-Karpinski V, Yamada A, Noguchi K, Gu JG. Kv4.3 channel dysfunction contributes to trigeminal neuropathic pain manifested with orofacial cold hypersensitivity in rats. J Neurosci. 2021 Mar 10;41(10):2091-105.

64. Zamponi GW, Striessnig J, Koschak A, Dolphin AC. The Physiology, Pathology, and Pharmacology of Voltage-Gated Calcium Channels and Their Future Therapeutic Potential. Pharmacol Rev. 2015 Oct;67(4):821-70.

65. Zamponi GW, Lewis RJ, Todorovic SM, Arneric SP, Snutch TP. Role of voltage-gated calcium channels in ascending pain pathways. Brain Res Rev. 2009 Apr;60(1):84-9. 
66. Adams DJ, Callaghan B, Berecki G. Analgesic conotoxins: block and G protein-coupled receptor modulation of $\mathrm{N}$-type $(\mathrm{Ca}(\mathrm{V}) 2.2)$ calcium channels. Br J Pharmacol. 2012 May;166(2):486-500.

67. Saegusa H, Kurihara T, Zong S, Kazuno A, Matsuda Y, Nonaka T, Han W, Toriyama $H$, Tanabe T. Suppression of inflammatory and neuropathic pain symptoms in mice lacking the $\mathrm{N}$-type Ca2+ channel. EMBO J. 2001 May 15;20(10):2349-56.

68. Saegusa H, Matsuda $\mathrm{Y}$, Tanabe T. Effects of ablation of $\mathrm{N}$ - and R-type $\mathrm{Ca}(2+)$ channels on pain transmission. Neurosci Res. 2002 Jun;43(1):1-7.

69. Matthews EA, Bee LA, Stephens GJ, Dickenson AH. The Cav2.3 calcium channel antagonist SNX-482 reduces dorsal horn neuronal responses in a rat model of chronic neuropathic pain. Eur J Neurosci. 2007 Jun;25(12):3561-9.

70. Bourinet E, Alloui A, Monteil A, Barrere C, Couette B, Poirot O, Pages A, McRory J, Snutch TP, Eschalier A, Nargeot J. Silencing of the Cav3.2 T-type calcium channel gene in sensory neurons demonstrates its major role in nociception. EMBO J. 2005 Jan 26;24(2):315-24.

71. Waldmann R, Champigny G, Bassilana F, Heurteaux C, Lazdunski M. A proton-gated cation channel involved in acid-sensing. Nature. 1997 Mar 13;386(6621):173-7.

72. Jasti J, Furukawa H, Gonzales EB, Gouaux E. Structure of acid-sensing ion channel 1 at 1.9 A resolution and low pH. Nature. 2007 Sep 20;449:316-23.

73. Baron A, Lingueglia E. Pharmacology of acid-sensing ion channels Physiological and therapeutical perspectives. Neuropharmacology. 2015 Jul;94:19-35.

74. Noel J, Salinas M, Baron A, Diochot S, Deval E, Lingueglia E. Current perspectives on acid-sensing ion channels: new advances and therapeutic implications. Expert Rev Clin Pharmacol. 2010 May;3(3):331-46.

75. Bohlen CJ, Priel A, Zhou S, King D, Siemens J, Julius D. A bivalent tarantula toxin activates the capsaicin receptor, TRPV1, by targeting the outer pore domain. Cell. 2010 May 28;141(5):834-45.

76. Mazzuca M, Heurteaux C, Alloui A, Diochot S, Baron A, Voilley N, Blondeau N, Escoubas P, Gelot A, Cupo A, Zimmer A, Zimmer AM, Eschalier A, Lazdunski M. A tarantula peptide against pain via ASIC1a channels and opioid mechanisms. Nat Neurosci. 2007 Aug;10(8):943-5.

77. Diochot S, Baron A, Salinas M, Douguet D, Scarzello S, Dabert-Gay AS, Debayle D, Friend V, Alloui A, Lazdunski M, Lingueglia E. Black mamba venom peptides target acid-sensing ion channels to abolish pain. Nature. 2012 Oct 3;490:552-5.

78. Verkest C, Piquet E, Diochot S, Dauvois M, Lanteri-Minet M, Lingueglia $E$, Baron A. Effects of systemic inhibitors of acid-sensing ion channels 1 (ASIC1) against acute and chronic mechanical allodynia in a rodent model of migraine. Br J Pharmacol. 2018 Nov;175(21):4154-6.

79. Sherwood TW, Lee KG, Gormley MG, Askwith CC. Heteromeric acidsensing ion channels (ASICs) composed of ASIC2b and ASIC1a display novel channel properties and contribute to acidosis-induced neuronal death. J Neurosci. 2011 Jun 29;31(26):9723-34.

80. Diochot S, Alloui A, Rodrigues P, Dauvois M, Friend V, Aissouni Y, Eschalier $A$, Lingueglia $E$, Baron A. Analgesic effects of mambalgin peptide inhibitors of acid-sensing ion channels in inflammatory and neuropathic pain. Pain. 2016 Mar;157(3):552-9.

81. Deval E, Noel J, Gasull X, Delaunay A, Alloui A, Friend V, Eschalier A, Lazdunski M, Lingueglia E. Acid-sensing ion channels in postoperative pain. J Neurosci. 2011 Apr 20;31(16):6059-66.

82. Deval E, Noel J, Lay N, Alloui A, Diochot S, Friend V, Jodar M, Lazdunski $M$, Lingueglia E. ASIC3, a sensor of acidic and primary inflammatory pain. EMBO J. 2008 Nov 19;27(22):3047-55.

83. Moran MM, Szallasi A. Targeting nociceptive transient receptor potential channels to treat chronic pain: current state of the field. $\mathrm{Br} J$ Pharmacol. 2018 Jun;175(12):2185-203.

84. Caterina MJ, Leffler A, Malmberg AB, Martin WJ, Trafton J, PetersenZeitz KR, Koltzenburg M, Basbaum, Al Julius D. Impaired nociception and pain sensation in mice lacking the capsaicin receptor. Science. 2000 Apr 14;288(5464):306-13.
85. Kasama S, Kawakubo M, Suzuki T, Nishizawa T, Ishida A, Nakayama J. RNA interference-mediated knock-down of transient receptor potential vanilloid 1 prevents forepaw inflammatory hyperalgesia in rat. Eur J Neurosci. 2007 May;25(10):2956-63.

86. Carreno O, Corominas R, Fernandez-Morales J, Camina M, Sobrido MJ, Fernandez-Fernandez JM, Pozo-Rosich P, Cormand B, Macaya A. SNP variants within the vanilloid TRPV1 and TRPV3 receptor genes are associated with migraine in the Spanish population. Am J Med Genet B Neuropsychiatr Genet. 2012 Jan;159B(1):94-103.

87. Park DJ, Kim SH, Nah SS, Lee JH, Kim SK, Lee YA, Hong SJ, Kim HS, Lee $\mathrm{HS}$, Kim HA, Joung Cl, Kim SH, Lee SS. Polymorphisms of the TRPV2 and TRPV3 genes associated with fibromyalgia in a Korean population. Rheumatology (Oxford). 2016 Aug;55(8):1518-27.

88. Duchatelet S, Guibbal L, de Veer S, Fraitag S, Nitschke P, Zarhrate M Bodemer C, Hovnanian A. Olmsted syndrome with erythromelalgia caused by recessive transient receptor potential vanilloid 3 mutations. $\mathrm{Br}$ J Dermatol. 2014 Sep;171(3):675-8.

89. Fleming J, Quan D. A case of congenital spinal muscular atrophy with pain due to a mutation in TRPV4. Neuromuscul Disord. 2016 Dec;26(12):841-3.

90. Gavva NR, Davis C, Lehto SG, Rao S, Wang W, Zhu DX. Transient receptor potential melastatin 8 (TRPM8) channels are involved in body temperature regulation. Mol Pain. 2012 May 9;8:36.

91. Vriens J, Owsianik G, Hofmann T, Philipp SE, Stab J, Chen X, Benoit M, Xue F, Janssens A, Kerselaers S, Oberwinkler J, Vennekens R, Gudermann T, Nilius B, Voets T. TRPM3 is a nociceptor channel involved in the detection of noxious heat. Neuron. 2011 May 12;70(3):482-94.

92. Moilanen LJ, Hamalainen M, Nummenmaa E, Ilmarinen P, Vuolteenaho K, Nieminen RM, Lehtimaki L, Moilanen E. Monosodium iodoacetateinduced inflammation and joint pain are reduced in TRPA1 deficient mice--potential role of TRPA1 in osteoarthritis. Osteoarthritis Cartilage. 2015 Nov;23(11):2017-26.

93. Nassini R, Gees M, Harrison S, De Siena G, Materazzi S, Moretto N, Failli P, Preti D, Marchetti N, Cavazzini A, Mancini F, Pedretti P, Nilius B, Patacchini R, Geppetti P. Oxaliplatin elicits mechanical and cold allodynia in rodents via TRPA1 receptor stimulation. Pain. 2011 Jul;152(7):1621-31.

94. Andersson DA, Gentry C, Light E, Vastani N, Vallortigara J, Bierhaus A, Fleming T, Bevan S. Methylglyoxal evokes pain by stimulating TRPA1. PLoS One. 2013 Oct 22;8(10):e77986.

95. Burnstock G. Purinergic Mechanisms and Pain. Adv Pharmacol. 2016;75:91137.

96. Seo HS, Roh DH, Kwon SG, Yoon SY, Kang SY, Moon JY, Choi SR, Beitz $\mathrm{AJ}$, Lee $\mathrm{JH}$. Acidic $\mathrm{pH}$ facilitates peripheral alphabetameATP-mediated nociception in rats: differential roles of P2X, P2Y, ASIC and TRPV1 receptors in ATP-induced mechanical allodynia and thermal hyperalgesia. Neuropharmacology. 2011 Dec 21;60(4):580-6.

97. Barclay J, Patel S, Dorn G, Wotherspoon G, Moffatt S, Eunson L, Abdel'al S, Natt F, Hall J, Winter J, Bevan S, Wishart W, Fox A, Ganju P. Functional downregulation of $\mathrm{P} 2 \times 3$ receptor subunit in rat sensory neurons reveals a significant role in chronic neuropathic and inflammatory pain. J Neurosci. 2002 Sep 15;22(18):8139-47.

98. Jarvis MF, Burgard EC, McGaraughty S, Honore P, Lynch K, Brennan TJ, Subieta A, Van Biesen T, Cartmell J, Bianchi B, Niforatos W, Kage K, Yu H, Mikusa J, Wismer CT, Zhu CZ, Chu K, Lee CH, Stewart AO, Polakowski J, Cox BF, Kowaluk E, Williams M, Sullivan J, Faltynek C. A-317491, a novel potent and selective non-nucleotide antagonist of $\mathrm{P} 2 \times 3$ and $\mathrm{P} 2 \times 2 / 3$ receptors, reduces chronic inflammatory and neuropathic pain in the rat. Proc Natl Acad Sci U S A. 2002 Dec 24;99(26):17179-84.

99. Trang T, Salter MW. P2X4 purinoceptor signaling in chronic pain. Purinergic Signal. 2012 Sep;8(3):621-8

100. Clark AK, Staniland AA, Marchand F, Kaan TK, McMahon SB, Malcangio M. P2X7-dependent release of interleukin-1beta and nociception in the spinal cord following lipopolysaccharide. J Neurosci. 2010 Jan 13;30(2):573-82.

101. Walstab J, Rappold G, Niesler B. 5-HT(3) receptors: role in disease and target of drugs. Pharmacol Ther. 2010 Oct;128(1):146-69. 
102. Morton RA, Baptista-Hon DT, Hales TG, Lovinger DM. Agonist- and antagonist-induced up-regulation of surface $5-\mathrm{HT} 3 \mathrm{~A}$ receptors. $\mathrm{Br}$ J Pharmacol. 2015 Aug;172(16):4066-77.

103. Wu ZS, Cheng H, Jiang $Y$, Melcher $K, X u H E$. Ion channels gated by acetylcholine and serotonin: structures, biology, and drug discovery. Acta Pharmacol Sin. 2015 Aug 3;36:895-907.

104. Liu QQ, Yao XX, Gao SH, Li R, Li BJ, Yang W, Cui RJ. Role of 5-HT receptors in neuropathic pain: potential therapeutic implications. Pharmacol Res. 2020 Sep;159:104949.

105. Coste B, Mathur J, Schmidt M, Earley TJ, Ranade S, Petrus MJ, Dubin AE, Patapoutian A. Piezo1 and Piezo2 are essential components of distinct mechanically activated cation channels. Science. 2010 Oct 1;330(6000):55-60.

106. Murthy SE, Loud MC, Daou I, Marshall KL, Schwaller F, Kuhnemund J, Francisco AG, Keenan WT, Dubin AE, Lewin GR, Patapoutian A. The mechanosensitive ion channel Piezo2 mediates sensitivity to mechanical pain in mice. Sci Transl Med. 2018 Oct 10;10(462):eaat9897.

107. Pagano J, Giona F, Beretta S, Verpelli C, Sala C. N-methyl-d-aspartate receptor function in neuronal and synaptic development and signaling. Curr Opin Pharmacol. 2021 Feb;56:93-101.

108. Zhuo M. lonotropic glutamate receptors contribute to pain transmission and chronic pain. Neuropharmacology. 2017 Jan;112(Pt A):228-34.

109. Qiu CS, Wyhe LL, Sasaki M, Sakai R, Swanson GT, Gereau RWt. Antinociceptive effects of MSVIII-19, a functional antagonist of the GluK1 kainate receptor. Pain. 2011 May;152(5):1052-60.

110. Wu LJ, Zhuo M. Targeting the NMDA receptor subunit NR2B for the treatment of neuropathic pain. Neurotherapeutics. 2009 Oct;6(4):693-702.

111. Lazdunski M, Frelin C, Barhanin J, Lombet A, Meiri H, Pauron D, Romey G, Schmid A, Schweitz H, Vigne P, Vijverberg H. Polypeptide toxins as tools to study voltage-sensitive $\mathrm{Na}+$ channels. Ann N Y Acad Sci. 1986;479(1):204-20.

112. Rochat H, Bernard P, Couraud F. Scorpion toxins: chemistry and mode of action. Adv Cytopharmacol. 1979;3:325-34.

113. Jover $E$, Couraud F, Rochat $H$. Two types of scorpion neurotoxins characterized by their binding to two separate receptor sites on rat brain synaptosomes. Biochem Biophys Res Commun. 1980 Aug 29;95(4):1607-14.

114. Bosmans F, Tytgat J. Voltage-gated sodium channel modulation by scorpion alpha-toxins. Toxicon. 2007 Feb;49(2):142-58.

115. Chen J, Tan ZY, Zhao R, Feng XH, Shi J, Ji YH. The modulation effects of $\mathrm{BmK} \mathrm{I}$, an alpha-like scorpion neurotoxin, on voltage-gated $\mathrm{Na}(+)$ currents in rat dorsal root ganglion neurons. Neurosci Lett. 2005;390:66-71.

116. Bai ZT, Liu T, Jiang F, Cheng M, Pang XY, Hua LM, Shi J, Zhou JJ, Shu $X Q$, Zhang JW, Ji YH. Phenotypes and peripheral mechanisms underlying inflammatory pain-related behaviors induced by BmK I, a modulator of sodium channels. Exp Neurol. 2010 Aug 22;226(1):159-72.

117. Zhou G, Jiao Y, Zhou Y, Qin S, Tao J, Jiang F, Tan ZY, Ji YH. Up-Regulation of Akt and Nav1.8 in BmK I-Induced Pain. Neurosci Bull. 2018 Jun;34(3):539-42.

118. Qin S, Jiang F, Zhou Y, Zhou G, Ye P, Ji Y. Local knockdown of Nav1.6 relieves pain behaviors induced by BmK I. Acta Biochim Biophys Sin (Shanghai). 2017 Aug;49(8):713-21.

119. Ye P, Jiao Y, Li Z, Hua L, Fu J, Jiang F, Liu T, Ji Y. Scorpion toxin BmK I directly activates Nav1.8 in primary sensory neurons to induce neuronal hyperexcitability in rats. Protein Cell. 2015 Jun;6(6):443-52.

120. Ye P, Hua L, Jiao Y, Li Z, Qin S, Fu J, Jiang F, Liu T, Ji Y. Functional upregulation of Nav1.8 sodium channel on dorsal root ganglia neurons contributes to the induction of scorpion sting pain. Acta Biochim Biophys Sin (Shanghai). 2016 Feb;48(2):132-44.

121. Fu J, Jiao YL, Li ZW, Ji YH. Spinal 5 -HT3AR contributes to BmK I-induced inflammatory pain in rats. Sheng Li Xue Bao. 2015 Jun 25;67(3):283-94.

122. Zhou J, Zhang X, Zhou Y, Wu B, Tan ZY. Up-regulation of P2X7 Receptors Contributes to Spinal Microglial Activation and the Development of Pain Induced by BmK-I. Neurosci Bull. 2019 Aug;35(4):624-36.

123. Abbas N, Gaudioso-Tyzra C, Bonnet C, Gabriac M, Amsalem M, Lonigro A, Padilla F, Crest M, Martin-Eauclaire MF, Delmas P. The scorpion toxin Amm VIII induces pain hypersensitivity through gain-of-function of TTXsensitive $\mathrm{Na}(+)$ channels. Pain. 2013;154(8):1204-15.
124. Chen H, Lu S, Leipold E, Gordon D, Hansel A, Heinemann SH. Differential sensitivity of sodium channels from the central and peripheral nervous system to the scorpion toxins Lqh-2 and Lqh-3. Eur J Neurosci. 2002 Aug;16(4):767-70.

125. Martin-Eauclaire MF, Abbas N, Sauze N, Mercier L, Berge-Lefranc JL, Condo J, Bougis PE, Guieu R. Involvement of endogenous opioid system in scorpion toxin-induced antinociception in mice. Neurosci Lett. 2010 Sep 20;482(1):45-50.

126. Durek T, Vetter I, Wang Cl, Motin L, Knapp O, Adams DJ, Lewis RJ, Alewood PF. Chemical engineering and structural and pharmacological characterization of the alpha-scorpion toxin OD1. ACS Chem Biol. 2013;8(6):1215-22.

127. Maertens C, Cuypers E, Amininasab M, Jalali A, Vatanpour H, Tytgat J. Potent modulation of the voltage-gated sodium channel Nav1.7 by OD1, a toxin from the scorpion Odonthobuthus doriae. Mol Pharmacol. 2006 Jul;70 (1):405-14.

128. Jalali A, Bosmans F, Amininasab M, Clynen E, Cuypers E, Zaremirakabadi A, Sarbolouki MN, Schoofs, L Vatanpour H, Tytgat J. OD1, the first toxin isolated from the venom of the scorpion Odonthobuthus doriae active on voltage-gated Na+ channels. FEBS Lett. 2005 Aug 1;579(19):4181-6.

129. Motin L, Durek T, Adams DJ. Modulation of human Nav1.7 channel gating by synthetic alpha-scorpion toxin OD1 and its analogs. Channels (Austin). 2016;10(2):139-47.

130. Billen B, Vassilevski A, Nikolsky A, Tytgat J, Grishin E. Two novel sodium channel inhibitors from Heriaeus melloteei spider venom differentially interacting with mammalian channel's isoforms. Toxicon. 2008 Aug 1;52(2):309-17.

131. Chen B, Ji Y. Antihyperalgesia effect of BmK AS, a scorpion toxin, in rat by intraplantar injection. Brain Res. 2002 Oct 18;952(2):322-6.

132. Liu T, Pang XY, Jiang F, Bai ZT, Ji YH. Anti-nociceptive effects induced by intrathecal injection of BmK AS, a polypeptide from the venom of Chinesescorpion Buthus martensi Karsch, in rat formalin test. J Ethnopharmacol. 2008 May 8;117(2):332-8.

133. Wang CY, Tan ZY, Chen B, Zhao ZQ, Ji YH. Antihyperalgesia effect of BmK IT2, a depressant insect-selective scorpion toxin in rat by peripheral administration. Brain Res Bull. 2000 Oct;53(3):335-8.

134. Zhang XY, Bai ZT, Chai ZF, Zhang JW, Liu Y, Ji YH. Suppressive effects of BmK IT2 on nociceptive behavior and c-Fos expression in spinal cord induced by formalin. J Neurosci Res. 2003 Oct 1;74(1):167-73.

135. Bai ZT, Liu T, Pang XY, Chai ZF, Ji YH. Suppression by intrathecal BmK IT2 on rat spontaneous pain behaviors and spinal c-Fos expression induced by formalin. Brain Res Bull. 2007;73(4-6):248-53.

136. Tan ZY, Xiao H, Mao X, Wang CY, Zhao ZQ, Ji YH. The inhibitory effects of BmK IT2, a scorpion neurotoxin on rat nociceptive flexion reflex and a possible mechanism for modulating voltage-gated $\mathrm{Na}(+)$ channels. Neuropharmacology. 2001 Mar;40(3):352-7.

137. Cui Y, Song YB, Ma L, Liu YF, Li GD, Wu CF, Zhang JH. Site-directed mutagenesis of the toxin from the Chinese scorpion Buthus martensii Karsch (BmKAS): insight into sites related to analgesic activity. Arch Pharm Res. 2010;33:1633-9.

138. Guan RJ, Wang M, Wang D, Wang DC. A new insect neurotoxin AngP1 with analgesic effect from the scorpion Buthus martensii Karsch: purification and characterization. J Pept Res. 2001 Jul;58(1):27-35.

139. Vandendriessche T, Olamendi-Portugal T, Zamudio FZ, Possani LD, Tytgat J. Isolation and characterization of two novel scorpion toxins: The alpha-toxin-like Cell8, specific for $\mathrm{Na}(\mathrm{v}) 1.7$ channels and the classical anti-mammalian Cell9, specific for $\mathrm{Na}(\mathrm{v}) 1.4$ channels. Toxicon. $2010 \mathrm{Sep}$ 15;56(4):613-23.

140. Camargos TS, Bosmans F, Rego SC, Mourao CB, Schwartz EF. The Scorpion Toxin Tf2 from Tityus fasciolatus Promotes Nav1.3 Opening. PLoS One. 2015 Jun 17;10(6):e0128578.

141. Israel MR, Dash TS, Bothe SN, Robinson SD, Deuis JR, Craik DJ, Lampert A, Vetter I, Durek T. Characterization of Synthetic Tf2 as a NaV1.3 Selective Pharmacological Probe. Biomedicines. 2020 Jun;8(6):155. 
142. Cologna CT, Peigneur S, Rustiguel JK, Nonato MC, Tytgat J, Arantes EC. Investigation of the relationship between the structure and function of Ts2, a neurotoxin from Tityus serrulatus venom. FEBS J. 2012 Apr;279(8):1495-1504.

143. Israel MR, Tanaka BS, Castro J, Thongyoo P, Robinson SD, Zhao P, Deuis JR, Craik DJ, Durek T, Brierley SM, Waxman SG, Dib-Hajj SD, Vetter I. NaV 1.6 regulates excitability of mechanosensitive sensory neurons. J Physiol. 2019 Jul;597(14):3751-68.

144. Deuis JR, Zimmermann K, Romanovsky AA, Possani LD, Cabot PJ, Lewis RJ, Vetter I. An animal model of oxaliplatin-induced cold allodynia reveals a crucial role for Nav1.6 in peripheral pain pathways. Pain. 2013 Sep;154(9):1749-57.

145. Israel MR, Thongyoo P, Deuis JR, Craik DJ, Vetter I, Durek T. The E15R Point Mutation in Scorpion Toxin Cn2 Uncouples Its Depressant and Excitatory Activities on Human NaV1.6. J Med Chem. 2018 Feb 22;61(4):1730-6.

146. Mao Q, Ruan J, Cai X, Lu W, Ye J, Yang J, Yang Y, Sun X, Cao J, Cao P. Antinociceptive effects of analgesic-antitumor peptide (AGAP), a neurotoxin from the scorpion Buthus martensii Karsch, on formalin-induced inflammatory pain through a mitogen-activated protein kinases-dependent mechanism in mice. PLoS One. 2013 Nov 14;8(11):e78239.

147. Ma R, Cui Y, Zhou Y, Bao YM, Yang WY, Liu YF, Wu CF, Zhang JH. Location of the analgesic domain in Scorpion toxin BmK AGAP by mutagenesis of disulfide bridges. Biochem Biophys Res Commun. 2010 Apr 2;394(2):330-4.

148. Cao ZY, Mi ZM, Cheng GF, Shen WQ, Xiao X, Liu XM, Liang XT, Yu DQ. Purification and characterization of a new peptide with analgesic effect from the scorpion Buthus martensi Karch. J Pept Res. 2004 Jul;64(1):33-41.

149. Deng L, Zhang HX, Wang Y, Zhang R, Wen X, Song YB, Zhao YS, Ma L, Wu CF, Zhang JH. Site-directed mutagenesis of BmK AGP-SYPU1: the role of two conserved Tyr (Tyr5 and Tyr42) in analgesic activity. Protein J. 2014 Apr;33(2):157-64.

150. Xiong YM, Lan ZD, Wang M, Liu B, Liu XQ, Fei H, Xu LG, Xia QC, Wang CG, Wang DC, Chi CW. Molecular characterization of a new excitatory insect neurotoxin with an analgesic effect on mice from the scorpion Buthus martensi Karsch. Toxicon. 1999 Aug;37(8):1165-80.

151. Meng $X, X u$, Wang F, Zhao $M$, Hou $X$, Ma $Y$, Jin $Y$, Liu $Y$, Song $Y$, Zhang J. The roles of conserved aromatic residues (Tyr5 and Tyr42) in interaction of scorpion toxin BmK AGP-SYPU1 with human Nav1.7. Int J Biol Macromol. 2017;99:105-11.

152. Feng YJ, Feng Q, Tao J, Zhao R, Ji YH. Allosteric interactions between receptor site 3 and 4 of voltage-gated sodium channels: a novel perspective for the underlying mechanism of scorpion sting-induced pain. J Venom Anim Toxins incl Trop Dis. 2015 Oct;21:42. DOI:10.1186/s40409-015-0043-6.

153. Rigo FK, Bochi GV, Pereira AL, Adamante G, Ferro PR, Dal-Toe De Pra S, Milioli AM, Damiani AP, da Silveira Prestes G, Dalenogare DP, ChavezOlortegui C, Moraes de Andrade V, Machado-de-Avila RA, Trevisan G. TsNTxP, a non-toxic protein from Tityus serrulatus scorpion venom, induces antinociceptive effects by suppressing glutamate release in mice. Eur J Pharmacol. 2019 Jul 15;855:65-74.

154. Maatoug R, Jebali J, Guieu R, De Waard M, Kharrat R. BotAF, a new Buthus occitanus tunetanus scorpion toxin, produces potent analgesia in rodents. Toxicon. 2018 Jul;149:72-85.

155. Chuang RS, Jaffe H, Cribbs L, Perez-Reyes E, Swartz KJ. Inhibition of T-type voltage-gated calcium channels by a new scorpion toxin. Nat Neurosci. 1998 Dec;1(8):668-74.

156. Sidach SS, Mintz IM. Kurtoxin, a gating modifier of neuronal high- and low-threshold ca channels. J Neurosci. 2002 Mar 15;22(6):2023-34.

157. Hu HJ, Carrasquillo Y, Karim F, Jung WE, Nerbonne JM, Schwarz TL, Gereau RWt. The kv4.2 potassium channel subunit is required for pain plasticity. Neuron. 2006 Apr 6;50(1):89-100.

158. Norton RS, Pallaghy PK. The cystine knot structure of ion channel toxins and related polypeptides. Toxicon. 1998 Nov;36(11):1573-83.

159. Wu G, Li Y, Wei D, He F, jiang S, Hu G, Wu H. Solution structure of BmP01 from the venom of scorpion Buthus martensii Karsch. Biochem Biophys Res Commun. 2000 Oct 5;276(3):1148-54.

160. Hakim MA, Jiang W, Luo L, Li B, Yang S, Song Y, Lai R. Scorpion Toxin, BmP01, Induces Pain by Targeting TRPV1 Channel. Toxins (Basel). 2015 Sep 14;7(9):3671-87.
161. Geron M, Hazan A, Priel A. Animal Toxins Providing Insights into TRPV1 Activation Mechanism. Toxins (Basel). 2017 Oct;9(10):326.

162. Yang S, Yang F, Zhang B, Lee BH, Li B, Luo L, Zheng J, Lai R. A bimodal activation mechanism underlies scorpion toxin-induced pain. Sci Adv. 2017 Aug 2;3(8):e1700810.

163. Lin King JV, Emrick JJ, Kelly MJS, Herzig V, King GF, Medzihradszky KF, Julius D. A Cell-Penetrating Scorpion Toxin Enables Mode-Specific Modulation of TRPA1 and Pain. Cell. 2019 Sep 5;178(6):1362-74.e1316

164. Bosmans F, Martin-Eauclaire MF, Swartz KJ. Deconstructing voltage sensor function and pharmacology in sodium channels. Nature. 2008 Nov 13;456:202-8.

165. Peigneur S, de Lima, ME, Tytgat J. Phoneutria nigriventer venom: A pharmacological treasure. Toxicon. 2018 Sep 1;151:96-110.

166. Cordeiro MN, Diniz CR, Valentim Ado C, von Eickstedt VR, Gilroy J, Richardson $M$. The purification and amino acid sequences of four $T \times 2$ neurotoxins from the venom of the Brazilian 'armed' spider Phoneutria nigriventer (Keys). FEBS Lett. 1992 Sep 28;310(2):153-6.

167. Leite KR, Andrade E, Ramos AT, Magnoli FC, Srougi M, Troncone LR. Phoneutria nigriventer spider toxin T×2-6 causes priapism and death: a histopathological investigation in mice. Toxicon. 2012 Oct;60(5):797-801.

168. Nunes KP, Torres FS, Borges MH, Matavel A, Pimenta AM, De Lima ME. New insights on arthropod toxins that potentiate erectile function. Toxicon. 2013 Jul;69:152-9.

169. Freitas AC, Pacheco DF, Machado MF, Carmona AK, Duarte ID, de Lima ME. PnPP-19, a spider toxin peptide, induces peripheral antinociception through opioid and cannabinoid receptors and inhibition of neutral endopeptidase. Br J Pharmacol. 2016 May;173(9):1491-501.

170. Matavel A, Cruz JS, Penaforte CL, Araujo DA, Kalapothakis E, Prado VF, Diniz CR, Cordeiro MN, Beirao PS. Electrophysiological characterization and molecular identification of the Phoneutria nigriventer peptide toxin PnTx2-6. FEBS Lett. 2002 Jul 17;523(1-3):219-23.

171. Silva CN, Nunes KP, Torres FS, Cassoli JS, Santos DM, Almeida Fde M Matavel A, Cruz JS, Santos-Miranda A, Nunes AD, Castro CH, Machado de Avila RA, Chavez-Olortegui C, Lauar SS, Felicori L, Resende JM, Camargos ER, Borges MH, Cordeiro MN, Peigneur S, Tytgat J, de Lima ME. PnPP-19, a Synthetic and Nontoxic Peptide Designed from a Phoneutria nigriventer Toxin, Potentiates Erectile Function via NO/cGMP. J Urol. 2015 Nov;194(5):1481-90.

172. Freitas ACN, Peigneur S, Macedo FHP, Menezes-Filho JE, Millns P, Medeiros LF, Arruda MA, Cruz J, Holliday ND, Tytgat J, Hathway G, de Lima ME. The Peptide PnPP-19, a Spider Toxin Derivative, Activates mu-Opioid Receptors and Modulates Calcium Channels. Toxins (Basel). 2018 Jan 15;10(1):43.

173. Zhou X, Ma T, Yang L, Peng S, Li L, Wang Z, Xiao Z, Zhang Q, Wang L, Huang Y, Chen M, Liang S, Zhang X, Liu JY, Liu Z. Spider venom-derived peptide induces hyperalgesia in Nav1.7 knockout mice by activating Nav1.9 channels. Nat Commun. 2020 May 8;11(1):2293.

174. Herzig V, Sunagar K, Wilson DTR, Pineda SS, Israel MR, Dutertre $S$, McFarland BS, Undheim EAB, Hodgson WC, Alewood PF, Lewis RJ, Bosmans F, Vetter I, King GF, Fry BG. Australian funnel-web spiders evolved human-lethal delta-hexatoxins for defense against vertebrate predators. Proc Natl Acad Sci U S A. 2020 Oct 6;117(40):24920-8.

175. Rash LD, Birinyi-Strachan LC, Nicholson GM, Hodgson WC. Neurotoxic activity of venom from the Australian eastern mouse spider (Missulena bradleyi) involves modulation of sodium channel gating. $\mathrm{Br} J$ Pharmacol. 2000 Aug;130(8):1817-24

176. Yamaji N, Little MJ, Nishio H, Billen B, Villegas E, Nishiuchi Y, Tytgat J, Nicholson GM, Corzo G. Synthesis, solution structure, and phylum selectivity of a spider delta-toxin that slows inactivation of specific voltagegated sodium channel subtypes. J Biol Chem. 2009 Sep 4;284(36):24568-82.

177. Siemens J, Zhou S, Piskorowski R, Nikai T, Lumpkin EA, Basbaum Al, King D, Julius D. Spider toxins activate the capsaicin receptor to produce inflammatory pain. Nature. 2006 Nov 9;444:208-12.

178. Bae C, Anselmi C, Kalia J, Jara-Oseguera A, Schwieters CD, Krepkiy D, Won Lee C, Kim EH, Kim JI, Faraldo-Gomez JD, Swartz KJ. Structural insights into the mechanism of activation of the TRPV1 channel by a membrane-bound tarantula toxin. Elife. 2016 Feb 10;5:e11273. 
179. Geron M, Kumar R, Zhou W, Faraldo-Gomez JD, Vasquez V, Priel A. TRPV1 pore turret dictates distinct DkTx and capsaicin gating. Proc Natl Acad Sci U S A. 2018 Dec 11;115(50):E11837-46.

180. Sutherland SK, Trinca JC. Survey of 2144 cases of red-back spider bites: Australia and New Zealand, 1963--1976. Med J Aust. 1978 Dec 30;2(14):620-3.

181. Maretic $Z$. Latrodectism: variations in clinical manifestations provoked by Latrodectus species of spiders. Toxicon. 1983;21(4):457-66.

182. Graudins A, Gunja N, Broady KW, Nicholson GM. Clinical and in vitro evidence for the efficacy of Australian red-back spider (Latrodectus hasselti) antivenom in the treatment of envenomation by a Cupboard spider (Steatoda grossa). Toxicon. 2002 Jun;40(6):767-75.

183. Peterson ME. Black widow spider envenomation. Clin Tech Small Anim Pract. 2006 Nov;21(4):187-90.

184. Grishin EV. Black widow spider toxins: the present and the future. Toxicon. 1998 Nov;36(11):1693-701.

185. Rosenthal L, Meldolesi J. Alpha-latrotoxin and related toxins. Pharmacol Ther. 1989;42(1):115-34.

186. Ushkaryov YA, Rohou A, Sugita S. alpha-Latrotoxin and its receptors. Handb Exp Pharmacol. 2008;(184):171-206.

187. Ushkaryov YA, Petrenko AG, Geppert M, Sudhof TC. Neurexins: synaptic cell surface proteins related to the alpha-latrotoxin receptor and laminin. Science. 1992 Jul 3;257(5066):50-6.

188. Ushkaryov YA, Volynski KE, Ashton AC. The multiple actions of black widow spider toxins and their selective use in neurosecretion studies. Toxicon. 2004 Apr;43(5):527-42.

189. Filippov AK, Tertishnikova SM, Alekseev AE, Tsurupa GP, Pashkov VN, Grishin EV. Mechanism of alpha-latrotoxin action as revealed by patchclamp experiments on Xenopus oocytes injected with rat brain messenger RNA. Neuroscience. 1994 Jul;61(1):179-89.

190. Van Renterghem C, Iborra C, Martin-Moutot N, Lelianova V, Ushkaryov Y, Seagar M. alpha-latrotoxin forms calcium-permeable membrane pores via interactions with latrophilin or neurexin. Eur J Neurosci. 2000 Nov;12(11):3953-62.

191. Volynski KE, Meunier FA, Lelianova VG, Dudina EE, Volkova TM, Rahman MA, Manser C, Grishin EV, Dolly JO, Ashley RH, Ushkaryov YA. Latrophilin, neurexin, and their signaling-deficient mutants facilitate alpha -latrotoxin insertion into membranes but are not involved in pore formation. J Biol Chem. 2000;275(52):41175-83.

192. Orlova EV, Rahman MA, Gowen B, Volynski KE, Ashton AC, Manser C, van Heel M, Ushkaryov YA. Structure of alpha-latrotoxin oligomers reveals that divalent cation-dependent tetramers form membrane pores. Nat Struct Biol. 2000 Jan;7(1):48-53.

193. King GF, Vetter I. No gain, no pain: NaV1.7 as an analgesic target. ACS Chem Neurosci. 2014 Sep 17;5(9):749-51.

194. Klint JK, Senff S, Rupasinghe DB, Er SY, Herzig V, Nicholson GM, King GF. Spider-venom peptides that target voltage-gated sodium channels: pharmacological tools and potential therapeutic leads. Toxicon. 2012 Sep 15;60(4):478-91.

195. Klint JK, Smith JJ, Vetter I, Rupasinghe DB, Er SY, Senff S, Herzig V, Mobli M, Lewis RJ, Bosmans F, King GF. Seven novel modulators of the analgesic target $\mathrm{NaV} 1.7$ uncovered using a high-throughput venom-based discovery approach. Br J Pharmacol. 2015 May;172(10):2445-58.

196. Chow CY, Cristofori-Armstrong B, Undheim EA, King GF, Rash LD. Three Peptide Modulators of the Human Voltage-Gated Sodium Channel 1.7, an Important Analgesic Target, from the Venom of an Australian Tarantula. Toxins (Basel). 2015 Jul;7(7):2494-513.

197. Silva AO, Peigneur S, Diniz MR, Tytgat J, Beirao PS. Inhibitory effect of the recombinant Phoneutria nigriventer Tx1 toxin on voltage-gated sodium channels. Biochimie. 2012 Dec;94(12):2756-63.

198. Cherki RS, Kolb E, Langut Y, Tsveyer L, Bajayo N, Meir A. Two tarantula venom peptides as potent and differential $\mathrm{Na}(\mathrm{V})$ channels blockers. Toxicon. 2014 Jan;77:58-67.

199. Rupasinghe DB, Herzig V, Vetter I, Dekan Z, Gilchrist J, Bosmans F, Alewood PF, Lewis RJ, King GF. Mutational analysis of ProTx-I and the novel venom peptide $\mathrm{Pe} 1 \mathrm{~b}$ provide insight into residues responsible for selective inhibition of the analgesic drug target NaV1.7. Biochem Pharmacol. 2020 Nov; 181:114080.
200. Wingerd JS, Mozar CA, Ussing CA, Murali SS, Chin YK, Cristofori-Armstrong B, Durek T, Gilchrist J, Vaughan CW, Bosmans F, Adams DJ, Lewis RJ, Alewood PF, Mobli M, Christie MJ, Rash LD. The tarantula toxin beta/ delta-TRTX-Pre1a highlights the importance of the S1-S2 voltage-sensor region for sodium channel subtype selectivity. Sci Rep. 2017 Apr 20;7(974).

201. Gonzales J, Pirovano G, Chow CY, de Souza Franca PD, Carter LM, Klint JK, Guru N, Lewis JS, King GF, Reiner T. Fluorescence labeling of a NaV1.7-targeted peptide for near-infrared nerve visualization. EJNMMI Res. 2020;10:49.

202. Li-Smerin Y, Swartz KJ. Gating modifier toxins reveal a conserved structural motif in voltage-gated $\mathrm{Ca} 2+$ and $\mathrm{K}+$ channels. Proc Natl Acad Sci U S A. 1998 Jul 21;95(15):8585-9.

203. Redaelli E, Cassulini RR, Silva DF, Clement H, Schiavon E, Zamudio FZ, Odell G, Arcangeli A, Clare JJ, Alagon A, de la Vega RC, Possani LD, Wanke E. Target promiscuity and heterogeneous effects of tarantula venom peptides affecting $\mathrm{Na}+$ and $\mathrm{K}+$ ion channels. J Biol Chem. 2010 Feb 5;285(6):4130-42.

204. Nicolas S, Zoukimian C, Bosmans F, Montnach J, Diochot S, Cuypers E, De Waard S, Beroud R, Mebs D, Craik D, Boturyn D, Lazdunski M, Tytgat J, De Waard M. Chemical Synthesis, Proper Folding, Nav Channel Selectivity Profile and Analgesic Properties of the Spider Peptide Phlotoxin 1. Toxins (Basel). 2019 Jun;11(6):367.

205. de Lima ME, Stankiewicz M, Hamon A, de Figueiredo SG, Cordeiro MN, Diniz CR, Martin-Eauclaire M, Pelhate $M$. The toxin Tx4(6-1) from the spider Phoneutria nigriventer slows down $\mathrm{Na}(+)$ current inactivation in insect CNS via binding to receptor site 3. J Insect Physiol. 2002 Jan;48(1):53-61.

206. Emerich BL, Ferreira RC, Cordeiro MN, Borges MH, Pimenta AM, Figueiredo SG, Duarte ID, de Lima ME. delta-Ctenitoxin-Pn1a, a Peptide from Phoneutria nigriventer Spider Venom, Shows Antinociceptive Effect Involving Opioid and Cannabinoid Systems, in Rats. Toxins (Basel). 2016;8(4):106.

207. Zeng X, Deng M, Lin Y, Yuan C, Pi J, Liang S. Isolation and characterization of Jingzhaotoxin- $\mathrm{V}$, a novel neurotoxin from the venom of the spider Chilobrachys jingzhao. Toxicon. 2007 Mar 1;49(3):388-99.

208. Luo J, Zhang Y, Gong M, Lu S, Ma Y, Zeng X, Liang S. Molecular surface of JZTX-V (beta-Theraphotoxin-Cj2a) interacting with voltage-gated sodium channel subtype NaV1.4. Toxins (Basel). 2014 Jul;6(7):2177-93.

209. Moyer BD, Murray JK, Ligutti J, Andrews K, Favreau P, Jordan JB, Lee JH, Liu D, Long J, Sham K, Shi L, Stocklin R, Wu B, Yin R, Yu V, Zou A, Biswas $K$, Miranda LP. Pharmacological characterization of potent and selective NaV1.7 inhibitors engineered from Chilobrachys jingzhao tarantula venom peptide JzTx-V. PLoS One. 2018 May 3;13(5):e0196791.

210. Wu B, Murray JK, Andrews KL, Sham K, Long J, Aral J, Ligutti J, Amagasu S, Liu D, Zou A, Min X, Wang Z, Ilch CP, Kornecook TJ, Lin MJ, Be X, Miranda LP, Moyer BD, Biswas K. Discovery of Tarantula Venom-Derived NaV1.7-Inhibitory JzTx-V Peptide 5-Br-Trp24 Analogue AM-6120 with Systemic Block of Histamine-Induced Pruritis. J Med Chem. 2018 Nov 8;61(21):9500-12.

211. Chen J, Zhang $Y$, Rong $M$, Zhao L, Jiang L, Zhang D, Wang M, Xiao Y, Liang S. Expression and characterization of jingzhaotoxin-34, a novel neurotoxin from the venom of the tarantula Chilobrachys jingzhao. Peptides. 2009 Jun;30(6):1042-8.

212. Zeng X, Li P, Chen B, Huang J, Lai R, Liu J, Rong M. Selective Closed-State Nav1.7 Blocker JZTX-34 Exhibits Analgesic Effects against Pain. Toxins (Basel). 2018 Feb;10(2):64.

213. Goncalves TC, Benoit E, Kurz M, Lucarain L, Fouconnier S, Combemale S, Jaquillard L, Schombert B, Chambard JM, Boukaiba R, Hessler G, Bohme A, Bialy L, Hourcade S, Beroud R, De Waard M, Servent D, Partiseti $M$. From identification to functional characterization of cyriotoxin-1a, an antinociceptive toxin from the spider Cyriopagopus schioedtei. Br J Pharmacol. 2019 May;176(9):1298-314.

214. Zhang Y, Peng D, Huang B, Yang Q, Zhang Q, Chen M, Rong M, Liu Z. Discovery of a Novel Nav1.7 Inhibitor From Cyriopagopus albostriatus Venom With Potent Analgesic Efficacy. Front Pharmacol. 2018;9:1158.

215. Zhang YX, Peng DZ, Zhang QF, Huang B, Yang QC, Tang DF, Chen $M Z$, Rong MQ, Liu ZH. micro-TRTX-Ca1a: a novel neurotoxin from Cyriopagopus albostriatus with analgesic effects. Acta Pharmacol Sin. 2019 Jul;40(7):859-66. 
216. Murray JK, Ligutti J, Liu D, Zou A, Poppe L, Li H, Andrews KL, Moyer BD, McDonough SI, Favreau P, Stocklin R, Miranda LP. Engineering potent and selective analogues of GpTx-1, a tarantula venom peptide antagonist of the $\mathrm{Na}(\mathrm{V}) 1.7$ sodium channel. J Med Chem. 2015 Mar 12;58(5):2299-314.

217. Murray JK, Long J, Zou A, Ligutti J, Andrews KL, Poppe L, Biswas K, Moyer BD, McDonough SI, Miranda LP. Single Residue Substitutions That Confer Voltage-Gated Sodium lon Channel Subtype Selectivity in the NaV1.7 Inhibitory Peptide GpTx-1. J Med Chem. 2016 Mar 24;59(6):2704-17.

218. Deuis JR, Wingerd JS, Winter Z, Durek T, Dekan Z, Sousa SR, Zimmermann K, Hoffmann T, Weidner C, Nassar MA, Alewood PF, Lewis RJ, Vetter I. Analgesic Effects of GpTx-1, PF-04856264 and CNV1014802 in a Mouse Model of NaV1.7-Mediated Pain. Toxins (Basel). 2016 Mar 17;8(3):78.

219. Chen C, Xu B, Shi X, Zhang M, Zhang Q, Zhang T, Zhao W, Zhang R, Wang Z, Li N, Fang Q. GpTx-1 and [Ala(5), Phe(6), Leu(26), Arg(28)] GpTx-1, two peptide NaV 1.7 inhibitors: analgesic and tolerance properties at the spinal level. Br J Pharmacol. 2018 Oct;175(20):3911-27.

220. Xiao Y, Luo X, Kuang F, Deng M, Wang M, Zeng X, Liang S. Synthesis and characterization of huwentoxin-IV, a neurotoxin inhibiting central neuronal sodium channels. Toxicon. 2008 Feb;51(2):230-9.

221. Revell JD, Lund PE, Linley JE, Metcalfe J, Burmeister N, Sridharan S, Jones C, Jermutus L, Bednarek MA. Potency optimization of Huwentoxin-IV on $\mathrm{hNav1.7:} \mathrm{a} \mathrm{neurotoxin} \mathrm{TTX-S} \mathrm{sodium-channel} \mathrm{antagonist} \mathrm{from} \mathrm{the}$ venom of the Chinese bird-eating spider Selenocosmia huwena. Peptides. 2013 Jun;44:40-6.

222. Goncalves TC, Boukaiba R, Molgo J, Amar M, Partiseti M, Servent D, Benoit E. Direct evidence for high affinity blockade of NaV1.6 channel subtype by huwentoxin-IV spider peptide, using multiscale functional approaches. Neuropharmacology. 2018 May 1;133:404-14.

223. Xiao Y, Jackson JO 2nd, Liang S, Cummins TR. Common molecular determinants of tarantula huwentoxin-IV inhibition of $\mathrm{Na}+$ channel voltage sensors in domains II and IV. J Biol Chem. 2011 Aug 5;286(31):27301-10.

224. Liu Y, Li D, Wu Z, Li J, Nie D, Xiang Y, Liu Z. A positively charged surface patch is important for hainantoxin-IV binding to voltage-gated sodium channels. J Pept Sci. 2012 Oct;18(10):643-9.

225. Minassian NA, Gibbs A, Shih AY, Liu Y, Neff RA, Sutton SW, Mirzadegan T, Connor J, Fellows R, Husovsky M, Nelson S, Hunter MJ, Flinspach M, Wickenden AD. Analysis of the structural and molecular basis of voltagesensitive sodium channel inhibition by the spider toxin huwentoxin-IV (mu-TRTX-Hh2a). J Biol Chem. 2013 Aug 2;288(31):22707-20.

226. Neff RA, Flinspach M, Gibbs A, Shih AY, Minassian NA, Liu Y, Fellows R, Libiger O, Young S, Pennington MW, Hunter MJ, Wickenden AD. Comprehensive engineering of the tarantula venom peptide huwentoxin-IV to inhibit the human voltage-gated sodium channel hNav1.7. J Biol Chem. 2020 Jan 31;295(5):1315-27.

227. Liu Y, Wu Z, Tang D, Xun X, Liu L, Li X, Nie D, Xiang Y, Yi J, Yi J. Analgesic effects of Huwentoxin-IV on animal models of inflammatory and neuropathic pain. Protein Pept Lett. 2014;21(2):153-8.

228. Xiao YC, Liang SP. Inhibition of sodium channels in rat dorsal root ganglion neurons by Hainantoxin-IV, a novel spider toxin. Sheng Wu Hua Xue Yu Sheng Wu Wu Li Xue Bao (Shanghai). 2003 Jan;35(1):82-5.

229. Liu Z, Cai T, Zhu Q, Deng M, Li J, Zhou X, Zhang F, Li D, Li J, Liu Y, Hu W, Liang $S$. Structure and function of hainantoxin-III, a selective antagonist of neuronal tetrodotoxin-sensitive voltage-gated sodium channels isolated from the Chinese bird spider Ornithoctonus hainana. J Biol Chem. 2013 Jul 12;288(28):20392-403.

230. Cai T, Luo J, Meng E, Ding J, Liang S, Wang S, Liu Z. Mapping the interaction site for the tarantula toxin hainantoxin-IV (beta-TRTX-Hn2a) in the voltage sensor module of domain II of voltage-gated sodium channels. Peptides. 2015 Jun;68:148-56.

231. Liu Y, Liu Z, Wang Q, Wang Z, Zhang Y. HNTX-III alleviates inflammatory and neuropathic pain in animal models. Int J Pept Res Ther 2019;25:799-806.

232. Goncalves TC, Lesport P, Kuylle S, Stura E, Ciolek J, Mourier G, Servent D, Bourinet E, Benoit E, Gilles N. Evaluation of the Spider (Phlogiellus genus) Phlotoxin 1 and Synthetic Variants as Antinociceptive Drug Candidates. Toxins (Basel). 2019 Sep;11(9):484.

233. Deuis JR, Dekan Z, Wingerd JS, Smith JJ, Munasinghe NR, Bhola RF, Imlach WL, Herzig V, Armstrong DA, Rosengren KJ, Bosmans F, Waxman SG, Dib-Hajj SD, Escoubas P, Minett MS, Christie MJ, King GF, Alewood PF, Lewis RJ, Wood JN, Vetter I. Pharmacological characterisation of the highly NaV1.7 selective spider venom peptide Pn3a. Sci Rep. 2017 Jan 20;7:40883.
234. Middleton RE, Warren VA, Kraus RL, Hwang JC, Liu CJ, Dai G, Brochu RM, Kohler MG, Gao YD, Garsky VM, Bogusky MJ, Mehl JT, Cohen C], Smith MM. Two tarantula peptides inhibit activation of multiple sodium channels. Biochemistry. 2002 Dec 17;41(50):14734-47.

235. Priest BT, Blumenthal KM, Smith JJ, Warren VA, Smith MM. ProTx-I and ProTx-II: gating modifiers of voltage-gated sodium channels. Toxicon. 2007 Feb;49(2):194-201.

236. Xiao Y, Blumenthal K, Jackson JO 2nd, Liang S, Cummins TR. The tarantula toxins ProTx-II and huwentoxin-IV differentially interact with human Nav1.7 voltage sensors to inhibit channel activation and inactivation. Mol Pharmacol. 2010 Dec;78(6):1124-34.

237. Schmalhofer WA, Calhoun J, Burrows R, Bailey T, Kohler MG, Weinglass $A B$, Kaczorowski GJ, Garcia ML, Koltzenburg M, Priest BT. ProTx-II, a selective inhibitor of NaV1.7 sodium channels, blocks action potential propagation in nociceptors. Mol Pharmacol. 2008 Nov;74(5):1476-84.

238. Torres-Perez JV, Adamek P, Palecek J, Vizcaychipi M, Nagy I, Varga A. The NAv1.7 blocker protoxin II reduces burn injury-induced spinal nociceptive processing. J Mol Med (Berl). 2018;96(1):75-84.

239. Cardoso FC, Dekan Z, Rosengren KJ, Erickson A, Vetter I, Deuis JR, Herzig $V$, Alewood PF, King GF, Lewis RJ. Identification and Characterization of ProTx-III [mu-TRTX-Tp1a], a New Voltage-Gated Sodium Channel Inhibitor from Venom of the Tarantula Thrixopelma pruriens. Mol Pharmacol. 2015;88:291-303

240. Park JH, Carlin KP, Wu G, Ilyin VI, Musza LL, Blake PR, Kyle DJ. Studies examining the relationship between the chemical structure of protoxin II and its activity on voltage gated sodium channels. J Med Chem. 2014 Aug 14:57(15):6623-31.

241. Cardoso FC, Dekan Z, Smith JJ, Deuis JR, Vetter I, Herzig V, Alewood PF, King GF, Lewis RJ. Modulatory features of the novel spider toxin mu-TRTX-Df1a isolated from the venom of the spider Davus fasciatus. Br J Pharmacol. 2017 Aug;174(15):2528-44.

242. Sousa SR, Wingerd JS, Brust A, Bladen C, Ragnarsson L, Herzig V, Deuis JR, Dutertre S, Vetter I, Zamponi, GW King, GF Alewood PF, Lewis RJ. Discovery and mode of action of a novel analgesic beta-toxin from the African spider Ceratogyrus darlingi. PLoS One. 2017 Sep 7;12(9):e0182848.

243. Cardoso FC, Castro J, Grundy L, Schober G, Garcia-Caraballo S, Zhao T, Herzig V, King GF, Brierley SM, Lewis RJ. A spider-venom peptide with multitarget activity on sodium and calcium channels alleviates chronic visceral pain in a model of irritable bowel syndrome. Pain. 2021 Feb 1;162(2):569-81.

244. Meng P, Huang H, Wang G, Yang S, Lu Q, Liu J, Lai R, Rong M. A novel toxin from Haplopelma lividum selectively inhibits the NaV1. 8 channel and possesses potent analgesic efficacy. Toxins. 2017 Jan;9(1):7.

245. Bosmans F, Rash L, Zhu S, Diochot S, Lazdunski M, Escoubas P, Tytgat J. Four novel tarantula toxins as selective modulators of voltage-gated sodium channel subtypes. Mol Pharmacol. 2006 Feb;69(2):419-29.

246. Cordeiro Mdo N, de Figueiredo SG, Valentim Ado C, Diniz CR, von Eickstedt VR, Gilroy J, Richardson M. Purification and amino acid sequences of six Tx3 type neurotoxins from the venom of the Brazilian 'armed' spider Phoneutria nigriventer (Keys). Toxicon. 1993 Jan;31(1):35-42.

247. Leao RM, Cruz JS, Diniz CR, Cordeiro MN, Beirao PS. Inhibition of neuronal high-voltage activated calcium channels by the omegaphoneutria nigriventer T×3-3 peptide toxin. Neuropharmacology. 2000 Jul 24;39(10):1756-67.

248. Cassola AC, Jaffe H, Fales HM, Afeche SC, Magnoli F, Cipolla-Neto J. omega-Phonetoxin-IIA: a calcium channel blocker from the spider Phoneutria nigriventer. Pflugers Arch. 1998 Jul;436(4):545-52.

249. Dos Santos RG, Van Renterghem C, Martin-Moutot N, Mansuelle P, Cordeiro MN, Diniz CR, Mori Y, De Lima ME, Seagar M. Phoneutria nigriventer omega-phonetoxin IIA blocks the Cav2 family of calcium channels and interacts with omega-conotoxin-binding sites. J Biol Chem. 2002 Apr 19;277(16):13856-62.

250. Dalmolin GD, Silva CR, Rigo FK, Gomes GM, do Nascimento Cordeiro M, Richardson M, Silva MAR, Prado MAM, Gomez MV, Ferreira J. Antinociceptive effect of Brazilian armed spider venom toxin Tx3-3 in animal models of neuropathic pain. Pain. 2011 Oct;152(10):2224-32.

251. Dalmolin GD, Bannister K, Goncalves L, Sikandar S, Patel R, Cordeiro MDN, Gomez MV, Ferreira J, Dickenson AH. Effect of the spider toxin Tx3-3 on spinal processing of sensory information in naive and neuropathic rats: an in vivo electrophysiological study. Pain Rep. 2017 Jul 6;2(4):e610. 
252. Goncaves JM, Ferreira J, Prado MA, Cordeiro MN, Richardson M, Pinheiro AC, Silva MA, Junior CJ, Souza AH, Gomez MV. The effect of spider toxin PhTx3-4, omega-conotoxins MVIIA and MVIIC on glutamate uptake and on capsaicin-induced glutamate release and [Ca2+]i in spinal cord synaptosomes. Cell Mol Neurobiol. 2011 Mar;31(2):277-83.

253. da Silva JF, Castro-Junior CJ, Oliveira SM, Dalmolin GD, Silva CR, Vieira LB, Diniz DM, Cordeiro Mdo N, Ferreira J, Souza AH, Gomez MV. Characterization of the antinociceptive effect of PhTx3-4, a toxin from Phoneutria nigriventer, in models of thermal, chemical and incisional pain in mice. Toxicon. 2015 Dec 15;108:53-61.

254. Vieira LB, Kushmerick C, Hildebrand ME, Garcia E, Stea A, Cordeiro MN, Richardson M, Gomez MV, Snutch TP. Inhibition of high voltage-activated calcium channels by spider toxin PnTx3-6. J Pharmacol Exp Ther. 2005 Sep;314(3):1370-7.

255. Tenza-Ferrer H, Magno LAV, Romano-Silva MA, da Silva JF, Gomez MV. Phalpha1beta Spider Toxin Reverses Glial Structural Plasticity Upon Peripheral Inflammation. Front Cell Neurosci. 2019;13:306.

256. Castro-Junior CJ, Milano J, Souza AH, Silva JF, Rigo FK, Dalmolin G, Cordeiro MN, Richardson M, Barros AG, Gomez RS, Silva MA, Kushmerick C, Ferreira J, Gomez MV. Phalpha1beta toxin prevents capsaicin-induced nociceptive behavior and mechanical hypersensitivity without acting on TRPV1 channels. Neuropharmacology. 2013 Aug;71:237-46.

257. Palhares MR, Silva JF, Rezende MJS, Santos DC, Silva-Junior CA, Borges $\mathrm{MH}$, Ferreira J, Gomez MV, Castro-Junior CJ. Synergistic antinociceptive effect of a calcium channel blocker and a TRPV1 blocker in an acute pain model in mice. Life Sci. 2017 Aug 1;182:122-8.

258. Rigo FK, Trevisan G, De Pra SD, Cordeiro MN, Borges MH, Silva JF, Santa Cecilia FV, de Souza AH, de Oliveira Adamante G, Milioli AM, de Castro Junior C], Ferreira J, Gomez MV. The spider toxin Phalpha1beta recombinant possesses strong analgesic activity. Toxicon. 2017 Jul;133:145-52.

259. Diniz DM, de Souza AH, Pereira EM, da Silva JF, Rigo FK, Romano-Silva MA, Binda N, Castro CJ, Jr, Cordeiro MN, Ferreira J, Gomez MV. Effects of the calcium channel blockers Phalpha1beta and omega-conotoxin MVIIA on capsaicin and acetic acid-induced visceral nociception in mice. Pharmacol Biochem Behav. 2014 Nov;126:97-102.

260. Sousa SR, Vetter I, Lewis RJ. Venom peptides as a rich source of cav2.2 channel blockers. Toxins (Basel). 2013 Feb;5(2):286-314.

261. de Souza AH, Lima MC, Drewes CC, da Silva JF, Torres KC, Pereira EM, de Castro Junior CJ, Vieira LB, Cordeiro MN, Richardson M, Gomez RS, Romano-Silva MA, Ferreira J, Gomez MV. Antiallodynic effect and side effects of Phalpha1beta, a neurotoxin from the spider Phoneutria nigriventer: comparison with omega-conotoxin MVIIA and morphine. Toxicon. 2011;58:626-33.

262. de Souza AH, da Costa Lopes AM, Castro CJ Jr, Pereira EM, Klein CP, da Silva CA Jr, da Silva JF, Ferreira J, Gomez MV. The effects of Phalpha1beta, a spider toxin, calcium channel blocker, in a mouse fibromyalgia model. Toxicon. 2014 Apr;81:37-42.

263. Souza AH, Ferreira J, Cordeiro MDN, Vieira LB, De Castro CJ, Trevisan G, Reis H, Souza IA, Richardson M, Prado MAM, Prado VF, Gomez MV. Analgesic effect in rodents of native and recombinant $\mathrm{Ph}$ alpha 1 beta toxin, a high-voltage-activated calcium channel blocker isolated from armed spider venom. Pain. 2008 Nov 15;140(1):115-26.

264. Tonello R, Fusi C, Materazzi S, Marone IM, De Logu F, Benemei S, Goncalves MC, Coppi E, Castro-Junior CJ, Gomez MV, Geppetti P, Ferreira J, Nassini R. The peptide Phalpha1beta, from spider venom, acts as a TRPA1 channel antagonist with antinociceptive effects in mice. $\mathrm{Br}$ J Pharmacol. 2017 Jan;174(1):57-69.

265. Schmidtko A, Lotsch J, Freynhagen R, Geisslinger G. Ziconotide for treatment of severe chronic pain. Lancet. 2010 May 1;375(9725):1569-77.

266. Penn RD, Paice JA. Adverse effects associated with the intrathecal administration of ziconotide. Pain. 2000 Mar;85(1-2):291-6.

267. Dallegrave E, Taschetto E, Bainy Leal M, Techera Antunes FT, Gomez MV, Hubner de Souza A. Acute Toxicity of the Recombinant and Native Phalpha1beta Toxin: New Analgesic from Phoneutria nigriventer Spider Venom. Toxins (Basel). 2018 Dec 12;10(12):531.
268. Mintz IM, Venema VJ, Swiderek KM, Lee TD, Bean BP, Adams ME. P-type calcium channels blocked by the spider toxin omega-Aga-IVA. Nature. 1992 Feb 27;355(6363):827-9.

269. Nebe J, Ebersberger A, Vanegas H, Schaible HG. Effects of omegaagatoxin IVA, a P-type calcium channel antagonist, on the development of spinal neuronal hyperexcitability caused by knee inflammation in rats. J Neurophysiol. 1999 Jun;81(6):2620-6.

270. Nebe J, Vanegas H, Neugebauer V, Schaible HG. Omega-agatoxin IVA, a P-type calcium channel antagonist, reduces nociceptive processing in spinal cord neurons with input from the inflamed but not from the normal knee joint--an electrophysiological study in the rat in vivo. Eur J Neurosci. 1997 Oct;9(10):2193-2201.

271. Sluka KA. Blockade of $\mathrm{N}$ - and $\mathrm{P} / \mathrm{Q}$-type calcium channels reduces the secondary heat hyperalgesia induced by acute inflammation. J Pharmacol Exp Ther. 1998 Oct;287(1):232-7.

272. Venema VJ, Swiderek KM, Lee TD, Hathaway GM, Adams ME. Antagonism of synaptosomal calcium channels by subtypes of omega-agatoxins. J Biol Chem. 1992 Feb 5;267(4):2610-5.

273. Cohen CJ, Ertel EA, Smith MM, Venema VJ, Adams ME, Leibowitz MD. High affinity block of myocardial L-type calcium channels by the spider toxin omega-Aga-toxin IIIA: advantages over 1,4-dihydropyridines. Mol Pharmacol. 1992 Dec;42(6):947-51.

274. Mintz IM. Block of $\mathrm{Ca}$ channels in rat central neurons by the spider toxin omega-Aga-IIIA. J Neurosci. 1994 May;14(5 Pt 1):2844-53.

275. Newcomb R, Szoke B, Palma A, Wang G, Chen X, Hopkins W, Cong R, Miller J, Urge L, Tarczy-Hornoch K, Loo JA, Dooley DJ, Nadasdi L, Tsien RW, Lemos J, Miljanich G. Selective peptide antagonist of the class E calcium channel from the venom of the tarantula Hysterocrates gigas. Biochemistry. 1998 Nov 3;37(44):15353-62.

276. Kimm T, Bean BP. Inhibition of A-type potassium current by the peptide toxin SNX-482. J Neurosci. 2014 Jul 9;34(28):9182-9.

277. Peng K, Chen XD, Liang SP. The effect of Huwentoxin-I on $\mathrm{Ca}(2+)$ channels in differentiated NG108-15 cells, a patch-clamp study. Toxicon. 2001;39:491-8.

278. Chen JQ, Zhang YQ, Dai J, Luo ZM, Liang SP. Antinociceptive effects of intrathecally administered huwentoxin-I, a selective $\mathrm{N}$-type calcium channel blocker, in the formalin test in conscious rats. Toxicon. 2005 Jan;45(1):15-20.

279. Tao ZW, Yang TG, Ying R, Lin L, Peng H, Qin CJ. The antinociceptive efficacy of HWTX-I epidurally administered in rheumatoid arthritis rats. Int J Sports Med. 2011 Nov;32(11):869-74.

280. Liu Z, Dai J, Dai L, Deng M, Hu Z, Hu W, Liang S. Function and solution structure of Huwentoxin- $X$, a specific blocker of $\mathrm{N}$-type calcium channels, from the Chinese bird spider Ornithoctonus huwena. J Biol Chem. 2006 Mar 31;281(13):8628-35.

281. Deng M, Luo X, Xiao Y, Sun Z, Jiang L, Liu Z, Zeng X, Chen H, Tang J, Zeng $\mathrm{W}$, Songping, L. Huwentoxin- $\mathrm{XVI}$, an analgesic, highly reversible mammalian $\mathrm{N}$-type calcium channel antagonist from Chinese tarantula Ornithoctonus huwena. Neuropharmacology. 2014 Apr;79:657-67.

282. Ugawa S, Ueda T, Ishida Y, Nishigaki M, Shibata Y, Shimada S. Amilorideblockable acid-sensing ion channels are leading acid sensors expressed in human nociceptors. J Clin Invest. 2002 Oct;110(8):1185-90.

283. Baron A, Diochot S, Salinas M, Deval E, Noel J, Lingueglia E. Venom toxins in the exploration of molecular, physiological and pathophysiological functions of acid-sensing ion channels. Toxicon. 2013 Dec 1;75:187-204.

284. Escoubas P, De Weille JR, Lecoq A, Diochot S, Waldmann R, Champigny G, Moinier D, Menez A, Lazdunski M. Isolation of a tarantula toxin specific for a class of proton-gated $\mathrm{Na}+$ channels. J Biol Chem. 2000 Aug 18;275(33):25116-21.

285. Chen X, Kalbacher H, Grunder S. Interaction of acid-sensing ion channel (ASIC) 1 with the tarantula toxin psalmotoxin 1 is state dependent. J Gen Physiol. 2006 Mar;127(3):267-76.

286. Baconguis I, Gouaux E. Structural plasticity and dynamic selectivity of acidsensing ion channel-spider toxin complexes. Nature. 2012 Jul 29;489:400-5.

287. Chen X, Kalbacher $\mathrm{H}$, Grunder $\mathrm{S}$. The tarantula toxin psalmotoxin 1 inhibits acid-sensing ion channel (ASIC) 1a by increasing its apparent $\mathrm{H}+$ affinity. J Gen Physiol. 2005 Jul;126(1):71-9. 
288. Salinas M, Besson T, Delettre Q, Diochot S, Boulakirba S, Douguet D, Lingueglia $E$. Binding site and inhibitory mechanism of the mambalgin-2 pain-relieving peptide on acid-sensing ion channel 1a. J Biol Chem. 2014 May 9;289(19):13363-73.

289. Matricon J, Gelot A, Etienne M, Lazdunski M, Muller E, Ardid D. Spinal cord plasticity and acid-sensing ion channels involvement in a rodent model of irritable bowel syndrome. Eur J Pain. 2011 Apr;15(4):335-43.

290. Er SY, Cristofori-Armstrong B, Escoubas P, Rash LD. Discovery and molecular interaction studies of a highly stable, tarantula peptide modulator of acidsensing ion channel 1. Neuropharmacology. 2017 Dec;127:185-95.

291. Chassagnon IR, McCarthy CA, Chin YK, Pineda SS, Keramidas A, Mobli M, Pham V, De Silva TM, Lynch JW, Widdop RE, Rash LD, King GF. Potent neuroprotection after stroke afforded by a double-knot spider-venom peptide that inhibits acid-sensing ion channel 1a. Proc Natl Acad Sci U S A. 2017 Apr 4;114(14):3750-5.

292. Kitaguchi T, Swartz KJ. An inhibitor of TRPV1 channels isolated from funnel Web spider venom. Biochemistry. 2005 Nov 29;44(47):15544-9.

293. Spassova MA, Hewavitharana T, Xu W, Soboloff J, Gill DL. A common mechanism underlies stretch activation and receptor activation of TRPC6 channels. Proc Natl Acad Sci U S A. 2006 Oct 31;103(44):16586-91.

294. Alessandri-Haber N, Dina OA, Chen X, Levine JD. TRPC1 and TRPC6 channels cooperate with TRPV4 to mediate mechanical hyperalgesia and nociceptor sensitization. J Neurosci. 2009 May 13;29(19):6217-28.

295. Bowman CL, Gottlieb PA, Suchyna TM, Murphy YK, Sachs F. Mechanosensitive ion channels and the peptide inhibitor GsMTx-4: history, properties, mechanisms and pharmacology. Toxicon. 2007 Feb;49(2):249-70.

296. Hill K, Schaefer M. TRPA1 is differentially modulated by the amphipathic molecules trinitrophenol and chlorpromazine. J Biol Chem. 2007 Mar 9;282(10):7145-53.

297. Park SP, Kim BM, Koo JY, Cho H, Lee CH, Kim M, Na HS, Oh U. A tarantula spider toxin, GsMTx4, reduces mechanical and neuropathic pain. Pain. 2008 Jul;137(1):208-17.

298. Rita Pereira EM, Souza JM, Carobin NV, Silva JF, Santos DC, Silva Junior CA, Binda NS, Borges MH, Pinto Nagem RA, Kushmerick C, Ferreira J, Castro Junior CJ, Ribeiro FM, Gomez MV. Phoneutria toxin PnTx3-5 inhibits TRPV1 channel with antinociceptive action in an orofacial pain model. Neuropharmacology. 2020 Jan 1;162:107826.

299. Oliveira SM, Silva CR, Trevisan G, Villarinho JG, Cordeiro MN, Richardson M, Borges MH, Castro CJjr, Gomez MV, Ferreira J. Antinociceptive effect of a novel armed spider peptide Tx3-5 in pathological pain models in mice. Pflugers Arch. 2016 May;468(5):881-94.

300. Gui J, Liu B, Cao G, Lipchik AM, Perez M, Dekan Z, Mobli M, Daly NL, Alewood PF, Parker LL, King GF, Zhou Y, Jordt SE, Nitabach MN. A tarantulavenom peptide antagonizes the TRPA1 nociceptor ion channel by binding to the S1-S4 gating domain. Curr Biol. 2014 Mar 3;24(5):473-83.

301. Grishin EV, Savchenko GA, Vassilevski AA, Korolkova YV, Boychuk YA, Viatchenko-Karpinski VY, Nadezhdin KD, Arseniev AS, Pluzhnikov KA, Kulyk VB, Voitenko NV, Krishtal OO. Novel peptide from spider venom inhibits P2X3 receptors and inflammatory pain. Ann Neurol. 2010 May;67(5):680-3.

302. Bae C, Sachs F, Gottlieb PA. The mechanosensitive ion channel Piezo1 is inhibited by the peptide GsMTx4. Biochemistry. 2011 Jul 26;50(29):6295-300.

303. Alcaino C, Knutson K, Gottlieb PA, Farrugia G, Beyder A. Mechanosensitive ion channel Piezo2 is inhibited by D-GsMTx4. Channels (Austin). 2017 May 4;11(3):245-53.

304. Gottlieb PA, Sachs F. Piezo1: properties of a cation selective mechanical channel. Channels (Austin). 2012 Jul-Aug;6(4):214-9.

305. Stromgaard K, Jensen LS, Vogensen SB. Polyamine toxins: development of selective ligands for ionotropic receptors. Toxicon. 2005 Mar 1;45(3):249-54.

306. Savidge JR, Bristow DR. Ca2+ permeability and joro spider toxin sensitivity of AMPA and kainate receptors on cerebellar granule cells. Eur J Pharmacol. 1998 Jun 12;351(1):131-8.

307. Sorkin LS, Yaksh TL, Doom CM. Pain models display differential sensitivity to Ca2+-permeable non-NMDA glutamate receptor antagonists. Anesthesiology. 2001 Oct;95(4):965-73.

308. Silva FR, Batista EM, Gomez MV, Kushmerick C, Da Silva JF, Cordeiro MN, Vieira LB, Ribeiro FM. The Phoneutria nigriventer spider toxin, PnTx4$5-5$, promotes neuronal survival by blocking NMDA receptors. Toxicon. 2016 Mar 15;112:16-21.
309. Oliveira CFB, Alves DP, Emerich BL, de Figueiredo SG, Cordeiro MDN, Borges MH, Richardson M, Pimenta AMC, Duarte IDG, de Lima ME. Antinociceptive effect of PnTx4(5-5), a peptide from Phoneutria nigriventer spider venom, in rat models and the involvement of glutamatergic system. J Venom Anim Toxins incl Trop Dis. 2019;25:e20190022. https://doi. org/10.1590/1678-9199-JVATITD-2019-0022.

310. Lee SY, MacKinnon R. A membrane-access mechanism of ion channel inhibition by voltage sensor toxins from spider venom. Nature. $2004 \mathrm{Jul}$ 8;430(6996):232-5.

311. Milescu M, Bosmans F, Lee S, Alabi AA, Kim JI, Swartz KJ. Interactions between lipids and voltage sensor paddles detected with tarantula toxins. Nat Struct Mol Biol. 2009 Sep 27;16:1080-5.

312. Posokhov YO, Gottlieb PA, Morales MJ, Sachs F, Ladokhin AS. Is lipid bilayer binding a common property of inhibitor cysteine knot ion-channel blockers? Biophys J. 2007 Aug 15;93(4):L20-2.

313. Nishizawa M, Nishizawa K. Molecular dynamics simulations of a stretchactivated channel inhibitor GsMTx4 with lipid membranes: two binding modes and effects of lipid structure. Biophys J. 2007;92:4233-43.

314. Suchyna TM, Tape SE, Koeppe RE 2nd, Andersen OS, Sachs F, Gottlieb PA. Bilayer-dependent inhibition of mechanosensitive channels by neuroactive peptide enantiomers. Nature. 2004 Jul 8;430:235-40.

315. Henriques ST, Deplazes E, Lawrence N, Cheneval O, Chaousis S, Inserra M, Thongyoo P, King GF, Mark AE, Vetter I, Craik DJ, Schroeder CI. Interaction of Tarantula Venom Peptide ProTx-II with Lipid Membranes Is a Prerequisite for Its Inhibition of Human Voltage-gated Sodium Channel NaV1.7. J Biol Chem. 2016 Aug 12;291(33):17049-65.

316. Agwa AJ, Lawrence N, Deplazes E, Cheneval O, Chen RM, Craik DJ, Schroeder $\mathrm{Cl}$, Henriques ST. Spider peptide toxin HwTX-IV engineered to bind to lipid membranes has an increased inhibitory potency at human voltage-gated sodium channel $\mathrm{hNaV1.7.} \mathrm{Biochim} \mathrm{Biophys} \mathrm{Acta} \mathrm{Biomembr.}$ 2017 May;1859(5):835-44.

317. Agwa AJ, Tran P, Mueller A, Tran HNT, Deuis JR, Israel MR, McMahon KL, Craik DJ, Vetter I, Schroeder Cl. Manipulation of a spider peptide toxin alters its affinity for lipid bilayers and potency and selectivity for voltage-gated sodium channel subtype 1.7. J Biol Chem. $2020 \mathrm{Apr}$ 10;295(15):5067-80.

318. Klint JK, Chin YK, Mobli M. Rational Engineering Defines a Molecular Switch That Is Essential for Activity of Spider-Venom Peptides against the Analgesics Target NaV1.7. Mol Pharmacol. 2015 Dec;88(6):1002-10.

319. Zhang Y, Wang L, Peng D, Zhang Q, Yang Q, Li J, Li D, Tang D, Chen M, Liang S, Liu Y, Wang S, Liu Z. Engineering of highly potent and selective HNTX-III mutant against hNav1.7 sodium channel for treatment of pain. J Biol Chem. 2021 Jan-Jun;296:100326.

320. Zhang Y, Yang Q, Zhang Q, Peng D, Chen M, Liang S, Zhou X, Liu Z. Engineering Gain-of-Function Analogues of the Spider Venom Peptide HNTX-I, A Potent Blocker of the hNaV1.7 Sodium Channel. Toxins (Basel). 2018 Sep;10(9):358.

321. Zhang AH, Sharma G, Undheim EAB, Jia X, Mobli M. A complicated complex: Ion channels, voltage sensing, cell membranes and peptide inhibitors. Neurosci Lett. 2018 Jul 13;679:35-47.

322. Bouhassira D, Lanteri-Minet M, Attal N, Laurent B, Touboul C. Prevalence of chronic pain with neuropathic characteristics in the general population. Pain. 2008 Jun;136(3):380-7.

323. Attal N, Cruccu G, Haanpaa M, Hansson P, Jensen TS, Nurmikko T, Sampaio C, Sindrup S, Wiffen P, Force ET. EFNS guidelines on pharmacological treatment of neuropathic pain. Eur J Neurol. 2006 Nov;13(11):1153-69.

324. Dworkin RH, Backonja M, Rowbotham MC, Allen RR, Argoff CR, Bennett GJ, Bushnell MC, Farrar JT, Galer BS, Haythornthwaite JA, Hewitt DJ, Loeser JD, Max MB, Saltarelli M, Schmader KE, Stein C, Thompson D, Turk DC, Wallace MS, Watkins LR, Weinstein SM. Advances in neuropathic pain: diagnosis, mechanisms, and treatment recommendations. Arch Neurol. 2003 Nov;60(11):1524-34.

325. Terpening CM, Johnson WM. Methadone as an analgesic: a review of the risks and benefits. W V Med J. 2007 Jan-Feb;103(1):14-8.

326. Ling GS, Spiegel K, Lockhart SH, Pasternak GW. Separation of opioid analgesia from respiratory depression: evidence for different receptor mechanisms. J Pharmacol Exp Ther. 1985 Jan;232(1):149-55. 
327. Del Vecchio G, Spahn V, Stein C. Novel Opioid Analgesics and Side Effects. ACS Chem Neurosci. 2017 Aug 16;8(8):1638-40.

328. Kampo S, Ahmmed B, Zhou T, Owusu L, Anabah TW, Doudou NR, Kuugbee ED, Cui Y, Lu Z, Yan Q, Wen QP. Scorpion Venom Analgesic Peptide, BmK AGAP Inhibits Stemness, and Epithelial-Mesenchymal Transition by Down-Regulating PTX3 in Breast Cancer. Front Oncol. 2019 Jan 25;9:21.

329. Richard SA, Kampo S, Sackey M, Hechavarria ME, Buunaaim ADB. The Pivotal Potentials of Scorpion Buthus Martensii Karsch-Analgesic-Antitumor Peptide in Pain Management and Cancer. Evid Based Complement Alternat Med. 2020;2020:4234273.

330. Rahnama S, Deuis JR, Cardoso FC, Ramanujam V, Lewis RJ, Rash LD, King GF, Vetter I, Mobli M. The structure, dynamics and selectivity profile of a NaV1.7 potency-optimised huwentoxin-IV variant. PLoS One. 2017 Mar 16;12(3):e0173551.

331. Neff RA, Wickenden AD. Selective Targeting of Nav1.7 with Engineered Spider Venom-Based Peptides. Channels (Austin). 2021 Dec;15(1):179-93.

332. Wright ZVF, McCarthy S, Dickman R, Reyes FE, Sanchez-Martinez S, Cryar A, Kilford I, Hall A, Takle AK, Topf M, Gonen T, Thalassinos K, Tabor AB. The Role of Disulfide Bond Replacements in Analogues of the Tarantula Toxin ProTx-II and Their Effects on Inhibition of the Voltage-Gated Sodium Ion Channel Nav1.7. J Am Chem Soc. 2017 Sep 20;139(37):13063-75.

333. Murray JK, Biswas K, Holder JR, Zou A, Ligutti J, Liu D, Poppe L, Andrews KL, Lin FF, Meng SY, Moyer BD, McDonough SI, Miranda LP. Sustained inhibition of the NaV1.7 sodium channel by engineered dimers of the domain II binding peptide GpTx-1. Bioorg Med Chem Lett. 2015 Nov 1;25(21):4866-71.

334. Agwa AJ, Blomster LV, Craik DJ, King GF, Schroeder Cl. Efficient Enzymatic Ligation of Inhibitor Cystine Knot Spider Venom Peptides: Using Sortase A To Form Double-Knottins That Probe Voltage-Gated Sodium Channel NaV1.7. Bioconjug Chem. 2018;29:3309-19.

335. Peschel A, Cardoso FC, Walker AA, Durek T, Stone MRL, Braga Emidio N, Dawson PE, Muttenthaler M, King GF. Two for the Price of One: Heterobivalent Ligand Design Targeting Two Binding Sites on VoltageGated Sodium Channels Slows Ligand Dissociation and Enhances Potency. J Med Chem. 2020 Oct 20;63(21):12773-85.

336. Peigneur S, Cheneval O, Maiti M, Leipold E, Heinemann SH, Lescrinier E, Herdewijn P, De Lima ME, Craik DJ, Schroeder Cl,Tytgat J. Where cone snails and spiders meet: design of small cyclic sodium-channel inhibitors. FASEB J. 2019 Mar;33(3):3693-703.

337. Murray JK, Wu B, Tegley CM, Nixey TE, Falsey JR, Herberich B, Yin L, Sham K, Long J, Aral J, Cheng Y, Netirojjanakul C, Doherty L, Glaus C, Ikotun T, Li H, Tran L, Soto M, Salimi-Moosavi H, Ligutti J, Amagasu S, Andrews KL, Be X, Lin MJ, Foti RS, Ilch CP, Youngblood B, Kornecook TJ, Karow M, Walker KW, Moyer BD, Biswas K, Miranda LP. Engineering NaV1.7 Inhibitory JzTx-V Peptides with a Potency and Basicity Profile Suitable for Antibody Conjugation To Enhance Pharmacokinetics. ACS Chem Biol. 2019 Apr 19;14(4):806-18.

338. Biswas K, Nixey TE, Murray JK, Falsey JR, Yin L, Liu H, Gingras J, Hall BE, Herberich B, Holder JR, Li H, Ligutti J, Lin MJ, Liu D, Soriano BD, Soto M, Tran L, Tegley CM, Zou A, Gunasekaran K, Moyer BD, Doherty L, Miranda LP. Engineering Antibody Reactivity for Efficient Derivatization to Generate NaV1.7 Inhibitory GpTx-1 Peptide-Antibody Conjugates. ACS Chem Biol. 2017 Sep 15;12(9):2427-35.
339. Wang $Y$, Wang L, Cui Y, Song YB, Liu YF, Zhang R, Wu CF, Zhang JH. Purification, characterization and functional expression of a new peptide with an analgesic effect from Chinese scorpion Buthus martensii Karsch (BmK AGP-SYPU1). Biomed Chromatogr. 2011;25:801-7.

340. Shao JH, Cui Y, Zhao MY, Wu CF, Liu YF, Zhang JH. Purification, characterization, and bioactivity of a new analgesic-antitumor peptide from Chinese scorpion Buthus martensii Karsch. Peptides. 2014 Mar;53:89-96.

341. Pineda SS, Chaumeil PA, Kunert A, Kaas Q, Thang MWC Le, L Nuhn M, Herzig V, Saez NJ, Cristofori-Armstrong B, Anangi R, Senff S, Gorse $D$, King GF. ArachnoServer 3.0: an online resource for automated discovery, analysis and annotation of spider toxins. Bioinformatics. 2018 Mar 15;34(6):1074-6.

342. Mintz IM, Venema VJ, Adams ME, Bean BP. Inhibition of N- and L-type $\mathrm{Ca} 2+$ channels by the spider venom toxin omega-Aga-IIIA. Proc Natl Acad Sci U S A. 1991;88:6628-31.

343. McDonough SI, Boland LM, Mintz IM, Bean BP. Interactions among toxins that inhibit $\mathrm{N}$-type and P-type calcium channels. J Gen Physiol. 2002 Apr;119(4):313-28.

344. Xiao Y, Liang S. Inhibition of neuronal tetrodotoxin-sensitive $\mathrm{Na}+$ channels by two spider toxins: hainantoxin-III and hainantoxin-IV. Eur J Pharmacol. 2003 Sep 5;477(1):1-7.

345. Liu Y, Tang J, Zhang Y, Xun X, Tang D, Peng D, Yi J, Liu Z, Shi X. Synthesis and analgesic effects of mu-TRTX-Hhn1b on models of inflammatory and neuropathic pain. Toxins (Basel). 2014 Aug 13;6(8):2363-78.

346. Wang M, Guan X, Liang S. The cross channel activities of spider neurotoxin huwentoxin-I on rat dorsal root ganglion neurons. Biochem Biophys Res Commun. 2007 Jun 8;357(3):579-83.

347. Wen Tao Z, Gu Yang T, Ying R, Mao Cai W, Lin L, Chi Miao L, Peng H, Joa Qin C. The antinociceptive efficacy of HWTX-I epidurally administered in rheumatoid arthritis rats. Int J Sports Med. 2011 Nov;32(11):869-74.

348. Peng K, Shu Q, Liu Z, Liang S. Function and solution structure of huwentoxin-IV, a potent neuronal tetrodotoxin (TTX)-sensitive sodium channel antagonist from Chinese bird spider Selenocosmia huwena. J Biol Chem. 2002 Dec;277(49):47564-71.

349. Lampe RA, Defeo PA, Davison MD, Young J, Herman JL, Spreen RC, Horn MB, Mangano TJ, Keith RA. Isolation and pharmacological characterization of omega-grammotoxin SIA, a novel peptide inhibitor of neuronal voltage-sensitive calcium channel responses. Mol Pharmacol. 1993 Aug;44(2):451-60.

350. McDonough SI, Lampe RA, Keith RA, Bean BP. Voltage-dependent inhibition of $\mathrm{N}$ - and P-type calcium channels by the peptide toxin omegagrammotoxin-SIA. Mol Pharmacol. 1997 Dec;52(6):1095-104.

351. Suchyna TM, Johnson JH, Hamer K, Leykam JF, Gage DA, Clemo HF, Baumgarten CM, Sachs F. Identification of a peptide toxin from Grammostola spatulata spider venom that blocks cation-selective stretchactivated channels. J Gen Physiol. 2000 May;115(5):583-98.

352. Martin-Moutot N, Mansuelle P, Alcaraz G, Dos Santos RG, Cordeiro MN, De Lima ME, Seagar M, Van Renterghem C. Phoneutria nigriventer toxin 1: a novel, state-dependent inhibitor of neuronal sodium channels that interacts with micro conotoxin binding sites. Mol Pharmacol. 2006 Jun;69(6):1931-7.

353. Bladen C, Hamid J, Souza IA, Zamponi GW. Block of T-type calcium channels by protoxins I and II. Mol Brain. 2014 May 9;7:36. 